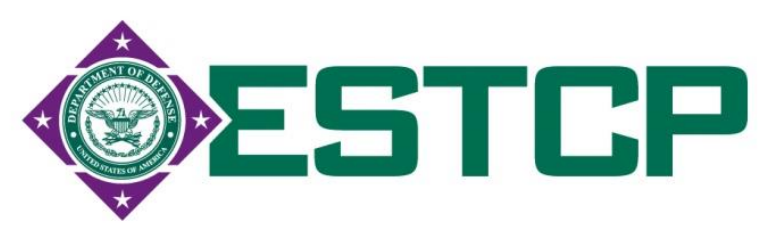

\title{
DEMONSTRATION REPORT FOR VISUAL SAMPLE PLAN REMEDIAL INVESTIGATION (VSP-RI) SAMPLING METHODS AT THE MOTLOW SITE IN TENNESSEE
}

\author{
MUNITIONS RESPONSE PROJECT \\ STATISTICAL VERIFICATION AND REMEDIATION \\ SAMPLING METHODS (200837)
}

March 2014

Pacific Northwest National Laboratory

Brent Pulsipher, John Hathaway, Brett Matzke, John Wilson, and Lisa Newburn 


\section{Table of Contents}

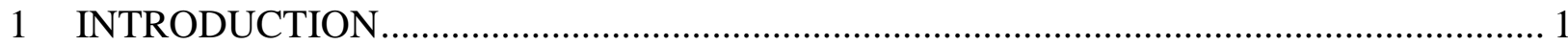

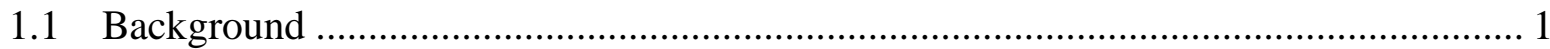

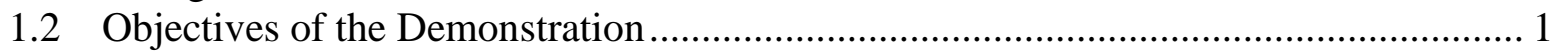

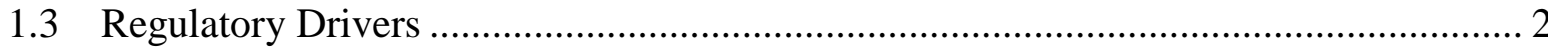

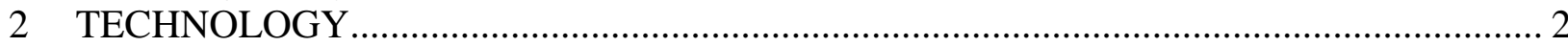

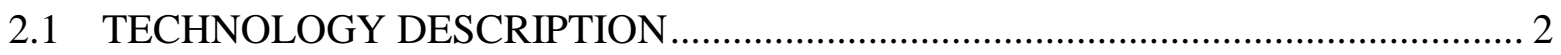

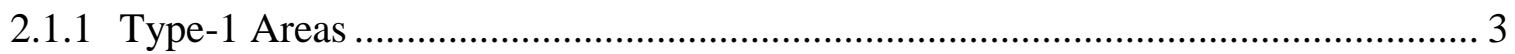

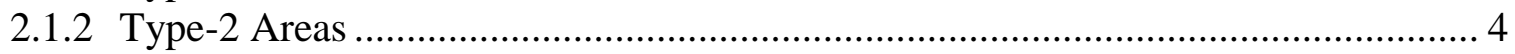

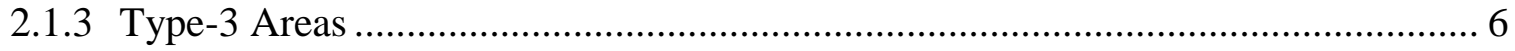

2.2 ADVANTAGES AND LIMITATIONS OF THE TECHNOLOGY ………................. 7

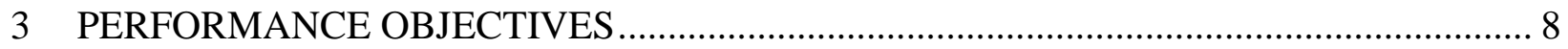

3.1 Objective 1: Show Application of VSP-RI Modules For Three Types Of Areas ......... 9

3.1.1 Metric, Data Requirements, and Success Criteria ................................................. 10

3.2 Objective 2: Gain Experience For Developing VSP-RI Workflow Process Guidance 10

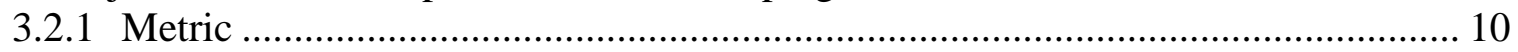

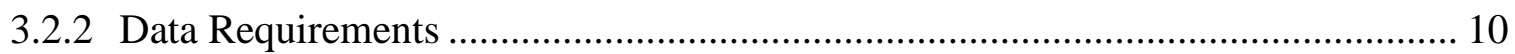

3.2.3 Success Criteria ......................................................................................... 10

3.3 Objective 3: Evaluate Usability of VSP and Identify Needed Improvements ............ 10

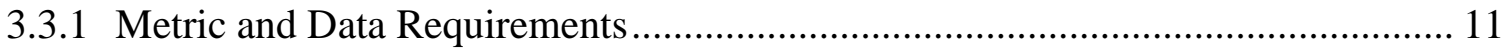

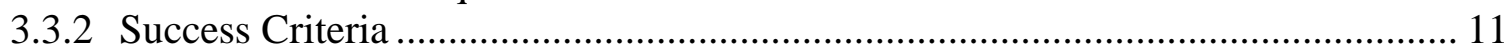

3.4 Objective 4: VSP-RI Module Comparison with UXO Estimator ................................ 11

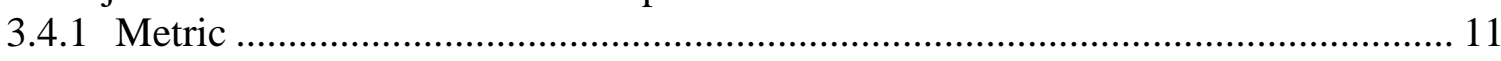

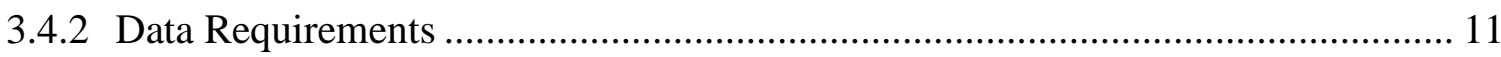

3.4.3 Success Criteria ....................................................................................... 11

3.5 Objective 5: Evaluate Performance of Transects Vs. Grids for UXO/Acre Estimation

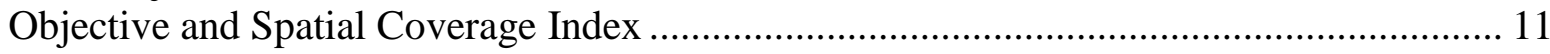

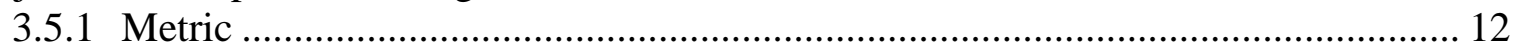

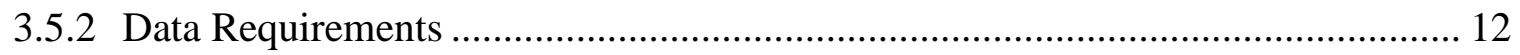

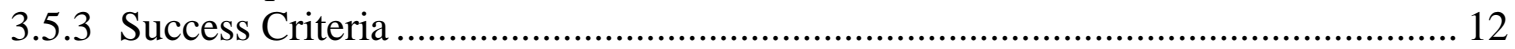

3.6 Objective 6: Compare the Utility of Different Possible Target Area Boundary

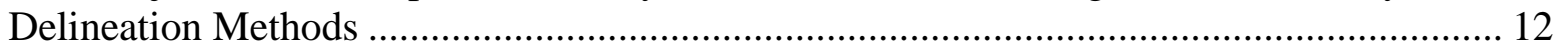

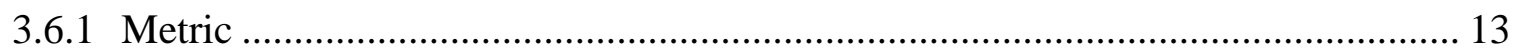

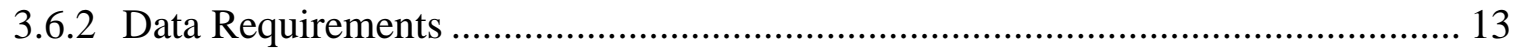

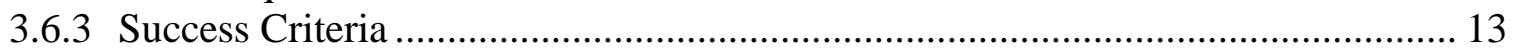

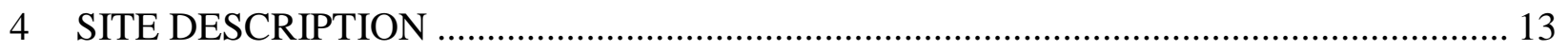

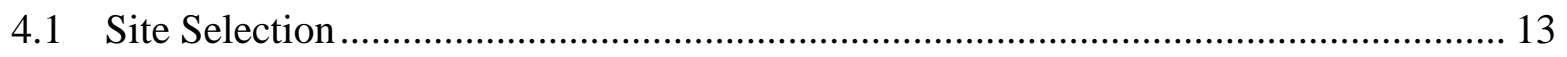

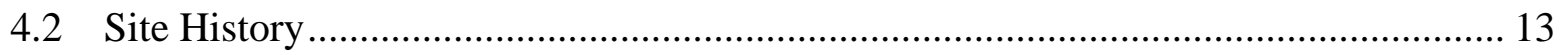

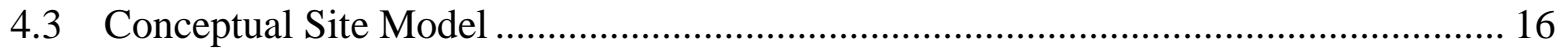

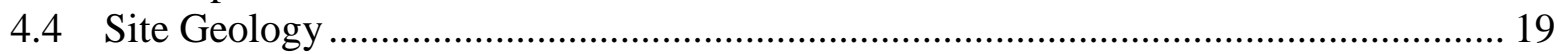

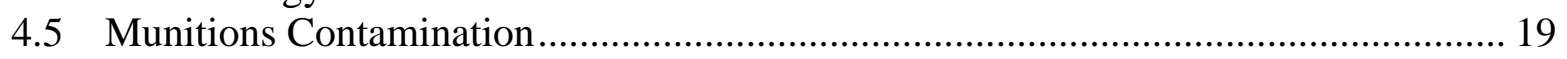

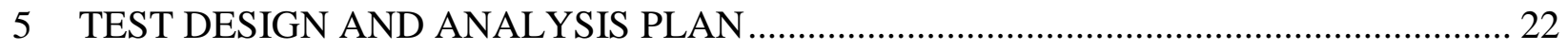

5.1 Transect Design Options for Three Types Of Areas .................................................... 23

5.1.1 Type-1 Area Demonstration (Area 2a) ........................................................... 23

5.1.2 Type-2 Area Demonstration (Area 3a) .............................................................. 24

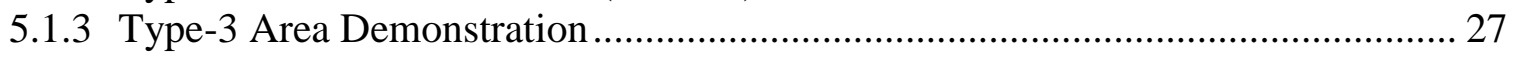

5.2 Survey Unit Evaluation ......................................................................................... 27

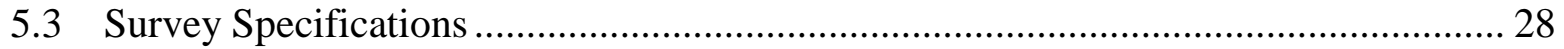




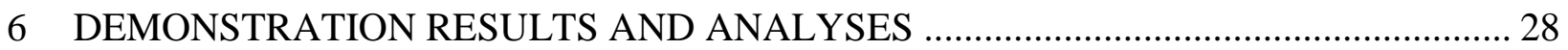

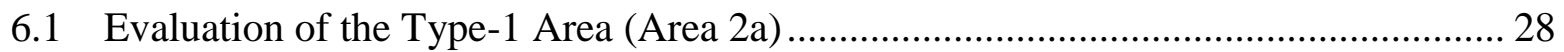

6.2 Evaluation of Type-2 Area (Area 3a) ................................................................. 30

6.2.1 Anomaly Dig Results and Estimation of TOI Per Acre ........................................ 31

6.3 Evaluation of Type-3 Area (Area 3a revisited) ……….............................................. 33

6.4 Evaluation of Effects of Varied Dimension Transect Surveys and Grid Surveys on

Confidence and Spatial Representation........................................................................... 35

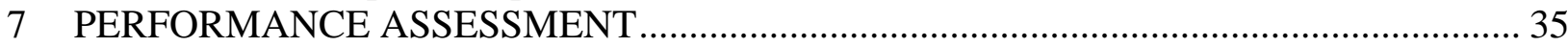

7.1 Objective 1 Assessment: Show Application of VSP-RI Modules for 3 Types Of Areas 36

7.2 Objective 2 Assessment: Gain Experience for Developing VSP-RI Workflow Process

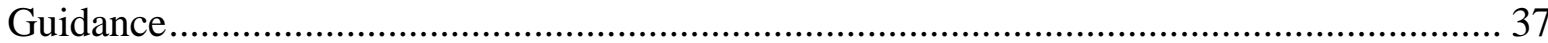

7.3 Objective 3 Assessment: Evaluate Usability of VSP and Identify Needed

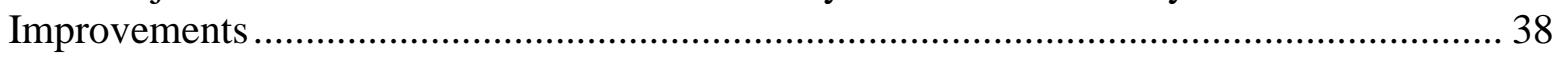

7.4 Objective 4 Assessment: VSP-RI Module Comparison with UXO Estimator ............ 38

7.5 Objective 5 Assessment: Evaluate Performance of Transects Vs. Grids for UXO/Acre

Estimation Objective and Spatial Coverage Index ………............................................... 39

7.6 Objective 6 Assessment: Compare the Utility of Different Possible Target Area

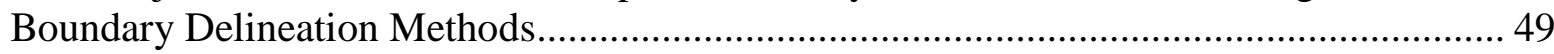

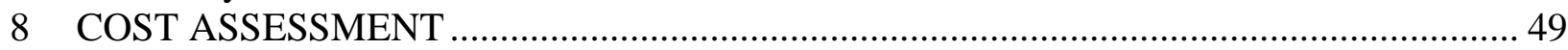

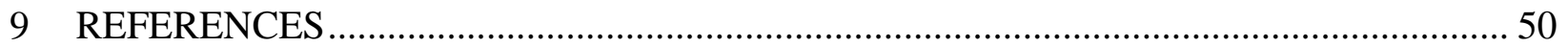

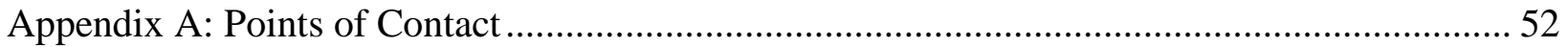

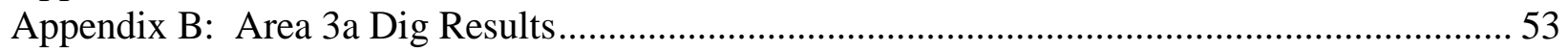

Appendix C: Additional Cluster Pattern Plots and Achieved Confidence for Many of the

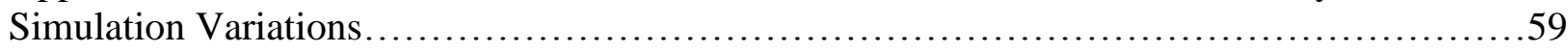




\section{Figures}

Figure 1. VSP Screen Shot of Target-Area Detection Survey Design .......................................... 4 Figure 2. VSP Screen Shot of Non-Bayesian UXO/Acre Estimation and Bounding Survey Design 5

Figure 3. VSP Screen Shot of Bayesian UXO/Acre Estimation and Bounding Survey Design .... 6 Figure 4. VSP Screen Shot of Presumptively Clean Survey Design .............................................. 7

Figure 5. Summary of Prior Motlow Site Investigations ............................................................. 15

Figure 6. Conceptual Site Model and Proposed Investigation Areas .......................................... 17

Figure 7. Planned Transect Survey for the Type-1 Area (Area 2a) ………................................ 24

Figure 8. Proposed Option 1 Transect Design for Area 3a............................................................. 26

Figure 9. Proposed Option 2 Transect Design for Area 3a............................................................. 27

Figure 10. Area 2a Transects and Anomaly Locations .............................................................. 28

Figure 11. Geostatistical Mapping and Target Area Delineation for Area 2a ............................. 29

Figure 12. Actual Transects Performed and Anomalies Identified on Area 3a ........................... 31

Figure 13. VSP Design Using a Conservative Informed Prior ................................................... 32

Figure 14. VSP Screenshot Showing Calculated Confidence for Achieved Survey Acreage ..... 33

Figure 15. Example of VSP-RI Presumptively Clean Module Applied to Area 3a .................... 34

Figure 16. VSP-UXO Expert Guide Initial Page ………......................................................... 37

Figure 17. Uniform Point Patterns for the Five Different TOI per Acre Rates ........................... 40 Figure 18. The 16 TOI Spatial Point Patterns Using a Rate of 1 TOI Per Acre Used to Evaluate the Confidence Performance for Different Sampling Unit Dimensions ......................................... 41

Figure 19. The 16 TOI Spatial Point Patterns Using a Rate of 0.1 TOI Per Acre Used to Evaluate the Confidence Performance for Different Sampling Unit Dimensions ........................ 42 Figure 20. Achieved confidence (y-axis) for the varied confidence (panel), TOI rates (color of points) and sampling unit dimension ( $\mathrm{x}$-axis) for the uniformly distributed points as shown in Figure 20. 44

Figure 21. Achieved confidence (y-axis) for the varied confidence (panel), TOI rates (color of points) and sampling unit dimension ( $\mathrm{x}$-axis) for the TOI point patterns that restrain points to fall in no more than $12 \%$ of the sample area. The solid horizontal line is the 3 standard deviation lower bound of confidence performance from a simulation study using 2300 simulations to evaluate confidence. The vertical dashed lines separate the three transect widths and the grid

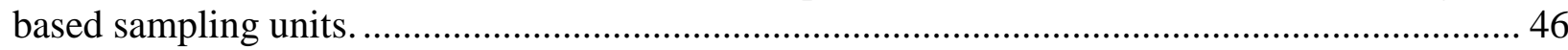
Figure 22. Achieved confidence (y-axis) for the varied confidence (panel), TOI rates (color of points) and sampling unit dimension ( $\mathrm{x}$-axis) for the TOI point patterns that restrain points to fall in no more than $50 \%$ but greater than $23 \%$ of the sample area. The solid horizontal line is the 3 standard deviation lower bound of confidence performance from a simulation study using 2300 simulations to evaluate confidence. The vertical lines separate the three transect widths and the grid based sampling units................................................................................................. 47 Figure 23. Achieved confidence (y-axis) for the varied confidence (panel), TOI rates (color of points) and sampling unit dimension (x-axis) for the TOI point patterns that restrain points to fall in greater than $90 \%$ of the sample area. The solid horizontal line is the 3 standard deviation lower bound of confidence performance from a simulation study using 2300 simulations to evaluate confidence. The vertical lines separate the three transect widths and the grid based sampling units. 


\section{Tables}

Table 1. Performance Objectives ................................................................................. 8

Table 2. Munitions Potentially Present at the Former Motlow Range, Chemical Compositions, and MCs 19

Table 3. Description and VSP-RI Objectives for Different Types of Areas 23

Table 4. Summary of Design Parameters for Area 3a....

Table 6. VSP Presumptively Clean Module Survey Requirements for Area 3a Assuming Various Input Parameters for a 1/4 Acre Parcel Size

Table 7. Achieved Confidence Given Actual Survey Results (2.7 acres surveyed and no TOI found) for Area 3a for a 1/4 Acre Parcel Size of Concern..................................................... 35

Table 8. Performance Objectives and Evaluation Summary ................................................ 36

Table 9. VSP-RI Module Output Compared with UXO Estimator ........................................ 39 Table 10. Summary of the Calculated Number of Acres Required for Each Confidence Design

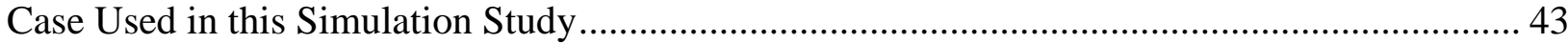

Table 11. Potential Costs of Using VSP-RI Modules......................................................... 49 


\section{Acronyms}

$\begin{array}{ll}\text { ASR } & \text { Archive Search Report } \\ \text { bgs } & \text { below ground surface } \\ \text { USACE } & \text { U.S. Army Corps Of Engineers } \\ \text { CSM } & \text { Conceptual Site Model } \\ \text { DoD } & \text { U.S. Department of Defense } \\ \text { EE/CA } & \text { engineering evaluation and cost analysis } \\ \text { EM } & \text { electromagnetic } \\ \text { ESTCP } & \text { Environmental Security Technology Certification Program } \\ \text { GPS } & \text { global positioning system } \\ \text { HE } & \text { high explosive } \\ \text { MC } & \text { munitions constituents } \\ \text { MEC } & \text { munitions and explosives of concern } \\ \text { MRS } & \text { munitions response site } \\ \text { MSCC } & \text { Motlow State Community College } \\ \text { mV } & \text { millivolt } \\ \text { PNNL } & \text { Pacific Northwest National Laboratory } \\ \text { PRV } & \text { post-remediation verification } \\ \text { QA/QC } & \text { quality assurance and quality control } \\ \text { RI } & \text { Remediation Investigation } \\ \text { SERDP } & \text { Strategic Environmental Research and Development Program } \\ \text { TEC } & \text { Topographic Engineering Center } \\ \text { TOI } & \text { targets of interest } \\ \text { UTM } & \text { universal transverse mercator } \\ \text { UXO } & \text { unexploded ordnance } \\ \text { VSP } & \text { Visual Sample Plan } \\ & \\ & \end{array}$




\section{Acknowledgments}

Pacific Northwest National Laboratory (PNNL) acknowledges the Environmental Security Technology Certification Program for their support of this demonstration. Specifically, we acknowledge Herb Nelson and Anne Andrews for their management, technical guidance, and leadership. We are grateful to the Parsons team, namely Carrie Ross, Craig Murray, and Chris TenBraak, who graciously provided information about the Motlow, Tennessee, site; helped us understand the Remediation Investigation (RI) objectives; performed all site work; and shared data results. We also appreciate Chris Cochrane and Elise Goggin from the U.S. Army Corps of Engineers, Huntsville Office, for their support of this demonstration. Finally, we acknowledge the contributions of the entire PNNL Visual Sample Plan (VSP) project team who developed, modified, and tested pertinent VSP-RI modules. 


\section{Executive Summary}

The U.S. Department of Defense (DoD) is currently removing, or will be removing, munitions and explosives of concern (MEC) from millions of acres of land and sea. The DoD has established and continues to improve the full process of transferring military land for public use. As a part of this continued improvement and to provide greater confidence that the MEC threat is acceptably low, during the Remedial Investigation (RI) stage the DoD requires sites to be adequately characterized to identify and remediate potential target areas where MEC is most likely present and to demonstrate that the risk of MEC (or Targets of Interest [TOI]) on nontarget areas is sufficiently low.

With support from the Strategic Environmental Research and Development Program (SERDP) and Environmental Security Technology Certification Program (ESTCP), Pacific Northwest National Laboratory (PNNL) has developed a statistical sampling and analysis software-Visual Sample Plan (VSP) - that helps design transect surveys to detect and delineate target areas, estimate and bound TOI/acre, verify presumptively clean assumptions, and validate the quality of MEC remediation. This report summarizes the objectives and results of a demonstration focused on the Visual Sample Plan-Remediation Investigation (VSP-RI) methodology and modules and how those were used during an actual RI process on the site located in Motlow, Tennessee.

The primary objectives of this demonstration were to evaluate, illustrate, and determine acceptability of the VSP-RI methodology as it is applied to two of three possible application scenarios. The first scenario evaluated was for a region (Area 3a) that had little if any munitions use, and was not expected to contain target areas but needed validation that the TOI rate was confidently low. The second scenario evaluated was for a region (Area 2a) where there was real potential for encountering target areas and it was expected to contain TOI.

In support of the objectives of this demonstration, a transect survey design was developed for Area 3a using the VSP-RI module where the primary objective was to estimate TOI/acre and determine whether one can confidently (i.e., with $90 \%$ confidence) conclude that it is less than $0.5 /$ acre. Two options were considered, one in which no prior information was used to design the survey and another in which some prior information was used that was available from remediation of an adjacent parcel. Using the prior information resulted in less survey acreage required and because of limited funding available to perform this survey, that reduced-scope survey option was evaluated. The survey resulted in 43 reacquired anomalies that were subsequently dug with none of those listed as TOI. Based on this finding, a TOI/ac rate of less than $0.5 /$ acre was demonstrated with $90 \%$ confidence. This new VSP-RI methodology, which allowed consideration of prior knowledge about the potential number of TOI on the site, required significantly less (about half as much) survey acreage than methods that do not account for prior information or similar methods employed by the UXO Estimator software.

In the other area suspected to contain TOI (known as Area 2a), a more tightly spaced systematic transect survey was designed to support the objective of target-area identification and delineation. Using target-area delineation and kriging methods in VSP, the survey results were analyzed, and several potential target areas were identified based on anomaly densities that were much higher than background density. This confirmed that using VSP transect surveys designed to detect and delineate target areas of concerns does help identify those potential target areas where unexploded ordnance (UXO) presence is most likely. 
Area 3a results also were used to demonstrate the use and performance of VSP transect design methods for presumptively clean sites (sites where no TOI is expected but additional geophysical surveys are required for confirmation). This VSP module allows one to state that they are X\% confident that at least Y\% of all possible parcels of a specified size do not contain TOI if no TOI are found in the limited survey. Because only a limited amount of transect surveying and digging could be performed in Area 3a, it was shown that, with reasonable assumptions on the maximum number of parcels that could possibly contain TOI, one may state with $90 \%$ confidence that no more than $5.4 \%$ of all possible parcels of $1 / 4$-acre size would contain TOI.

It was also demonstrated that the UXO Estimator software tool and the VSP-RI module for estimating TOI/acre and confidently showing that it is less than some value using an uninformative Bayesian prior both require exactly the same amount of survey acreage to be performed. However, this VSP-RI module with reasonable, defensible informed priors can result in significantly reduced required survey acreage while maintaining the desired confidence or significantly increased confidence using the same survey acreage.

Finally, the performance of transect surveys as compared to grid surveys for the TOI/acre estimation and comparison module was examined through a series of simulations, varying the spatial distribution of TOI and other key parameters. We validated previously documented findings that grid sampling is not recommended in most cases because it does not achieve desired confidence levels as well as transect sampling. In fact, traditionally sized transect widths of $1 \mathrm{~m}$ and $3 \mathrm{~m}$ were quite robust to extreme variations in the TOI clustering patterns. The grid sampling performance was acceptable in a few limited cases and performed poorly as the TOI clustering patterns became more extreme. Results were consistent across designs with varying desired confidence levels $(90,95,99$, and $99.9 \%)$. Designs based on confidently estimating rates of 1.5 and $2 \mathrm{TOI} /$ acre were not as robust to TOI clustering. 


\section{INTRODUCTION}

\subsection{Background}

The U.S. Department of Defense (DoD) is currently performing many remedial investigations (RI) to identify locations where concentrated regions of munitions and explosives of concern (MEC) and unexploded ordnance (UXO) may be present, estimate potential remediation efforts and costs, and support land transfer decisions and no further remediation on some areas. Statistical methods are needed to support transect survey designs and statistical analyses during an RI. These tools need to:

- address the number and spacing of transects needed to detect and delineate target areas

- estimate and map the number and density of anomalies and targets of concern (MEC or $\mathrm{UXO}$ )

- demonstrate that the likelihood of targets of concern is sufficiently low to require no further remediation.

Through the Strategic Environmental Research and Development Program (SERDP) and Environmental Security Technology Certification Program (ESTCP), DoD has supported the development of statistical design modules that assist with UXO remediation within Visual Sample Plan (VSP), a statistical support software program developed by Pacific Northwest National Laboratory (PNNL). Transect survey design and analysis methods have been developed and demonstrated for use on wide-area assessments and post-remediation verification. Several of these VSP methods are also pertinent for some RI objectives. However, some of the previously developed VSP modules have been misapplied at some sites in an attempt to meet specific RI objectives for which VSP was not designed to address. Now, additional methods have recently been added to VSP to support these other important RI objectives. This demonstration report outlines the steps that were taken to demonstrate the methods in VSP during the actual remedial investigation process on the Motlow, Tennessee, site.

Given these new VSP methods and the need for demonstrating how the new and existing tools should appropriately be used during an RI, this demonstration evaluates these tools on a real site and provides important experience that will be used to develop an RI workflow process within VSP to better guide the user through the VSP-RI experience. This will provide the DoD services and their contractors a single tool for most RI transect design and statistical spatial analyses.

\subsection{Objectives of the Demonstration}

Under SERDP/ESTCP sponsorship, PNNL developed VSP modules to support wide-area transect design, target-area detection and delineation, anomaly spatial mapping and density estimation, and post-remediation verification. Some of these tools are also applicable within the RI phase of a project. PNNL has recently been developing other modules and enhancements that more fully support other goals of an RI. This demonstration illustrates how all these RI-pertinent VSP tools are used during an RI.

The primary objectives were to demonstrate the statistical and correct implementation of VSP-RI tools to support the RI process on an actual site. Other objectives included supporting the development of an RI transect survey design and statistical analysis process workflow document, 
improving VSP online help functionality, and gaining regulator support for this VSP-RI module and process workflow.

\subsection{Regulatory Drivers}

DoD is required to perform RIs on many sites where explosive risks are of concern. Regulatory and DoD objectives require that a defensible evaluation be performed during an RI to identify any areas where remediation likelihood is high and/or validate no further remediation as well as establish use controls. In these areas, sufficient information is needed regarding the number and spatial distribution of anomalies, the expected number of UXO and/or MEC, and the boundaries of the areas that must be remediated. Based on this and other relevant information, various remediation options can be explored during the follow-on feasibility study.

Regulators have expressed concerns that VSP methods developed for wide-area assessment or post-remediation verification purposes have been misapplied during RIs. DoD also developed RI requirements that contractors have interpreted to suggest that VSP can be used to meet those RI requirements. Based on the misapplication concern and the need for a complete VSP-RI toolkit that addresses a more complete suite of RI objectives, new VSP-RI methods have been developed and demonstrated on this Motlow site application.

The ESTCP office also established a VSP-RI advisory group consisting of regulators, DoD staff, and contractors to guide the development of this VSP-RI module. This group has been instrumental in identifying all pertinent RI objectives and decision rules that have led to the development of the VSP-RI module. They have also been briefed on this methodology as it has been applied within this demonstration.

\section{TECHNOLOGY}

\subsection{TECHNOLOGY DESCRIPTION}

With sponsorship from US Departments of Energy, Defense, and Homeland Security and the U.S. Environmental Protection Agency, PNNL has developed VSP. VSP is a software tool that supports the development of a defensible sampling plan based on statistical sampling theory and the statistical analysis of sample results to support confident decision-making. VSP couples site, building, and sample location visualization capabilities with optimal sampling design and statistical analysis strategies. VSP is currently focused on design and analysis for the following applications:

- environmental characterization and remediation

- environmental monitoring and stewardship

- response and recovery of chemical/biological/radiation terrorist event

- footprint reduction and remediation of UXO sites

- $\quad$ sampling of soils, buildings, groundwater, sediment, surface water, subsurface layers.

Under the SERDP and ESTCP programs, several VSP modules have been developed and demonstrated to support sites where unexploded ordnance is a primary concern. Initially, methods were added to VSP to support the wide area assessment objectives of transect design, 
target-area detection and delineation, and anomaly density mapping and estimation. Later, methods were included to support post-remediation verification efforts.

Now an additional set of VSP tools have been developed that are focused primarily on RI objectives and are the subject of this demonstration on a real site. During an RI, typically there are three types of areas encountered within a munitions response site (MRS).

- Type-1 Areas: Areas with known munitions use and or suspected target areas.

- Type-2 Areas: Areas with no clear target area discovery needs (regions around known target areas that have some potential munition use or areas with known munitions use but no clear target at which munitions were fired).

- Type-3 Areas: Areas that are presumptively clean but more evidence is required to support this claim.

The decision objectives and therefore survey and analysis objectives are different for each of these types of areas. Below, the primary decision/survey objectives and most appropriate VSP tool is presented for each type of area.

\subsubsection{Type-1 Areas}

These are areas where targets areas are known or are likely to exist, but the amount and location are uncertain. The primary VSP-RI survey purposes then are to:

- identify any target areas if they exist

- delineate identified target areas

- estimate the number of anomalies or anomaly density

- explore the spatial anomaly distribution.

Other objectives include distinguishing between culturally cluttered high anomaly density areas and munitions related areas and exploring the nature and types of munitions.

For Type-1 areas, the VSP tools developed for wide area applications are directly applicable and were used in this demonstration and many previous demonstrations. These tools help the user determine the required transect spacing needed to have a high probability of detecting target areas of concern. The technical descriptions and underlying mathematics/statistics have been adequately covered in previous wide area assessment demonstration plans and reports. An example is shown in Figure 1.

No new design tools were implemented in VSP to address the Type-1 areas as they already exist. This demonstration included improved statistical uncertainty methods for bounding target areas and the density estimate within the target area. 


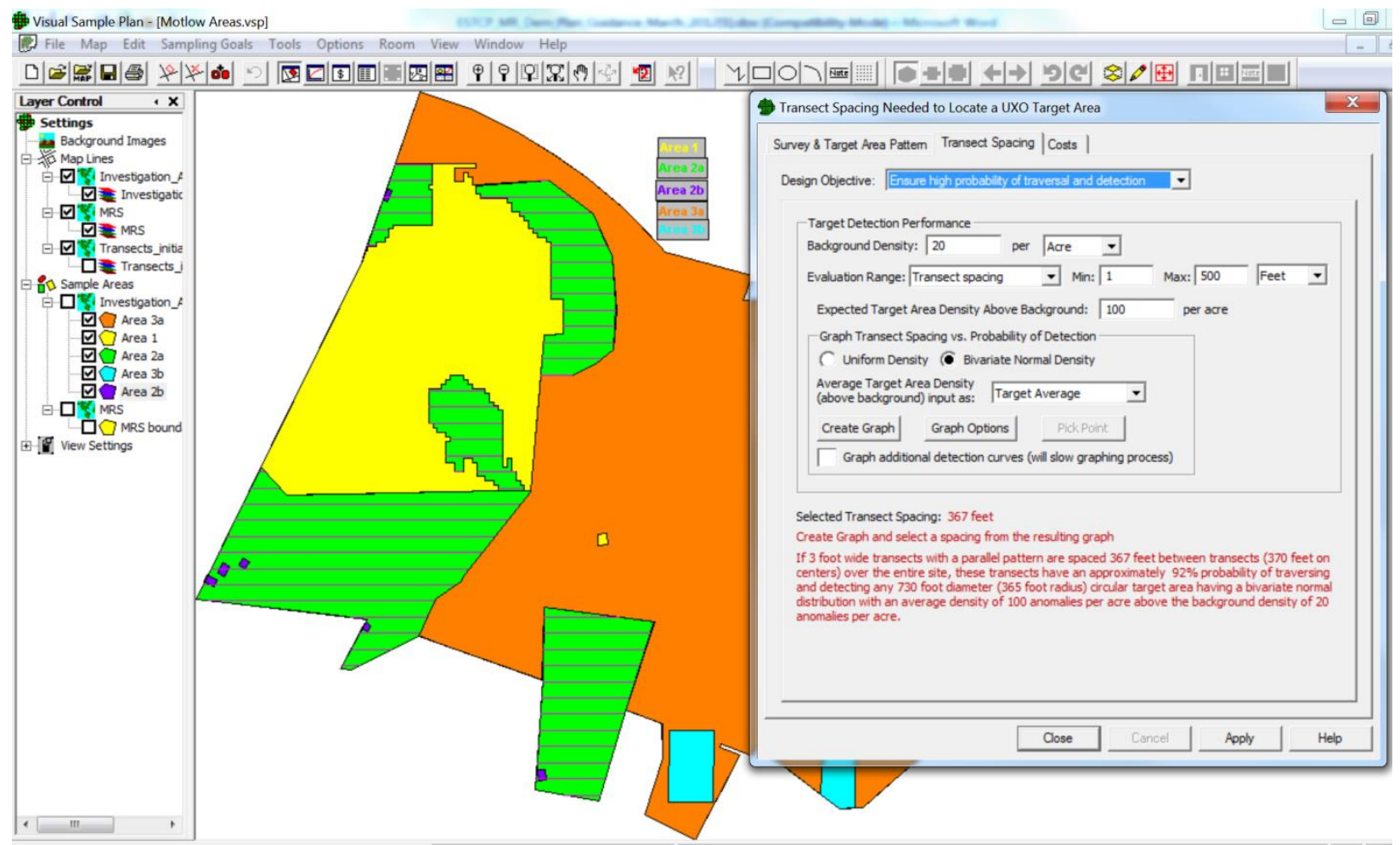

Figure 1. VSP Screen Shot of Target-Area Detection Survey Design

\subsubsection{Type-2 Areas}

These are areas where target areas are very unlikely but some limited munitions use is possible. For these areas, the primary objective is to estimate targets of interest (TOI)/acre (or MEC/acre or other rate) or the number of possible TOI (or MEC or other count) and show confidence that it is less than some pre-specified limit.

For Type-2 areas, a new VSP module has been developed. This module helps determine the survey acreage required and the number of randomly placed transects needed to confidently demonstrate that the rate of the TOI (e.g., UXO/acre) is less than a specified limit. This method also ensures that at least one TOI will be discovered with X\% confidence, if the TOI rate actually is above the specified limit. Figure 2 shows the VSP user input dialog box for this tool. 


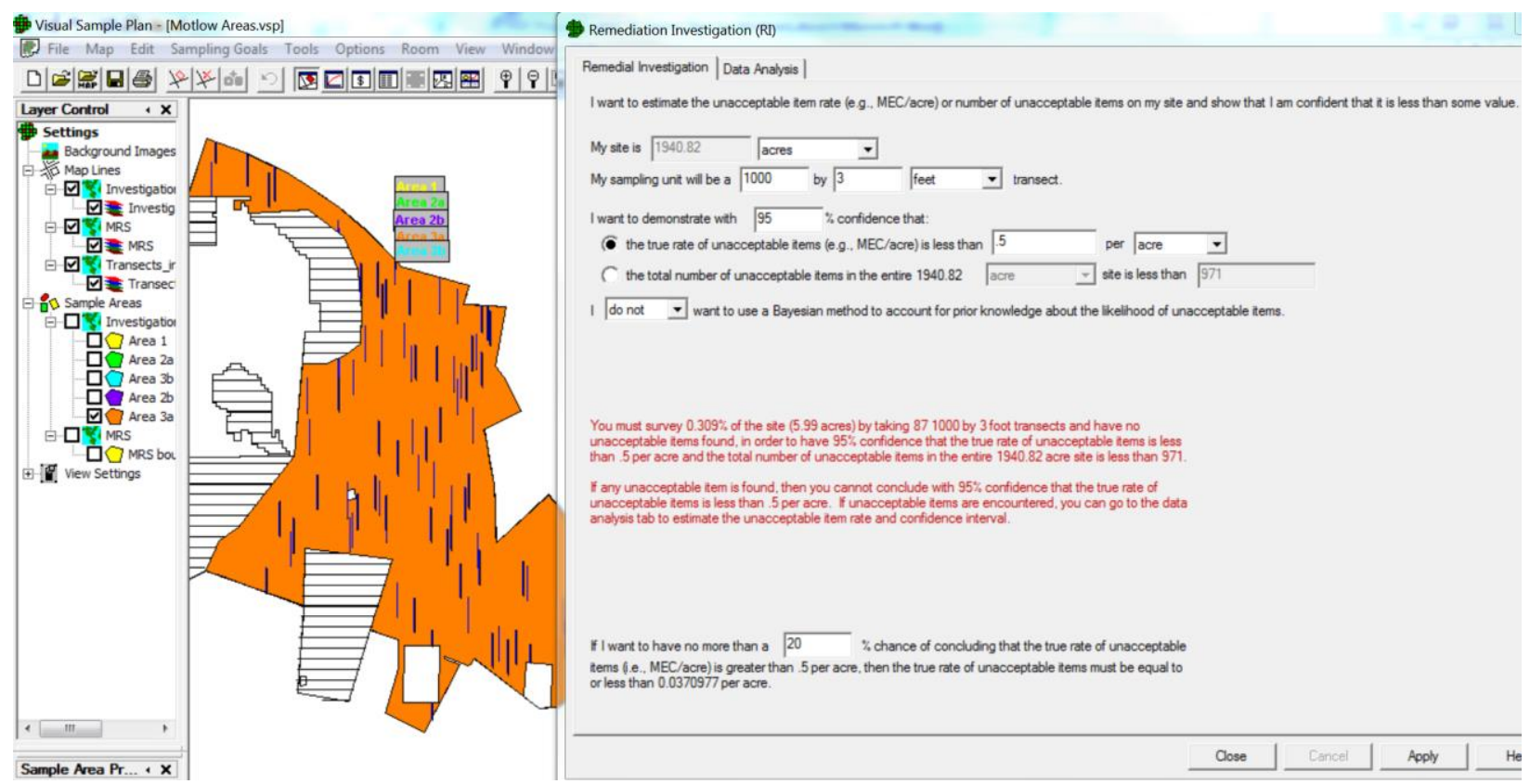

Figure 2. VSP Screen Shot of Non-Bayesian UXO/Acre Estimation and Bounding Survey Design

Both a non-Bayesian and Bayesian approach are available within this new VSP tool. The Bayesian approach requires additional input and assumptions as shown in Figure 3. It should be noted that, if the user chooses a non-informative prior, the amount of survey acreage required will be the same as the amount that the UXO-Estimator tool outputs. This VSP tool can provide substantially less required survey acreage than the UXO-Estimator if an informative prior is used. In many cases, an informative prior in the form of "I'm quite sure that the maximum number of UXO on my site is less than Y." is easily justified and can result in less required survey acreage. This demonstration illustrates how this tool is used for a Type-2 area. 


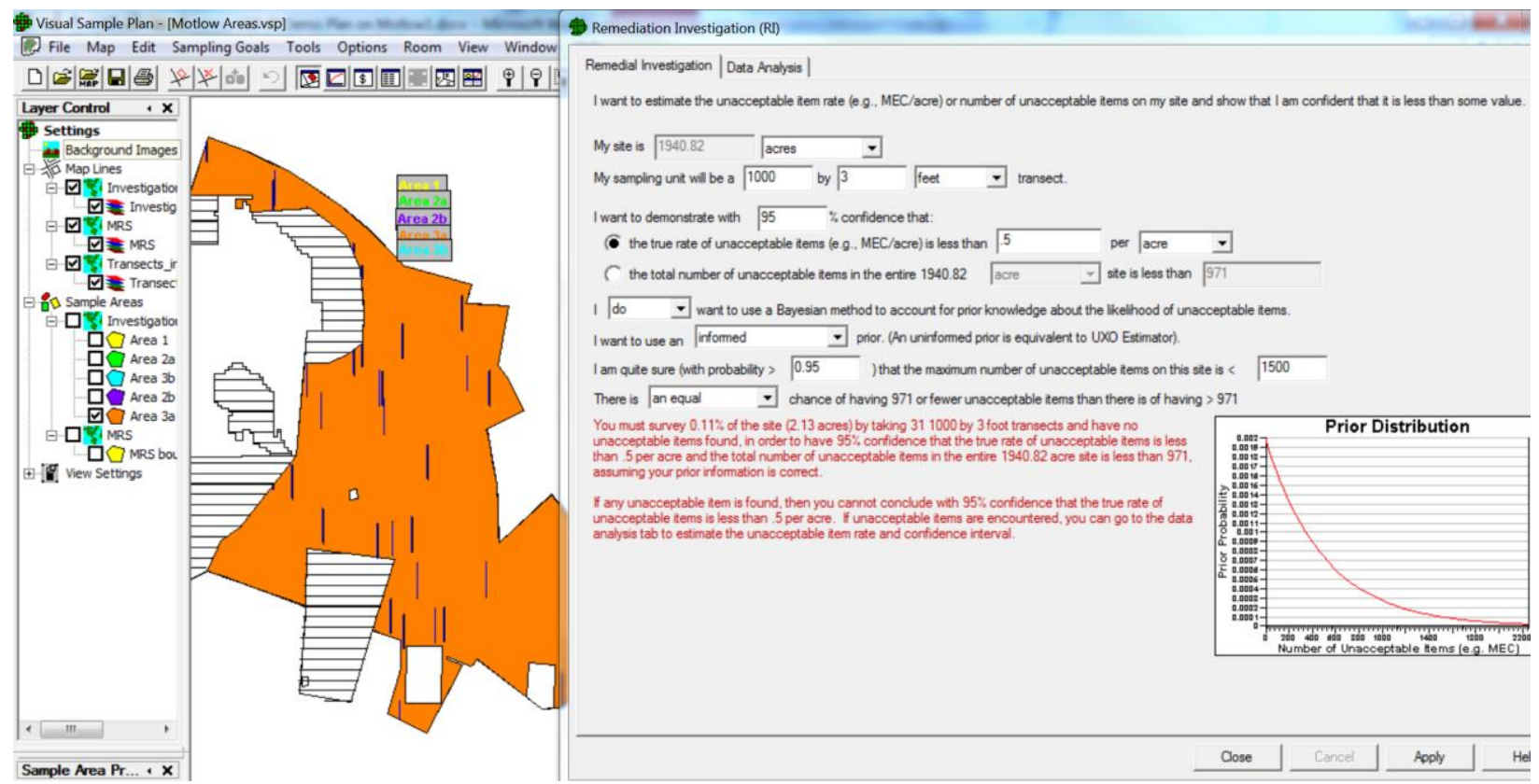

Figure 3. VSP Screen Shot of Bayesian UXO/Acre Estimation and Bounding Survey Design

\subsubsection{Type-3 Areas}

These areas are presumably munitions-free based on a lack of evidence that any munitions were used within them. Although some may argue that these areas should not be included in an RI, many sites are encountering such areas and they are required to either support their presumed clean-site assumption with additional documentation and historical evidence or perform a few transect surveys to provide additional confirmation. This approach requires that the users carefully define what would constitute a TOI. TOI could be defined in a number of different ways including:

- items of explosive hazard

- any fragments related to high explosive munitions

- any munitions debris.

For these areas, two objectives may be possible that would drive the transect survey design requirements.

- Show that you are $\mathrm{X} \%$ confident that at least $\mathrm{Y} \%$ of all possible parcels of a prescribed size do not contain TOI.

- Estimate TOI/acre (such as MEC/acre or some other rate) or the number of possible TOI (e.g., MEC or UXO) and show that we are confident that it is less than some prespecified limit.

The second objective is the same as that for the Type- 2 areas and would draw upon the same VSP tools outlined in that section. For the first objective, a new VSP user dialog has been developed. This new VSP tool draws upon the same underlying mathematical model as the VSP post-remediation verification (VSP-PRV) module, but the user input dialog structure was 
changed to better reflect RI objectives and avoid misuse of this tool. The VSP-PRV user dialog is shown below in Figure 4.

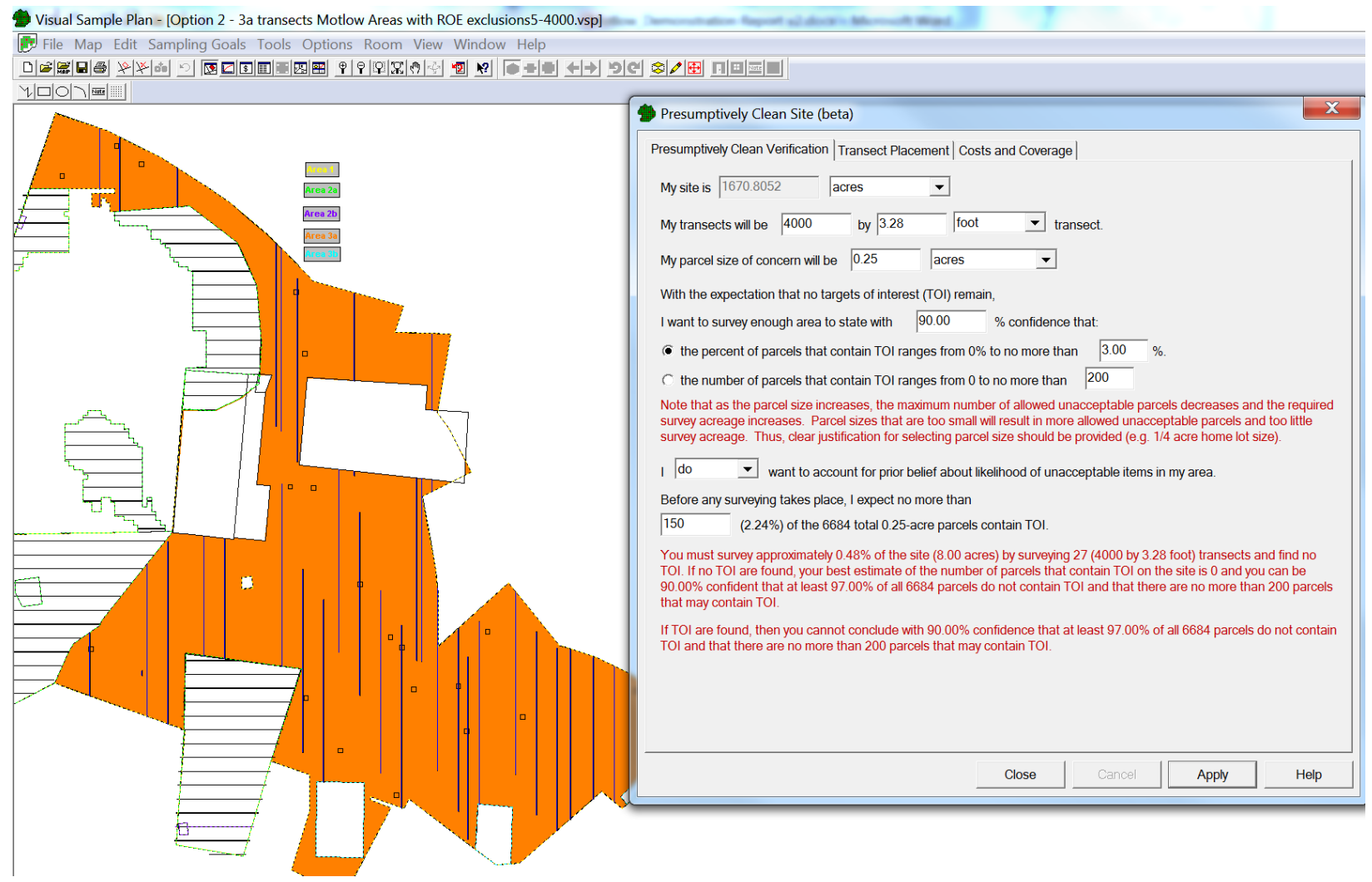

Figure 4. VSP Screen Shot of Presumptively Clean Survey Design

This new VSP module for presumptively clean sites requires the user to specify a parcel size of interest and solves for the survey acreage required to make statistical statements about parcel equivalent areas. Non-Bayesian and Bayesian options exist to provide the user flexibility if prior information is available. For example, if on similar sites or historical use of similar sites suggests that the likelihood of TOI within parcels is rare, that information can be accounted for to reduce the survey acreage required and increase the confidence of few if any TOI in the parcels.

\subsection{ADVANTAGES AND LIMITATIONS OF THE TECHNOLOGY}

The VSP-RI modules provide all the transect design and statistical analysis tools needed to support RIs. Having a single software tool with clear instructions on which module is appropriate for a particular RI objective and type of area significantly improves the standardization and technical defensibility of RI studies on DoD sites.

UXO Estimator is a software tool that has been used to determine the required acreage for one of the RI objectives. However, this tool has several limitations. It only provides the amount of survey acreage required when the objective is to estimate (or confidently bound) MEC or UXO per acre and has no ability to apply a random selection of transects on maps. It also assumes an uninformed Bayesian prior, which suggests that the likelihood of many, many UXO is the same 
as the likelihood of few UXO. The VSP-RI module overcomes these limitations and also addresses the other RI objectives.

\section{PERFORMANCE OBJECTIVES}

The primary objective of this demonstration is to demonstrate the validity and applicability of the VSP-RI modules through onsite demonstrations and with simulations. Specific objectives include:

1. Clearly identify the application of the VSP-RI module and methodologies for three types of areas within an MRS and show how the decision objectives and VSP module use are different for each type of area.

2. Gain real site application experience that can be used to guide the development of an online workflow process for VSP-RI use.

3. Evaluate usability of VSP user dialogs and identify needed improvements.

4. Provide comparison of VSP-RI methodology to UXO Estimator results.

5. Evaluate performance of transects versus grids when applying UXO/acre estimation objective and provide recommendations of appropriate transect dimensions (this will require simulations).

6. Compare the utility of target area boundary delineation methods and density estimation uncertainty.

Each of these performance objectives is defined and summarized in Table 1. Some performance objectives were accomplished using the Motlow, Tennessee, site demonstration and others required a simulation study.

Table 1. Performance Objectives

\begin{tabular}{|c|c|c|c|}
\hline $\begin{array}{l}\text { Performance } \\
\text { Objective }\end{array}$ & Metric & Data Required & Success Criteria \\
\hline \multicolumn{4}{|c|}{ Motlow Site VSP-RI Demonstration Performance Objectives } \\
\hline $\begin{array}{l}\text { 1. Show application of } \\
\text { VSP-RI modules for } \\
3 \text { types of areas }\end{array}$ & $\begin{array}{l}\text { Application of the VSP-RI } \\
\text { modules to three different } \\
\text { types of areas within Motlow } \\
\text { site. }\end{array}$ & $\begin{array}{l}\text { - Clear agreement on } \\
\text { decision objectives for } \\
\text { the } 3 \text { types of areas. } \\
\text { - Transect surveys } \\
\text { - All identified anomalies } \\
\text { to be dug }\end{array}$ & $\begin{array}{l}\text { - Well delineated target } \\
\text { areas (see description) } \\
\text { - Estimate an upper } \\
\text { bound on TOI/acre } \\
\text { - Acceptance of transect } \\
\text { design input parameters. }\end{array}$ \\
\hline $\begin{array}{l}\text { 2. Experience for } \\
\text { developing VSP-RI } \\
\text { workflow process } \\
\text { guidance. }\end{array}$ & $\begin{array}{l}\text { Agreement within VSP-RI } \\
\text { advisory committee of } \\
\text { general workflow process. }\end{array}$ & $\begin{array}{l}\text { - Summary of all steps in } \\
\text { workflow consistent with } \\
\text { site work plan } \\
\text { - Information on objectives } \\
\text { and decision criteria for } \\
\text { each area within MRS }\end{array}$ & $\begin{array}{l}\text { Draft of VSP-RI workflow } \\
\text { process developed. }\end{array}$ \\
\hline
\end{tabular}




\begin{tabular}{||l|l|l|l||}
\hline $\begin{array}{l}\text { Performance } \\
\text { Objective }\end{array}$ & Metric & Data Required & Success Criteria \\
\hline $\begin{array}{l}\text { 3. Demonstrate } \\
\text { usability of VSP-RI } \\
\text { modules and } \\
\text { imprify needed }\end{array}$ & $\begin{array}{l}\text { Contractor understanding/use } \\
\text { of VSP-RI and list of } \\
\text { recommended improvements. }\end{array}$ & $\begin{array}{l}\text { - Transect surveys } \\
\text { - Dug anomalies } \\
\text { - Contractor feedback }\end{array}$ & $\begin{array}{l}\text { Successful application of } \\
\text { VSP-RI modules and } \\
\text { minimal list of needed } \\
\text { improvements. }\end{array}$ \\
\hline $\begin{array}{l}\text { 4. VSP-RI module } \\
\text { comparison with }\end{array}$ & $\begin{array}{l}\text { Cost of transects and } \\
\text { simplicity of use. } \\
\text { Demonstrate that VSP and } \\
\text { UXO Estimator answers are } \\
\text { same when same assumption } \\
\text { is used. }\end{array}$ & $\begin{array}{l}\text { - Cost of transect surveys } \\
\text { under each }\end{array}$ & $\begin{array}{l}\text { VSP-RI survey acreage } \\
\text { required is same as UXO } \\
\text { estimator under certain } \\
\text { conditions. VSP-RI shown } \\
\text { to require less acreage } \\
\text { under alternative } \\
\text { assumptions. }\end{array}$ \\
\hline $\begin{array}{l}\text { 5. Evaluate } \\
\text { performance of } \\
\text { transects vs. grids for } \\
\begin{array}{l}\text { UXO/acre estimation } \\
\text { objective and spatial } \\
\text { coverage index. }\end{array}\end{array}$ & $\begin{array}{l}\text { Desired confidence equals } \\
\text { achieved confidences for } \\
\text { simulations where UXO } \\
\text { spatial density patterns and } \\
\text { number of UXO are varied }\end{array}$ & $\begin{array}{l}\text { - Simulated site data } \\
\text { varying spatial } \\
\text { distribution and number } \\
\text { of UXO. }\end{array}$ & $\begin{array}{l}\text { Guidance to provide VSP- } \\
\text { RI user help on selecting } \\
\text { transect surveys or grid } \\
\text { surveys. }\end{array}$ \\
\hline $\begin{array}{l}\text { 6. Compare the utility } \\
\text { of different possible } \\
\text { target area boundary } \\
\text { delineation methods. }\end{array}$ & $\begin{array}{l}\text { Ease of use } \\
\text { Are boundaries, based } \\
\text { on systematic transects, } \\
\text { sufficiently bounding } \\
\text { high-density areas for } \\
\text { future remediation } \\
\text { efforts? }\end{array}$ & $\begin{array}{l}\text { - Synthesized scenarios } \\
\text { and transect surveys } \\
\text { - Actual Transect surveys } \\
\text { Delineation objectives } \\
\text { (e.g., confidence } \\
\text { boundary area is } \\
\text { associated with target } \\
\text { area or not associated } \\
\text { with background) }\end{array}$ & $\begin{array}{l}\text { - Boundary tools support } \\
\text { cost estimation and } \\
\text { associated uncertainty of } \\
\text { remediation needs. } \\
\text { Boundary delineation } \\
\text { results on synthesized } \\
\text { sites are conservative } \\
\text { (meet or exceed specified } \\
\text { delineation objectives). }\end{array}$ \\
\hline
\end{tabular}

\subsection{Objective 1: Show Application of VSP-RI Modules For Three Types Of Areas}

There was a need to clearly illustrate the application of the VSP-RI module and methodologies for the three types of areas typically found within an MRS during an RI as outlined in Section 2. The decision objectives and survey design requirements and, hence, the VSP module selected depend on the type of area being dealt with. The Motlow site had areas within the MRS that represent these three types of areas. A primary objective was to demonstrate which VSP-RI module is most appropriate for each type of site and illustrate its use. In summary, the three areas and recommend VSP modules are:

- Known munitions use at specific but unknown target locations (target area discovery with systematic transect design).

- Potential munition use with no clear firing at targets (RI rate estimation with systematic or random transect design).

- Little to no known munitions use site (presumptively clean) with stake holder or regulatory driver for validation of assumptions (RI rate estimation or verification sampling with random or systematic transect design). 


\subsubsection{Metric, Data Requirements, and Success Criteria}

Demonstrating a successful application of the VSP-RI modules to the Motlow site was the primary metric for this task. The geophysical survey data from transects that were designed using VSP along with anomaly locations, dig results, and types of munitions found were required. Success is defined as good estimates of and upper bounds on TOI/acre, and acceptance of transect design input parameters by project team and regulators. Although we wanted to demonstrate the performance of improved quantifiable target-area delineation methods (see performance objective 6), these new delineation methods were not sufficiently mature to use on this demonstration.

\subsection{Objective 2: Gain Experience for Developing VSP-RI Workflow Process Guidance}

There are several VSP tools that are appropriate for different aspects of the RI process and under certain conditions. To avoid misuse of VSP, ESTCP requested that we develop online guidance on using VSP for RIs at each step of the workflow process. This demonstration provided valuable experience in working through an RI on a real site. This experience was used to guide our development of the VSP-RI workflow process guidance. It also gave us a specific site context to use in our discussions with the VSP-RI advisory committee as we developed this workflow guidance system.

\subsubsection{Metric}

Acceptance by our VSP-RI advisory committee of a draft VSP-RI workflow that has now been developed based on the experience gained from this demonstration.

\subsubsection{Data Requirements}

The geophysical survey data from transects that are designed using VSP along with anomaly locations, dig results, and types of munitions found were required.

\subsubsection{Success Criteria}

Success was measured through the development of a draft outline of the RI workflow process as it pertains to all VSP-RI modules and identifying which modules should be used at each step of the RI process to satisfy each RI objective.

\subsection{Objective 3: Evaluate Usability of VSP and Identify Needed Improvements}

As we used the VSP-RI modules within this demonstration, we identified needed changes to the user dialogs, processing algorithms, outputs, or other features. This objective captures the need for continuous improvement within VSP to improve ease of use, protect against misuse, and provide needed information for decision-making. 


\subsubsection{Metric and Data Requirements}

An important metric was whether the contractor understood how to properly apply the VSP-RI modules. A list of recommended improvements was also an important metric. Data requirements are the same as 3.2.2 above.

\subsubsection{Success Criteria}

Contractor feedback on ease of use and VSP clarity determined success. Also, the recommended VSP improvements were minimal, such that the quality of the initial VSP-RI modules was deemed acceptable.

\subsection{Objective 4: VSP-RI Module Comparison with UXO Estimator}

There are multiple VSP-RI modules that are applicable under different RI objectives. One of those modules focuses on providing an estimate of TOI/acre and showing that it is less than some pre-specified limit. One of the options under that module involves a Bayesian statistical model. When an uninformed Bayesian prior is selected as input into this VSP module, the amount of survey acreage calculated is the same as that calculated by UXO Estimator given the same input parameters. This performance objective is to illustrate VSP-RI vs. UXO Estimator equivalence using various input parameters and to contrast the VSP-RI methodology against UXO Estimator results when other assumptions are used.

\subsubsection{Metric}

Reduced survey acreage for comparable performance objectives resulting in cost savings was a key metric. Demonstrating simplicity of use and equivalency of VSP-RI module with UXO Estimator using certain inputs were also important metrics.

\subsubsection{Data Requirements}

We used dig information on the identified munitions items from previously remediated areas (See Figures 5 and 6), currently called Area 1 to form the basis for the Bayesian priors used in the VSP-RI module. Other data requirements are shown in Section 3.2.2.

\subsubsection{Success Criteria}

An equivalence of the VSP-RI and UXO Estimator results for the uninformed prior case provides a successful demonstration. Also showing that the VSP-RI module results in less survey acreage required than the UXO Estimator, thereby resulting in significant cost savings, when reasonable assumptions are used demonstrates success.

\subsection{Objective 5: Evaluate Performance of Transects Vs. Grids for UXO/Acre Estimation Objective and Spatial Coverage Index}

Most RI projects want to complete their survey objectives with sampling units that are as large as possible as it makes application easier. Many RI projects have used grids to meet the required 
area objectives as grids provide an easier area for reliably picking targets from the surveys as compared to transects. Other previously supported sampling design software products have promulgated the use of grids. In this objective, we explore the performance of grid-sized decision units $(100 \times 100,50 \times 50$, and $50 \times 100$ meter) and transect-sized decision units to be a representative sample when estimating the TOI rate within a study area. Within this demonstration, we explore the tradeoffs between transect and grid sampling through simulations and determine whether guidance and spatial coverage metrics should be added to VSP-RI modules in the future.

\subsubsection{Metric}

In the simulation study, the metric that supports the use of varied sampling unit dimensions is whether the simulated confidence matches the designed confidence within the simulation error tolerance. We evaluate this performance from repeated samplings using different transect dimensions and varied TOI spatial density patterns and TOI rates.

\subsubsection{Data Requirements}

Simulated sites that vary the number of TOI, their spatial distribution, and TOI/acre are required.

\subsubsection{Success Criteria}

The recommended sampling units meet the designed confidence for the majority of applications of the RI design tool.

\subsection{Objective 6: Compare the Utility of Different Possible Target Area Boundary Delineation Methods}

One objective of an RI is to delineate target areas for future remediation. An inaccurate delineation can result in either an over or under estimation of the remediation costs. VSP currently has reproducible boundary delineation tools that can automatically delineate target areas when the user specifies a threshold between background and high-density areas. However, the appropriateness of this threshold is not currently quantified in VSP nor are the uncertainties in the specified boundary. We are exploring different possible VSP additions to help users quantify the results of the boundary of delineated target areas and explore the sensitivity of remediation costs to changes in the boundary. We planned to use synthesized target areas to measure the performance of the developed delineation quantification methods. We also planned to demonstrate the tools on previously bounded high-density areas and some of the high-density areas identified at the Motlow site. However, we were unable to achieve this objective in this demonstration because of the complexity of the new delineation methodology that has delayed its development in VSP. When these methods become available, we plan to use data from the Motlow demonstration to test and demonstrate them .

The objective of the quantifiable boundary of delineation is to provide a statistical statement of confidence in the boundary's effectiveness of containing area associated with the high-density area and not containing area associated with the observed background rate and distribution. 


\subsubsection{Metric}

We planned to use the synthesized data as a baseline and the boundary delineations based on varied applied transect spacings to validate the quantifiable delineation methods. With synthesized high-density areas, the metric would be reported as percent of the high density correctly bounded. With respect to the Motlow site data, in the future we will determine ease of use and functional utility of each boundary delineation methodology based on our own use and feedback from users.

\subsubsection{Data Requirements}

The geophysical survey data from transects that are designed using VSP along with anomaly locations, dig results, and types of munitions found are required. We also will generate synthesized sites and target areas for evaluation and demonstration of the methods quantified statistical performance.

\subsubsection{Success Criteria}

Again, because of the delay in delineation methods development, this performance objective cannot be achieved during this demonstration. However, in the future, we will use data generated during this demonstration for testing and evaluation, and success will be measured by whether an improved more accurate quantifiable target area delineation tool can be provided or whether just providing a cost/boundary sensitivity analysis function is sufficient to meet the DoD cost estimation objectives. A successful method is one that correctly bounds the high-density area within the prescribe data quality objective.

\section{SITE DESCRIPTION}

\subsection{Site Selection}

The Motlow Range near Tullahoma, Tennessee, was selected for this demonstration because several site-selection considerations were met. First, the site is scheduled for an RI within the time frame required for our demonstration. The draft work plan was already under development but the site managers, U.S. Army Corps of Engineers (USACE), and regulators were open to some modifications in the work plan that were required to meet our demonstration objectives.

The site also contained two and perhaps three of the types of areas we needed for this demonstration. The contractor had already been using VSP to support transect survey design requirements and was very interested in learning more about the new VSP-RI methods and applying them on the Motlow site.

\subsection{Site History}

In 1941, the Motlow Range was created by leasing approximately 4000 acres of land approximately 3 miles west of Tullahoma, Tennessee. The Motlow Range was developed as an auxiliary training area for Camp Forrest, one of the U.S. Army's largest training bases during World War II. Camp Forrest, located approximately 5 miles east of Tullahoma, did not contain an adequate amount of land for artillery firing; therefore, the U.S. Government partially solved 
this issue in 1940 by leasing 36,000 acres for the creation of Spencer Artillery Range. The Spencer Range, however, was about 50 miles from Camp Forrest, so Motlow Range was created to develop nearby firing ranges for light artillery, mortars, and machine guns. Additional leases were subsequently established to augment the original land, building Motlow Range to approximately 7528 acres. Firing ranges within Motlow were typically oriented toward an interior impact area, which supported activities such as an anti-tank range, anti-aircraft (towed target) range, aircraft machine gun range, and various small arms ranges. By 1943, maneuvers taking place at the Motlow Range involved more than 13,000 troops. Based on the archives search report supplement (USACE 2004), nine ranges were located at the Motlow Range. These overlapping ranges total 3646 acres.

By 1946, Motlow and its ranges were deactivated by the U.S. War Department and declared surplus. The USACE South Atlantic Division conducted a preliminary inspection to determine the requirements for additional de-dudding operations in December 1954. This inspection revealed evidence of $60-\mathrm{mm}$ and $81-\mathrm{mm}$ mortar shells, as well as 30- and 50-caliber shells, hand grenades, and rifle grenades. It was recommended that the impact areas be burned to remove undergrowth and dead vegetation to allow ordnance searches and issuance of a certificate of clearance. Clearance activities were performed over 3604 acres from 1955 to 1956, with subsequent periodic inspections from 1957 through 1969. Occasional recoveries of a variety of ordnance were reported during these inspections.

Several MEC-related studies were completed previously at the Motlow Range. Summaries of the results of the prior investigations and removal actions are provided below and in Figure 5. As noted below, the majority of the MEC finds were along the western portion of the MRS.

1994 Archives Search Report. The USACE Rock Island District conducted a site visit and historical data collection for the former Motlow Range in 1994. The findings were documented in the archives search report (ASR) (USACE 1994). The ASR provided a detailed history of the site (including historical ordnance at the site), summarized the results of the visual site inspection, and evaluated potential hazards associated with ordnance. The former range was divided into 11 areas for the ASR site visit: Area A through Area K (Figure 5). All areas, except Areas F and G, were characterized as confirmed or potential areas containing a threat due to the suspected presence of ordnance. Area F was used for small arms training only, and Area G was not associated with any munitions-related activities. These area designations were adopted by and referenced in several subsequent removal actions and studies (see below). 


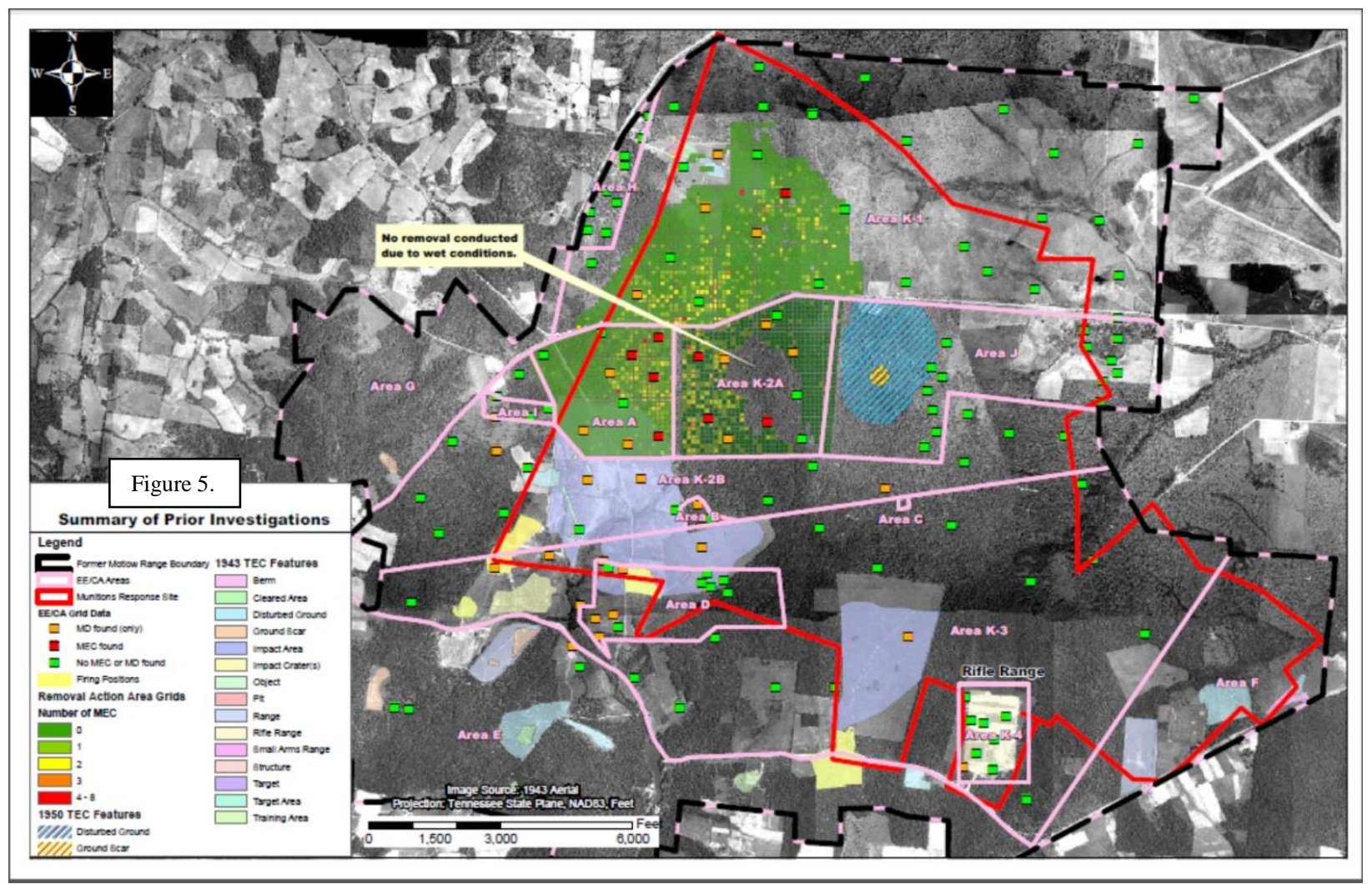

Figure 5. Summary of Prior Motlow Site Investigations

1995 Removal Action (Area A). In 1995, a removal action was performed within Area A, where the Motlow State Community College (MSCC) was building new library, nursing, and technology buildings, and some additional areas associated with the support of those buildings (covering approximately 14 acres). The clearance was conducted to 4 feet below ground surface (bgs) and revealed nine UXO, all of which were related to 37-mm projectiles. In addition, 722 anomalies were investigated in Area $\mathrm{C}$, adjacent to a roadside park. This clearance was conducted to 6 inches bgs over 1 acre; no UXO were discovered within Area C.

1998 Engineering Evaluation/Cost Analysis Report. An engineering evaluation and cost analysis (EE/CA) was completed for the former Motlow Range in 1998. The EE/CA investigated 2797 anomalies detected within 142 grids (most of which were 100-foot x 100-foot, although some grids in wooded areas and were 50 x 50 feet). Nine UXO items were discovered during this investigation (Figure 5 shows the grids in which these items were found). Areas A, $\mathrm{K}-1$, and $\mathrm{K}-2 \mathrm{a}$ were determined to be those areas where a risk of exposure to UXO existed; Areas $\mathrm{C}, \mathrm{E}$, and $\mathrm{H}$ were recommended for no further action; and the rest of the areas prescribed a minimal risk of exposure to UXO (Parsons 1998).

2002 Removal Action (Area A, K-1 and K-2a). A removal action was performed in 2002 to address the areas determined during the EE/CA that may contain UXO (i.e., Areas A, K-1, and K-2a). During the removal action, Area A was surveyed and flagged; however, the area was found to have an unexpectedly high anomaly density and removal actions in that area were postponed, being conducted under a separate effort in 2003 (see below). The removal action to 
6 inches below surface was performed within 293 grids in Area K-1 (approximately 67 acres), where $33 \mathrm{UXO}$ and 247 pounds of munitions debris were removed (Figure 5).

2003 Removal Action (MSCC parcel). A removal action also was performed on the MSCC parcel (approximately 180 acres) in 2003. Over 30,000 anomalies were investigated; 317 UXO were found (primarily 37-mm projectiles), and 1400 pounds of munitions debris were removed. Each of the 787 grids passed quality control (QC) and quality assurance (QA) inspection (ZAPATA Engineering 2004).

2004 Historic Photograph Analysis Report. In 2004, a Geographic Information System (GIS)based historical photographic analysis was completed by the U.S. Army Engineer Research and Development Center's Topographic Engineering Center (TEC). This analysis interpreted black and white, vertical aerial photography spanning selected years from 1943 to 1950. Selected features such as impact areas, disturbed ground, firing points, and other indications of military training were noted (Figure 5).

2007 Removal Action (Area K-1 and K-2a). A third removal action was performed in 2006 and 2007 over a portion of Area K-1 (431 acres) and Area K-2a (273 acres). The removal action cleared to 6 inches bgs, detecting 40,147 anomalies and recovering 367 UXO items, mostly associated with 37-mm projectiles (355 items); however, three 3-inch Stokes mortars, two 155$\mathrm{mm}$ projectiles, and a 2.36-inch rocket also were found during this operation (ZAPATA Engineering 2007).

\subsection{CONCEPTUAL SITE MODEL}

Prior to the RI study, a preliminary Conceptual Site Model (CSM) was prepared to facilitate the development of a technical approach for the RI at the Motlow Range Complex. The CSM describes the characteristics of the MRS, including the known or suspected types of MEC present, anticipated locations and distribution of MEC contamination, possible exposure media, receptors, and potentially complete contaminant exposure pathways. The CSM is a "living document" updated throughout the project as assumptions change and new data becomes available. The initial CSM was based on current site knowledge obtained from available site documents. The 3646-acre Range Complex MRS was divided into three general areas for this initial CSM: Area 1 (Prior Removal Action Areas), where MEC may have been present but have now been removed; Area 2 (Former Range Areas and Firing Points), where there is strong evidence of prior munitions use so MEC are potentially present; and Area 3 (Buffer Areas and Small Arms Ranges), where there is minimal or no evidence of MEC presence. The areas are shown on Figure 6 and are described further below.

For purposes of this CSM and the RI/Feasibility Study, a "MEC contaminated" area is defined as being affected by concentrated munitions use, which is characterized by both high subsurface anomaly density and the presence of MEC and/or large quantities of munitions debris. 


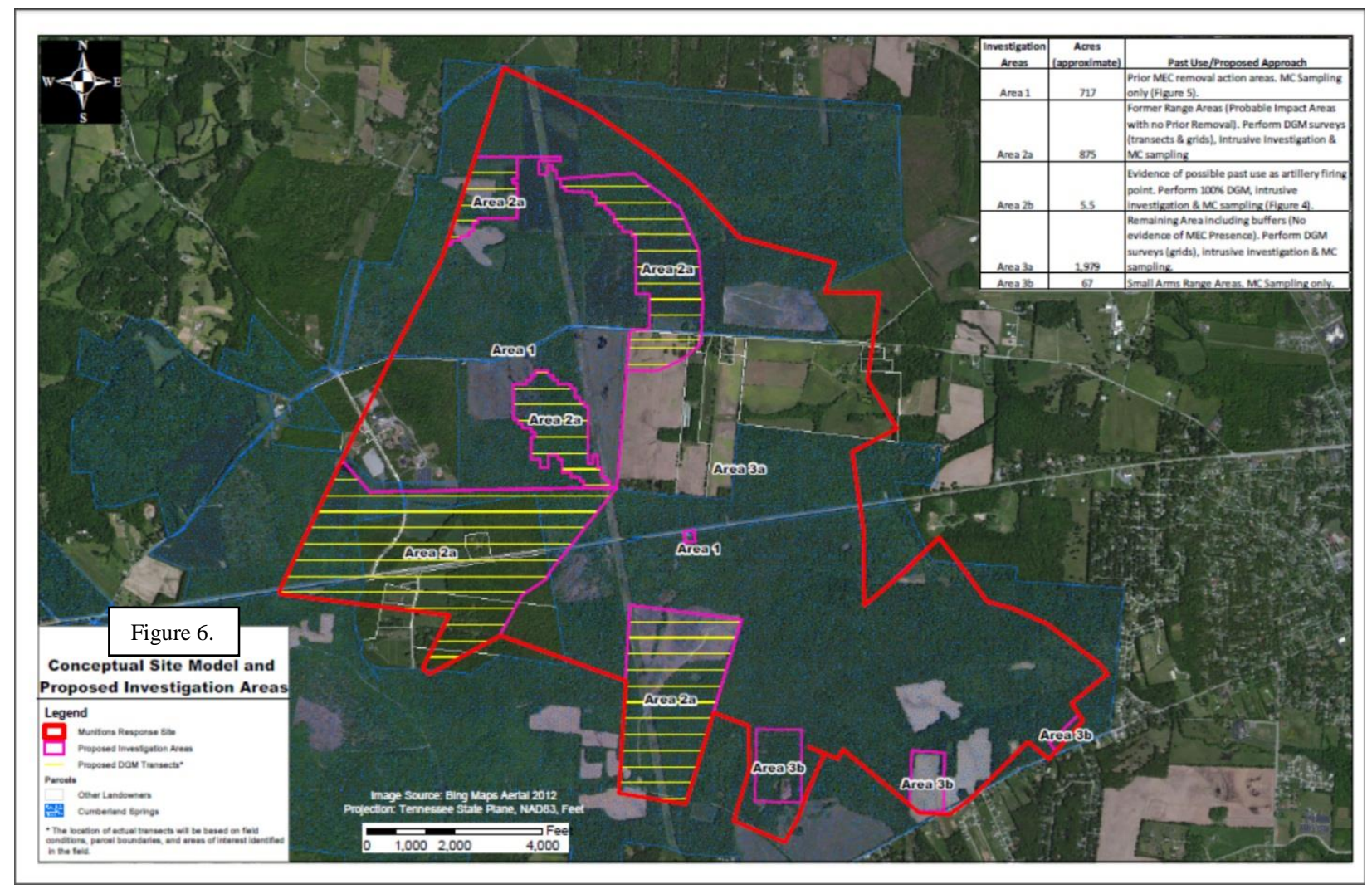

Figure 6. Conceptual Site Model and Proposed Investigation Areas

Area 1: Prior Removal Action Areas. These two parts of the MRS include the areas that were subject to previous removal actions in 1995, 2002, 2003, 2006, and 2007. These areas were previously designated in various historical documents as Areas A, C, K-1, and K-2a. Area 1 incorporates areas with known historic MEC impacts and evidence of prior concentrated munitions use. The land uses in Area 1 are primarily a combination of forestry and wildlife management, though the formerly designated Area A is largely occupied by Motlow State Community College (MSCC). Based on these land uses, potential receptors include MSCC staff and students, loggers, hunters, and site visitors, as well as ecological receptors. Area 1 includes grids within formerly designated Areas A, C, K-1, and K-2a where MEC have been found, and there is a high degree of confidence regarding the past use of Area 1 (i.e., target/impact area). The prior removal actions were completed to a depth of at least 6 inches bgs and, while unknown, it is considered unlikely that MEC remain at depths greater than 6 inches bgs. The 6-inch clearance depth was identified in the EE/CA action memorandum based on the characterized MEC hazards and exposure pathways. QA was conducted and passed by USACE over the removal action grids. The forms did not indicate that the QA inspection was limited to 6 inches; therefore, it is understood that the grids were cleared to depth of detection. Because of these previous removals, it is anticipated that the MEC exposure pathways in Area 1 are currently incomplete, and no additional MEC clearance will be necessary within Area 1. 
Area 2: Former Range Areas and Firing Points. Area 2 consists of portions of the Range Complex MRS that were not addressed during the previous removal actions but, based on known historic use and other available data (e.g., TEC photographic analysis), are either known or suspected to contain MEC and/or munitions constituents (MC) resulting from artillery or mortar training. For purposes of the initial CSM, Area 2 was subdivided into two parts, Areas 2 a and $2 b$, based on the prior use of the area (i.e., impact areas or firing points).

Area 2a encompasses parts of the MRS identified in the 1994 ASR and TEC photographic analysis as potential target or impact areas related to the former anti-tank and mortar ranges (Figure 6). The land uses in Area 2a are primarily a combination of forestry and agriculture, though there are small areas of residential land use. Based on these land uses, potential receptors include residents, commercial workers, loggers, hunters, and site visitors, as well as ecological receptors. The CSM for Area 2a assumes that the major concentration of MEC and munitions debris (i.e., "MEC contamination") will be focused on at least one former target location in a circular or elliptical pattern. The use of these former target or impact areas means that any MEC found are most likely to be UXO. The anomaly density at these target locations is anticipated to be significantly elevated above background levels, while the areas outside the target locations are anticipated to have lower anomaly density and be unaffected by concentrated munitions use.

Area $2 \mathrm{~b}$ includes several areas that were indicated to be possible firing positions, none of which have been investigated to date. The land uses in Area $2 \mathrm{~b}$ are primarily forestry and agriculture. Based on these land uses, potential receptors include agricultural workers, loggers, hunters, and site visitors, as well as ecological receptors. The CSM for Area $2 b$ assumes that the major concentration of MEC and munitions debris (i.e., "MEC contamination") would be found in burial pits or trenches in the vicinity of the former firing points. Based on current site data and recorded discoveries, the munitions that might be present at the former firing positions are 37-mm projectiles, 60-mm mortars, 3-inch Stokes mortars, 81-mm mortars, 155-mm projectiles, and 2.36-inch rockets. The possible presence of these munitions makes the MEC exposure pathways in Area $2 \mathrm{~b}$ potentially complete, which means that potential MEC hazards exist within Area 2b; however, the nature of these areas (burial pits) means that these hazards are only anticipated to be in the subsurface.

Area 3: Buffer Areas and Small Arms Ranges. These portions of the Range Complex MRS include areas that were not investigated extensively during the previous EE/CA but, based on known historic use and other available data (e.g., EE/CA and TEC photographic analysis), are considered unlikely to contain residual MEC. For the initial CSM, Area 3 has been subdivided into Areas $3 \mathrm{a}$ and $3 \mathrm{~b}$ based on their prior use (i.e., range buffer areas or small arms ranges).

Area 3a incorporates the buffer areas bordering Areas 1 and 2 (Figure 6). Some of these areas were subject to investigation during the $1998 \mathrm{EE} / \mathrm{CA}$, at which time they were largely concluded to present a minimal risk of exposure to UXO. The land uses in Area 3a are primarily forestry and agriculture, though small areas of residential land use are present. Based on these land uses, potential receptors include residents, commercial workers, agricultural workers, loggers, hunters, and site visitors, as well as ecological receptors. The CSM for Area 3a assumes that there are no areas affected by concentrated munitions use present. 
Area $3 \mathrm{~b}$ comprises several areas that were associated with former small arms ranges at the Range Complex MRS (Figure 6). The land uses in Area 3b are forestry and agriculture. Based on these land uses, potential receptors include agricultural workers, loggers, hunters, and site visitors, as well as ecological receptors. Intact small arms ammunition are not MEC, so no significant explosive hazards would be present at these former ranges.

\subsection{SITE GEOLOGY}

There are three soil associations in the former Motlow Range. The first and largest is the Dickson-Mountview-Armour association. It is composed of gently rolling and rolling, well drained and moderately well drained, silt loams on broad ridge caps, and nearly level, poorly drained silt loams in depressions, and near the head of drainage ways. The Dellrose- MimosaRock Outcrop association consists of steep, cherty, well drained upland soils with brown, cherty, silty clay loam sub soils greater than 6 feet to bedrock; and steep, well drained, cherty upland soils that have yellowish brown, firm, plastic subsoils 2 to 5 feet to bedrock; and areas of outcropping limestone. The third is the Bodine-Mountain-Ennis association. It consists of deep, well drained, silty soils on steep hillsides leading to narrow cherty bottom soils along meandering drainage ways.

\subsection{MUNITIONS CONTAMINATION}

The following summary was derived from the draft work plan prepared by Parsons. Multiple MEC and munitions debris items were previously recovered from the project site, indicating there is the potential for additional items to be present. There are several potential MEC items that might be found at the former Motlow Range including anti-tank rifle grenades, 37-mm projectiles, $75-\mathrm{mm}$ projectiles, 105-mm projectiles, 60-mm mortars, 3-inch Stokes mortars, 81-mm mortars, 155-mm projectiles, and 2.36-inch rockets. A list of the MEC known or suspected to be present at the project site is presented in Table 2.

Table 2. Munitions Potentially Present at the Former Motlow Range, Chemical Compositions, and MCs

\begin{tabular}{|c|c|c|}
\hline $\begin{array}{l}\text { Munitions } \\
\text { Type/Model }\end{array}$ & $\begin{array}{l}\text { Composition } \\
\text { (Case and Filler) }\end{array}$ & $\begin{array}{l}\text { MC Selected for } \\
\text { Analysis }\end{array}$ \\
\hline $\begin{array}{l}\text { Grenade, Rifle, } \\
\text { Anti-Tank, M9A1 }\end{array}$ & $\begin{array}{l}\text { Munition Case: Sheet Steel - Carbon, Iron, Manganese, Phosphorus, Sulfur } \\
\text { Munition Filler: Pentaerythritol Tetranitrate (PETN), Tetryl, Trinitrotoluene } \\
\text { (TNT) } \\
\text { Booster: Tetryl } \\
\text { Primer }{ }^{(4)} \text { : Antimony Sulfide, Barium Nitrate, Copper, Iron, Lead, Lead } \\
\text { Azide, Lead Styphnate, Tetrazene, Zinc }\end{array}$ & $\begin{array}{l}\text { Metals } \\
\text { N/A } \\
\underline{\text { Explosives }} \\
\text { As a conservative measure, a } \\
\text { full explosives panel will be } \\
\text { analyzed }\end{array}$ \\
\hline $\begin{array}{l}\text { Rocket, 2.36-inch, } \\
\text { HEAT (M6) }\end{array}$ & $\begin{array}{l}\text { Munition Case: Sheet Steel - Carbon, Iron, Manganese, Phosphorus, Sulfur } \\
\text { Rocket Motor: Barium Nitrate, Diazodinitrophenol, Nitrocellulose, } \\
\text { Nitroglycerin, Potassium Chlorate, Potassium Nitrate, Potassium Perchlorate } \\
\text { Warhead: Iron, PETN, TNT } \\
\text { Fuze: Iron, Lead Azide, PETN (Pentaerythritol Tetranitrate), Tetryl }\end{array}$ & $\begin{array}{l}\text { Metals } \\
\text { Barium } \\
\text { Explosives } \\
\text { As a conservative measure, a } \\
\text { full explosives panel will be } \\
\text { analyzed }\end{array}$ \\
\hline
\end{tabular}




\begin{tabular}{|c|c|c|}
\hline $\begin{array}{l}\text { Munitions } \\
\text { Type/Model }\end{array}$ & $\begin{array}{l}\text { Composition } \\
\text { (Case and Filler) }\end{array}$ & $\begin{array}{l}\text { MC Selected for } \\
\text { Analysis }^{(1)}\end{array}$ \\
\hline $\begin{array}{l}\text { Small Arms } \\
\text { General: Cartridge, } \\
\text {.30 caliber } \\
\text { (includes carbine) }\end{array}$ & $\begin{array}{l}\text { Cartridge case: Copper Alloy - Copper, Iron, Lead, Zinc } \\
\text { Propellant: Calcium Carbonate, Copper, Dibutylphthalate, Diphenylamine, } \\
\text { Dinitrotoluene }{ }^{(3)} \text {, Ethyl Centralite, Lead, Iron, Nitrocellulose }{ }^{(2)} \text {, Nitroglycerin, } \\
\text { Potassium Nitrate, Sodium Sulfate, Zinc } \\
\text { Primer }{ }^{(4)} \text { : Aluminum Powder, Antimony Sulfide, Barium Nitrate, Copper, } \\
\text { Iron, Lead, Lead Styphnate, Pentaerythritol Tetranitrate (PETN), Tetrazene, } \\
\text { Zinc } \\
\text { Projectile: Antimony, Carbon, Copper, Iron, Lead, Manganese, Silicon, } \\
\text { Sulfur, Zinc } \\
\text { Tracer }{ }^{(5)} \text { : Barium Peroxide, Calcium Resinate, Magnesium Powder, } \\
\text { Polyvinyl Chloride, Strontium Nitrate, Strontium Oxalate, Strontium } \\
\text { Peroxide, Zinc Stearate }\end{array}$ & $\begin{array}{l}\text { Metals } \\
\text { Antimony, Copper, Lead } \\
\text { Explosives } \\
\begin{array}{l}\text { A full explosives panel will be } \\
\text { analyzed }\end{array}\end{array}$ \\
\hline $\begin{array}{l}\text { Small Arms } \\
\text { General: } \\
\text { Cartridge, } \mathbf{. 4 5} \\
\text { caliber }\end{array}$ & $\begin{array}{l}\text { Cartridge case: Copper Alloy - Copper, Iron, Lead, Zinc } \\
\text { Propellant: Diphenylamine, Dinitrotoluene }{ }^{(3)} \text {, Nitrocellulose }{ }^{(2)} \text {, Nitroglycerin, } \\
\text { Potassium Nitrate, Potassium Sulfate } \\
\text { Primer }{ }^{(4)} \text { : Antimony Sulfide, Barium Nitrate, Calcium Silicide, Copper, Iron, } \\
\text { Lead Styphnate, Lead Thiocyanate, Nitrocellulose }{ }^{(5)} \text {, Pentaerythritol } \\
\text { Tetranitrate (PETN), Potassium Chlorate, Tetrazene, Trinitrotoluene (TNT), } \\
\text { Zinc } \\
\text { Projectile: Antimony, Carbon, Copper, Iron, Lead, Manganese, Phosphorus, } \\
\text { Silicon, Sulfur, Zinc } \\
\text { Tracer }{ }^{(5)} \text { : Barium Peroxide, Calcium Resinate, Magnesium, Strontium } \\
\text { Nitrate, Strontium Oxalate, Strontium Peroxide, Zinc Stearate }\end{array}$ & $\begin{array}{l}\underline{\text { Metals }^{(3)}} \\
\text { Antimony, Copper, Lead } \\
\underline{\text { Explosives }}{ }^{(4)} \\
\begin{array}{l}\text { A full explosives panel will be } \\
\text { analyzed }\end{array}\end{array}$ \\
\hline $\begin{array}{l}\text { Small Arms } \\
\text { General: Cartridge, } \\
\mathbf{5 0} \text { caliber, } \\
\text { Machine Gun }\end{array}$ & $\begin{array}{l}\text { Cartridge case: Brass - Copper, Zinc } \\
\text { Propellant: Calcium Carbonate, Dibutylphthalate, Diphenylamine, } \\
\text { Dinitrotoluene }{ }^{(3)} \text {, Nitrocellulose( }{ }^{(2)} \text { Nitroglycerin, Potassium Nitrate, } \\
\text { Potassium Sulfate, Sodium Sulfate } \\
\text { Primer }{ }^{(4)} \text { : Aluminum Powder, Antimony Sulfide, Barium Nitrate, Calcium } \\
\text { Silicide, Copper, Iron, Lead, Lead Styphnate, Lead Thiocyanate, Potassium } \\
\text { Chlorate, Pentaerythritol Tetranitrate (PETN), Tetrazene, Zinc } \\
\text { Projectile: Antimony, Carbon, Copper, Iron, Lead, Manganese, } \\
\text { Molybdenum, Sodium Carbonate Monohydrate, Silicon, Sulfur, Zinc } \\
\text { Tracer }{ }^{(5)} \text { : Barium Peroxide, Calcium Resinate, Magnesium Powder, } \\
\text { Polyvinyl Chloride, Potassium Perchlorate, Strontium Nitrate, Strontium } \\
\text { Oxalate, Strontium Peroxide, Zinc Stearate }\end{array}$ & $\begin{array}{l}\underline{\text { Metals }^{(3)}} \\
\text { Antimony, Copper, Lead } \\
\underline{\text { Explosives }}{ }^{(4)} \\
\text { A full explosives panel will be } \\
\text { analyzed } \\
\underline{\text { Miscellaneous }} \\
\text { Perchlorate }^{(6)}\end{array}$ \\
\hline $\begin{array}{l}\text { Shell, 37-mm, } \\
\text { Fixed, High } \\
\text { Explosive (HE), Mk } \\
\text { II }\end{array}$ & $\begin{array}{l}\text { Cartridge case: Copper Alloy - Copper, Iron, Lead, Zinc } \\
\text { Propellant: Dibutylphthalate, Dinitrotoluene }{ }^{(3)} \text {, Diphenylamine } \\
\text { Nitrocellulose }^{(2)} \text {, Nitroglycerin, Potassium Chlorate, Potassium Nitrate, Sulfur } \\
\text { Primer }^{(4)} \text { : Antimony Sulfide, Barium Nitrate, Lead Thiocyanate, } \\
\text { Trinitrotoluene (TNT) } \\
\text { Projectile/Rotating Band: Steel/Copper Alloy - Carbon, Copper, Iron, } \\
\text { Lead, Manganese, Phosphorus, Sulfur, Zinc } \\
\text { Projectile Filler: Trinitrotoluene (TNT) } \\
\text { Fuze, Projectile, Base Detonation, M38A1: Carbon, Iron, Manganese, } \\
\text { Phosphorus, Sulfur, Tetryl } \\
\text { Fuze Primer }{ }^{(4)} \text { : Antimony Sulfide, Lead Azide, Potassium Chlorate }\end{array}$ & $\begin{array}{l}\text { Metals } \\
\text { Copper, Zinc } \\
\text { Explosives } \\
\text { As a conservative measure, a } \\
\text { full explosives panel will be } \\
\text { analyzed }\end{array}$ \\
\hline
\end{tabular}




\begin{tabular}{|c|c|c|}
\hline $\begin{array}{l}\text { Munitions } \\
\text { Type/Model }\end{array}$ & $\begin{array}{l}\text { Composition } \\
\text { (Case and Filler) }\end{array}$ & $\begin{array}{l}\text { MC Selected for } \\
\text { Analysis }\end{array}$ \\
\hline $\begin{array}{l}\text { Shell, 75-mm, } \\
\text { Fixed, Shrapnel, } \\
\text { MkI }\end{array}$ & $\begin{array}{l}\text { Cartridge Case: Copper - Copper, Iron, Lead, Zinc } \\
\text { Propellant: Dibutylphthalate, Dinitrotoluene }{ }^{(3)} \text {, Diphenylamine, } \\
\text { Nitrocellulose }^{(2)} \text {, Nitroglycerin, Potassium Nitrate, Sulfur } \\
\text { Primer }{ }^{(4)} \text { : Antimony Sulfide, Barium Nitrate, Lead Thiocyanate, Potassium } \\
\text { Chlorate, Potassium Nitrate, TNT (Trinitrotoluene) } \\
\text { Projectile: Steel - Carbon, Iron, Manganese, Phosphorus, Sulfur } \\
\text { Projectile Filler: Lead, Potassium Nitrate, Sulfur } \\
\text { Fuze, Powder Train Time, M1907: Brass - Copper, Iron, Lead, Zinc } \\
\text { Fuze Filler:, Potassium Nitrate, Sulfur } \\
\text { Fuze Primer }{ }^{(4)} \text { : Antimony Sulfide, Mercury Fulminate, Potassium Chlorate }\end{array}$ & $\begin{array}{l}\text { Metals } \\
\text { Copper, Lead, Zinc } \\
\text { Explosives } \\
\text { As a conservative measure, a } \\
\text { full explosives panel will be } \\
\text { analyzed }\end{array}$ \\
\hline $\begin{array}{l}\text { Cartridge, 105-mm, } \\
\text { High Explosive } \\
\text { (HE), M1 }\end{array}$ & $\begin{array}{l}\text { Cartridge Case: Copper Alloy - Copper, Iron, Lead, Zinc } \\
\text { Propellant: Dibutylphthalate, Dinitrotoluene }{ }^{(3)} \text {, Diphenylamine, Lead } \\
{\text { Carbonate, Nitrocellulose }{ }^{(2)}} \\
\text { Primer }{ }^{(4)} \text { : Antimony sulfide, Carbon, Lead Thiocyanate, Potassium Chlorate, } \\
\text { Trinitrotoluene (TNT) } \\
\text { Projectile/Rotating Band: Steel, Copper Alloy - Carbon, Copper, Iron, } \\
\text { Lead, Manganese, Phosphorus, Sulfur. Zinc } \\
\text { Projectile Filler: Amatol or Composition B or TNT - Ammonium Nitrate, } \\
\text { Cyclotrimethylenetrinitramine (RDX), Trinitrotoluene (TNT) } \\
\text { Fuze, Projectile, Point Detonating (PD), M51 Steel - Carbon, Iron, } \\
\text { Manganese, Phosphorus, Sulfur } \\
\text { Fuze Filler: Tetryl } \\
\text { Fuze Primer }{ }^{(4)} \text { : Antimony Sulfide, Carborundum, Copper, Lead Azide, } \\
\text { Potassium Chlorate, Potassium Nitrate, Sodium Nitrate, Sulfur }\end{array}$ & $\begin{array}{l}\text { Metals } \\
\text { Copper, Zinc } \\
\text { Explosives } \\
\text { As a conservative measure, a } \\
\text { full explosives panel will be } \\
\text { analyzed }\end{array}$ \\
\hline $\begin{array}{l}\text { Projectile, 155-mm, } \\
\text { High Explosive } \\
\text { (HE), M101 }\end{array}$ & $\begin{array}{l}\text { Projectile/Rotating Band: Steel/Copper Alloy - Carbon, Copper, Iron, } \\
\text { Lead, Manganese, Phosphorus, Sulfur, Zinc } \\
\text { Projectile Filler: Trinitrotoluene (TNT) } \\
\text { Fuze, Projectile, Point Detonating (PD), M51 Steel - Carbon, Iron, } \\
\text { Manganese, Phosphorus, Sulfur } \\
\text { Fuze Filler: Tetryl } \\
\text { Fuze Primer }{ }^{(4)} \text { : Antimony Sulfide, Carborundum, Copper, Lead Azide, } \\
\text { Potassium Chlorate, Potassium Nitrate, Sodium Nitrate, Sulfur }\end{array}$ & $\begin{array}{l}\text { Metals } \\
\text { Copper, Lead, Zinc } \\
\text { Explosives } \\
\text { As a conservative measure, a } \\
\text { full explosives panel will be } \\
\text { analyzed }\end{array}$ \\
\hline $\begin{array}{l}\text { Cartridge, 60-mm, } \\
\text { High Explosive } \\
\text { (HE), M49A2 }\end{array}$ & $\begin{array}{l}\text { Propelling Assembly: Kraft Paper, Steel - Iron, Manganese, Paper, } \\
\text { Phosphorus, Sulfur, Zinc } \\
\text { Propellant: Diethylphthalate, Nitrocellulose }{ }^{(2)} \text {, Nitroglycerin, Potassium } \\
\text { Nitrate } \\
\text { Primer }{ }^{(4)} \text { : Antimony Sulfide, Lead Thiocyanate, Potassium Chlorate, } \\
\text { Potassium Nitrate, Trinitrotoluene (TNT) } \\
\text { Projectile: Steel - Carbon, Iron, Manganese, Phosphorus, Sulfur } \\
\text { Projectile Filler: Trinitrotoluene (TNT) } \\
\text { Fuze, Point Detonating (PD), M52 series: Aluminum Alloy, Zinc Alloy - } \\
\text { Aluminum, Bismuth, Cadmium, Copper, Iron, Magnesium, Manganese, } \\
\text { Nickel, Phosphorus, Silicon, Sulfur, Tin, Zinc } \\
\text { Fuze Filler: Tetryl } \\
\text { Fuze Primer }{ }^{(4)} \text { Antimony Sulfide, Carborundum, Copper, Lead Azide, } \\
\text { Potassium Chlorate, Zinc }\end{array}$ & $\begin{array}{l}\text { Metals } \\
\text { Aluminum, Copper, Zinc } \\
\text { Explosives } \\
\text { As a conservative measure, a } \\
\text { full explosives panel will be } \\
\text { analyzed }\end{array}$ \\
\hline
\end{tabular}




\begin{tabular}{|c|c|c|}
\hline $\begin{array}{l}\text { Munitions } \\
\text { Type/Model }\end{array}$ & $\begin{array}{l}\text { Composition } \\
\text { (Case and Filler) }\end{array}$ & $\begin{array}{l}\text { MC Selected for } \\
\text { Analysis }\end{array}$ \\
\hline $\begin{array}{l}\text { Shell, } 3 \text { inch, HE, } \\
\text { Trench Mortar } \\
\text { (Stokes Mortar), } \\
\text { MkI and MkII }\end{array}$ & $\begin{array}{l}\text { Propellant Assembly: N/A - Internal } \\
\text { Propellant: Diphenylamine, Nitrocellulose }{ }^{(2)} \\
\text { Primer }^{(4)} \text { : Antimony Sulfide, Barium Nitrate, Lead Styphnate, Tetrazene } \\
\text { Projectile: Steel - Carbon, Iron, Manganese, Phosphorus, Sulfur } \\
\text { Projectile Filler: Tetryl, Trinitrotoluene (TNT) } \\
\text { Fuze: Steel - Carbon, Iron, Manganese, Phosphorus, Sulfur } \\
\text { Fuze Filler: Potassium Nitrate, Sulfur, Tetryl, Trinitrotoluene (TNT) } \\
\text { Fuze Primer }{ }^{(4)} \text { : Copper, Mercury Fulminate, Phosphorus, Trinitrotoluene } \\
(\text { TNT), Zinc }\end{array}$ & $\begin{array}{l}\text { Metals } \\
\text { N/A } \\
\text { Explosives } \\
\text { As a conservative measure, a } \\
\text { full explosives panel will be } \\
\text { analyzed }\end{array}$ \\
\hline $\begin{array}{l}\text { Cartridge, 81-mm, } \\
\text { High Explosive } \\
\text { (HE), M43A1B1 }\end{array}$ & $\begin{array}{l}\text { Propelling Assembly: Kraft Paper, Steel - Iron, Manganese, Paper, } \\
\text { Phosphorus, Sulfur, Zinc } \\
\text { Propellant: Diethylphthalate, Nitrocellulose }{ }^{(2)} \text {, Nitroglycerin, Potassium } \\
\text { Nitrate } \\
\text { Primer }{ }^{(4)} \text { : Antimony Sulfide, Copper, Lead Thiocyanate, Potassium Chlorate, } \\
\text { Potassium Nitrate, Trinitrotoluene (TNT), Sulfur, Zinc } \\
\text { Projectile: Steel - Carbon, Iron, Manganese, Phosphorus, Sulfur } \\
\text { Projectile Filler: Trinitrotoluene (TNT) or Comp B - } \\
\text { Cyclotrimethylenetrinitramine (RDX), Trinitrotoluene (TNT) } \\
\text { Fuze, Point Detonating (PD), M52, M525: Aluminum Alloy - Aluminum, } \\
\text { Copper, Iron, Lead, Magnesium, Zinc } \\
\text { Fuze Filler: RDX, (Cyclotrimethylenetrinitramine), Tetryl } \\
\text { Fuze Primer }{ }^{(4)} \text { : Antimony Sulfide, Barium Nitrate, Lead Azide, Lead } \\
\text { Styphnate, Tetrazene }\end{array}$ & $\begin{array}{l}\underline{\text { Metals }} \\
\text { Aluminum, Copper, Zinc } \\
\text { Explosives } \\
\text { As a conservative measure, a } \\
\text { full explosives panel will be } \\
\text { analyzed }\end{array}$ \\
\hline
\end{tabular}

(1) MC selected for analysis are typically non-essential nutrient metals and indicative of known or suspected DOD munitions used at this area. MC not selected for analysis are essential nutrient metals, Semi-Volatile Organic Compounds (SVOCs) or materials that represent a very small percentage of the munitions weight. Lead was added to the analyte list at the request of the Project Team.

(2) Nitrocellulose is not considered toxic, has no risk-based screening values and there are no chemical analysis techniques that quantify nitrocellulose separately from the natural common essential nutrient nitrate. Based on this, nitrocellulose analysis will not be conducted during this SI.

(3) Dinitrotoluene products include: 2,4-and 2,6-dinitrotoluene; 2-Amino-4,6-dinitrotoluene; 2-and 3-nitrotoluene; 4-Amino-2,6dinitrotoluene; 4-nitrotoluene.

(4) Primer materials represent a very small percentage of the munitions weight, therefore, primer constituents will not be analyzed for at this area (if a primer constituent is associated with a larger component of the munition it may be analyzed for).

(5) Tracer element materials represent a very small percentage of the munitions weight and is consumed while the projectile travels to the target, therefore, tracer element constituents will not be analyzed for at this MRS (if a tracer element constituent is associated with a larger component of the munition it may be analyzed for).

(6) Surface and ground water samples (if available) will be analyzed for perchlorate.

Source - Munitions information was supplied by the Munitions Items Disposition Action System (MIDAS) database, and USACE Range Operations Reports RO-05, RO-14, RO-15 and RO-17.

\section{TEST DESIGN AND ANALYSIS PLAN}

The performance objectives described in Section 3 that apply to the test design and data analysis plan can be grouped into the demonstration performed on Motlow site or the simulated site demonstration.

The test plan was set up to evaluate and demonstrate the several aspects of the VSP-RI module and to support the performance objectives outlined in Section 3. Different VSP-RI modules were applied to the three types of areas discussed below with both the transect design and data 
visualization/analysis capabilities employed. We also simulated various ground-truth data sets varying the spatial TOI distribution across the site to evaluate the performance of transect and grid surveys.

\subsection{Transect Design Options for Three Types Of Areas}

During an RI, typically there are three types of areas encountered within an MRS.

- Type-1 Areas: Areas with known munitions use and suspected target areas

- Type-2 Areas: Areas with no clear target area discovery needs (outside of known target areas that have some potential munition use or areas with known munitions use but no clear target at which munitions were fired).

- Type-3 Areas: Areas that are presumptively clean but more evidence is required to support this claim.

The decision objectives and therefore survey and analysis objectives are different for each of these types of areas. The primary decision objectives that affect the survey design are listed in Table 3 for each type of area.

Table 3. Description and VSP-RI Objectives for Different Types of Areas

\begin{tabular}{|c|c|c|}
\hline Type of Area & Description & RI Objectives \\
\hline Type-1 Areas & $\begin{array}{l}\text { Areas with known munitions use and } \\
\text { suspected target areas }\end{array}$ & $\begin{array}{l}\text { - Identify any target areas if they exist } \\
\text { - Delineate those target areas } \\
\text { - Estimate the number of anomalies or anomaly } \\
\text { density } \\
\text { - Explore the spatial anomaly distribution }\end{array}$ \\
\hline Type-2 Areas & $\begin{array}{l}\text { Areas with no clear target area discovery } \\
\text { needs (outside of known target areas that } \\
\text { have some potential munition use or areas } \\
\text { with known munitions use but no clear } \\
\text { target at which munitions were fired). }\end{array}$ & $\begin{array}{l}\text { - Estimate UXO/acre (or MEC/acre or some } \\
\text { other rate) or the number of possible UXO (or } \\
\text { MEC or...) and show that we are confident that } \\
\text { it is less than some pre-specified limit. }\end{array}$ \\
\hline Type-3 Areas & $\begin{array}{l}\text { Areas that are presumptively clean but } \\
\text { additional evidence is needed to support } \\
\text { this claim }\end{array}$ & $\begin{array}{l}\text { - Show that you are X\% confident that at least } \\
\text { Y\% of all possible transects of a prescribed } \\
\text { length do not contain unacceptable items or, } \\
\text { - Estimate TOI/acre (UXO/acre or MEC/acre or } \\
\text { some other rate) or the total number of TOI and } \\
\text { show that we are confident that it is less than } \\
\text { some pre-specified limit. }\end{array}$ \\
\hline
\end{tabular}

\subsubsection{Type-1 Area Demonstration (Area 2a)}

For the Motlow site, the Type-1 area was designated as Area 2a in Figure 6. Based on previous studies, there was real potential for encountering target areas within Area 2a. In this area, the VSP transect design tools for target-area detection were recommended, and the contractor had already used those VSP tools to develop a proposed transect survey plan within their work plan. PNNL reviewed the VSP user parameter inputs used by Parsons for their proposed transect 
survey design and found it adequate for the purposes of this VSP-RI demonstration and did not require any modifications to that proposed transect survey plan. The proposed transect design shown in Figure 7 was based on achieving a high probability ( 90\%) of traversing and detecting a $37-\mathrm{mm}$ target area ( $\sim 333-\mathrm{ft}$ radius circular area) that has an average anomaly density that is approximately 100 anomalies/acre above a background of 20/acre with 3-foot wide transects. The VSP target area flagging and geostatisical mapping methods were employed using the actual course-over-ground and anomaly location survey results and are reported in Section 6.

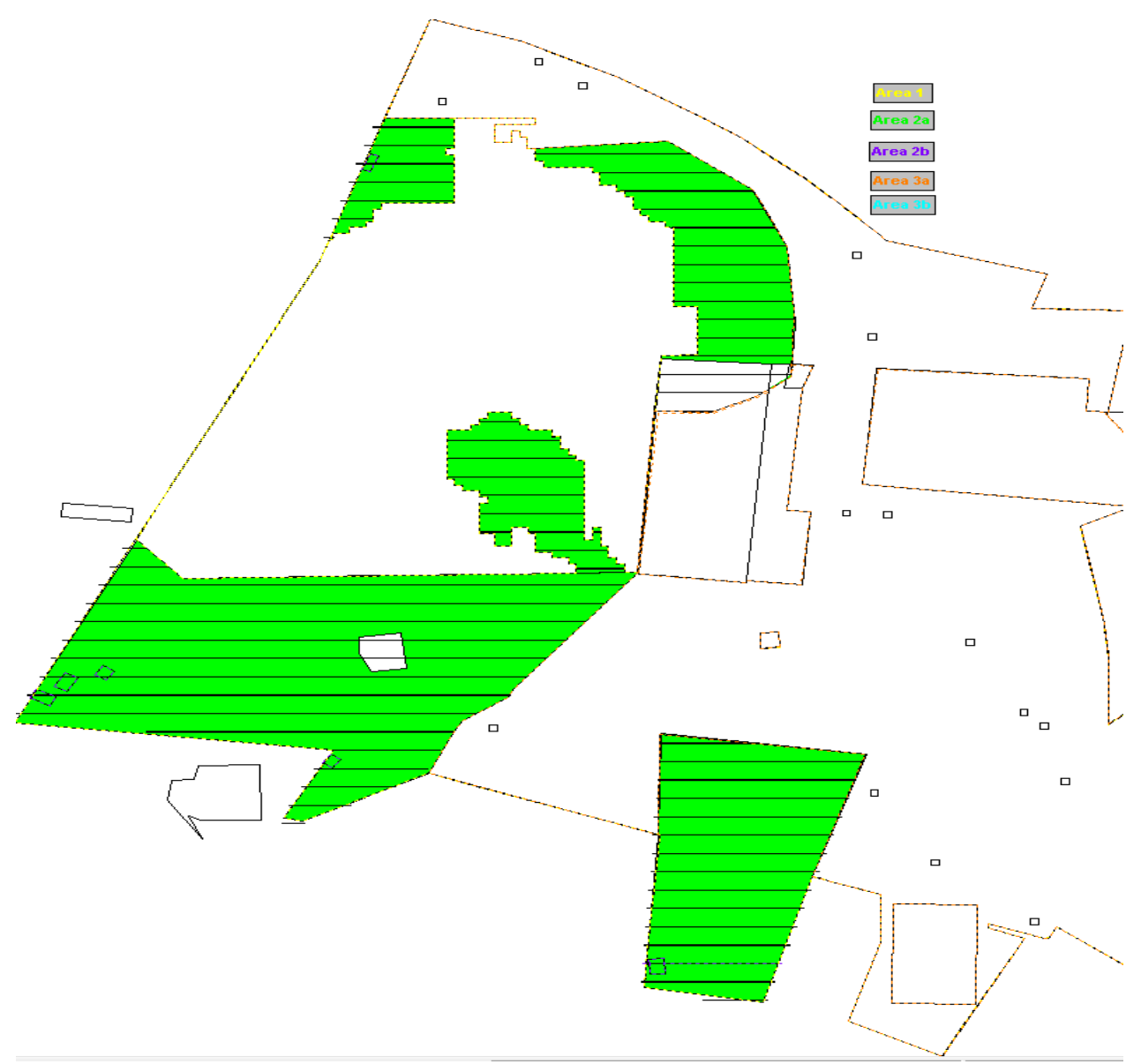

Figure 7. Planned Transect Survey for the Type-1 Area (Area 2a)

\subsubsection{Type-2 Area Demonstration (Area 3a)}

The Type-2 Areas on this Motlow site are designated as Area 3a ( 1940 acres) in Figure 6. Based on previous studies, there is no indication of target areas in these buffer areas and little, if any, munitions use. The contractor proposed using UXO Estimator to determine the survey acreage required to show that they are $90 \%$ confident that there are no more than $0.5 \mathrm{UXO} / \mathrm{acre}$ within this area. Based on this results in proposal, $\sim 0.28 \%$ of the site must be surveyed ( 4.6 acres). The contractor decided to perform grid surveys instead of transect surveys.

PNNL had concerns about employing grid surveys and believed that long transects would have greater likelihood of preserving the desired $90 \%$ confidence than grids. The contractors, USACE, and regulators were receptive to recommendations to augment their grid surveys with 
additional transect surveys to support a comparison between the two survey approaches. Based on a preliminary analysis using the new VSP-RI module that was designed to support the decision objective for Type- 2 areas, PNNL felt that the $\sim 0.28 \%$ survey acreage would be sufficient for this demonstration. We felt that this survey coverage was conservative because no prior information or reliance on our VSP-RI Bayesian model was necessary.

PNNL recommended two possible transect survey approaches rather than a grid survey that would meet the design objective of $90 \%$ confident of showing that the TOI/acre is less than $0.5 /$ acre. However, because of budgetary constraints, the complete proposed transect survey of $\sim 0.28 \%$ survey coverage (4.6 acres) could not be attained. It was determined that we could still use the reduced survey results to explore the Bayesian and non-Bayesian options of this VSP-RI approach and still support the objectives of this demonstration (see Section 6).

PNNL originally proposed two survey options for Area 3a, which are discussed below. Both options provide for $\sim 0.29 \%$ survey coverage ( 4.8 acres), and some right of entry exclusion zones were excluded from transect-survey possibilities. Note that the $0.29 \%$ and 4.8 acres is slightly higher than the calculated requirement because of the finite transect dimensions and random transect placement options. Option 1 uses equally-spaced, parallel transects that run across the entire site. Option 2 also uses parallel transects, but the placement is random and the transect lengths are roughly equal (except for narrow areas of the site). Initially Parsons was going to perform the transect surveys outlined in Option 1, but due to limited funding, they were only able to complete about every other transect (i.e., approximately half of the transects).

\subsubsection{Proposed Option 1 - Parallel Transects With Equal Spacing}

Figure 8 shows the option with equally spaced parallel transect placement with transects running across the length of Area 3a. Although the calculation results in $0.274 \%$ coverage, the actual survey coverage can vary due to the random start transect placement algorithm and the finite length of transects. Also, the transect dimension (10,000 feet long) is ignored for this transect placement option. The parameters used for this both Options 1 and 2 in VSP are shown in Table 4. 


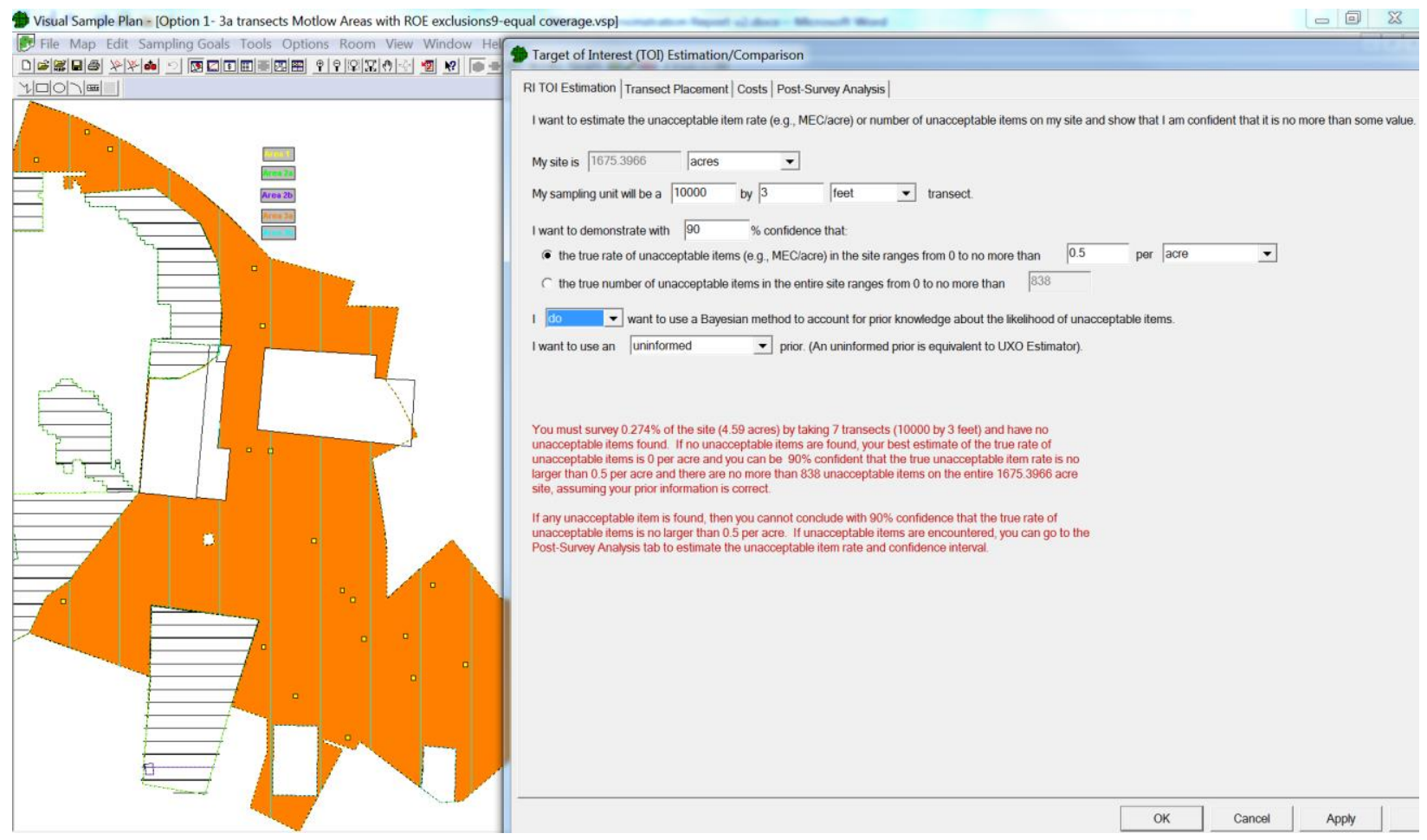

Figure 8. Proposed Option 1 Transect Design for Area 3a

Table 4. Summary of Design Parameters for Area 3a

\begin{tabular}{|l|l|}
\hline SUMMARY OF SAMPLING DESIGN & $\begin{array}{l}\text { Estimate TOI Rate for a site and confidently } \\
\text { demonstrate that the true rate is less than a } \\
\text { pre-specified value }\end{array}$ \\
\hline Primary Objective of Design & Transects \\
\hline TARGET AREA AND TRANSECT INPUTS & Parallel \\
\hline Type of Sampling Design & 3.281 feet \\
\hline Transect Pattern & 1 \\
\hline Transect Width & 1675.40 acres \\
\hline PROPOSED TRANSECT DESIGN & $0.5 /$ acre \\
\hline Number of selected sample areas ${ }^{\text {a }}$ & 838 \\
\hline Specified site area & $90 \%$ \\
\hline Upper bound for TOI rate & 12.12 miles \\
\hline Upper bound for number of TOI & 4.82 acres \\
\hline $\begin{array}{l}\text { Confidence required that upper bounds are not } \\
\text { exceeded }\end{array}$ & $\sim 0.29 \%$ \\
\hline Total length of surveyed transects & \\
\hline Area to be surveyed (area under the transects) &
\end{tabular}

\subsubsection{Proposed Option 2 - Parallel Transects Not Equally Spaced}

Figure 9 shows the UXO Estimator equivalent option which employs random parallel transect sampling with 4000 feet by 1-meter transects placed within Area 3a. 


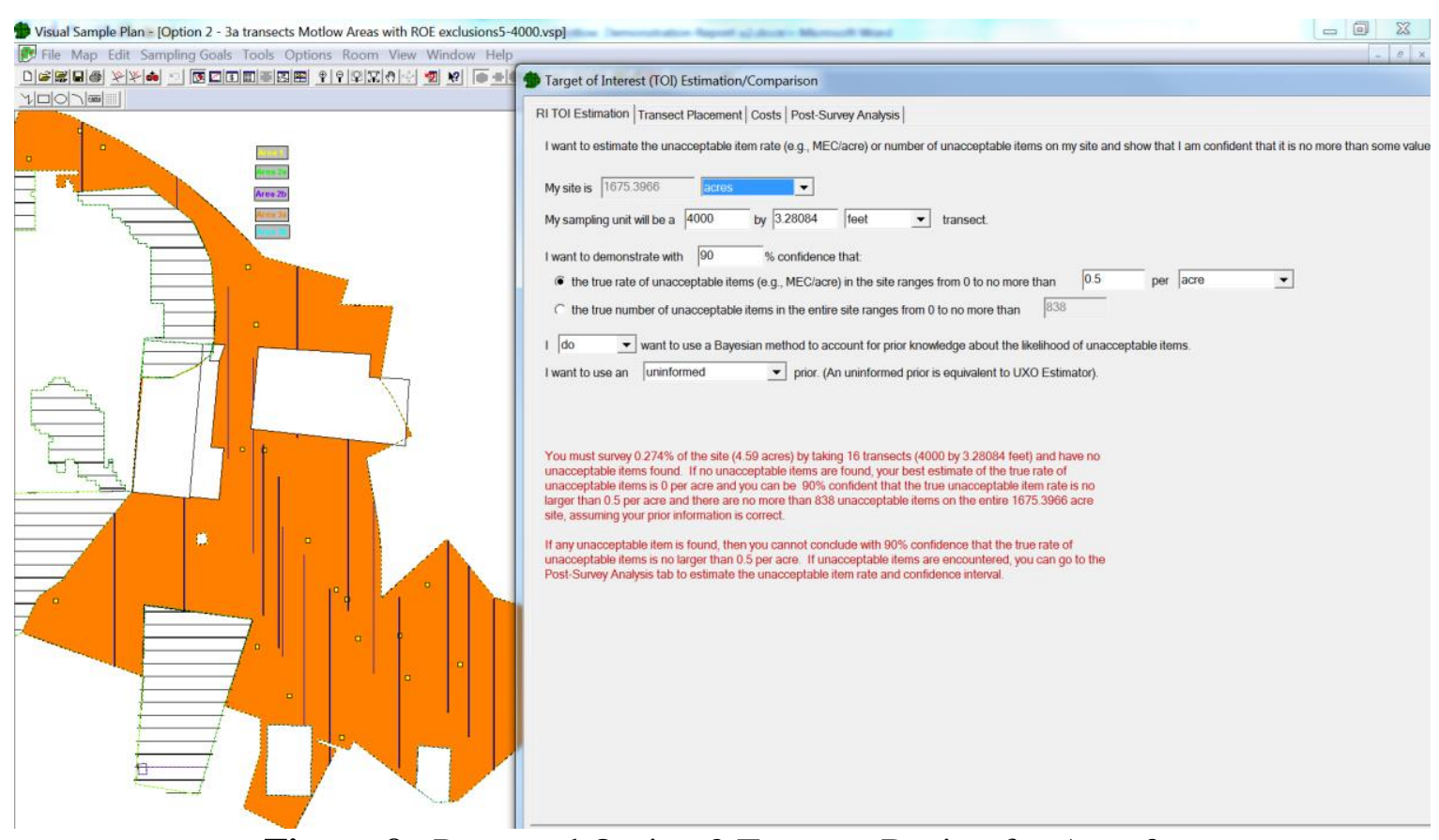

Figure 9. Proposed Option 2 Transect Design for Area 3a

\subsubsection{Type-3 Area Demonstration}

Although there are probably areas within Area 3a that might be considered Type- 3 areas, in the Motlow site, all low-likelihood UXO areas are combined into one area. For an example of Type-3 areas in this document, we assumed that Area 3a was a presumptively clean site to illustrate the application of the methods when the objective is to demonstrate with $\mathrm{X} \%$ confidence that no more than $\mathrm{Y} \%$ of all possible transects contain unacceptable items. However, the survey requirements were not imposed for this demonstration and we will illustrate the survey requirements for varying assumptions. We also show what $\mathrm{X} \% / \mathrm{Y} \%$ could be achieved given the actual and proposed amount of surveying for Area $3 \mathrm{a}$.

\subsection{Survey Unit Evaluation}

A major unknown for survey sampling when the new VSP-RI modules or UXO Estimator is used is whether grids or transects are more appropriate. For example, if these tools suggest that for $90 \%$ confidence, $0.27 \%$ of the area must be surveyed. An extreme implementation would be to survey one large grid that covers $0.27 \%$ of the site. This is spatially unappealing, and the achieved confidence surely would not be $90 \%$ in most cases for expected spatial patterns of UXO. Long narrow transects are expected to preserve the confidence based on a previous PNNL study. But at some point, many small grids may also preserve the desired confidence. To study this, a simulation is performed within this demonstration (see Section 7.6).

To study the effects of grid vs. transect surveys, we use the Motlow site Area 3a boundary as the basis for a typical area size as well as a more complex boundary shape. Various spatial patterns and number of TOI are used on the site to create numerous ground truths. Then, the VSP-RI module for estimating and showing that UXO/acre is less than some criteria is repeatedly employed varying the VSP input parameters and the grid and transect survey options. Any 
differences between the "as-designed" confidence and the "actually achieved" confidence are explored.

\subsection{Survey Specifications}

The survey sensors, calibration techniques, data collection procedures, quality control methods, and other logistical parameters were under the control of the Parsons contractor. These were specified within their work plan. PNNL did not make any alterations beyond the standard operating procedures typically deployed by the contractor. PNNL worked with the contractor and USACE staff to obtain the course-over-ground, anomaly location, and dig results files in an appropriate format for VSP ingestion.

\section{DEMONSTRATION RESULTS AND ANALYSES}

This demonstration project allowed an investigation of the performance of the VSP-RI sampling modules for the three scenarios outlined in Sections 2.1.1, 2.1.2, and 2.1.3.

\subsection{Evaluation of the Type-1 Area (Area 2a)}

For the Motlow site, the Type-1 area is designated as Area 2a in Figure 6. The primary objective was to detect and delineate target areas if they existed. The survey design outlined in Section 5.1 was performed by the contractor, and the actual course-over-ground transects and identified anomalies are shown in Figure 10.

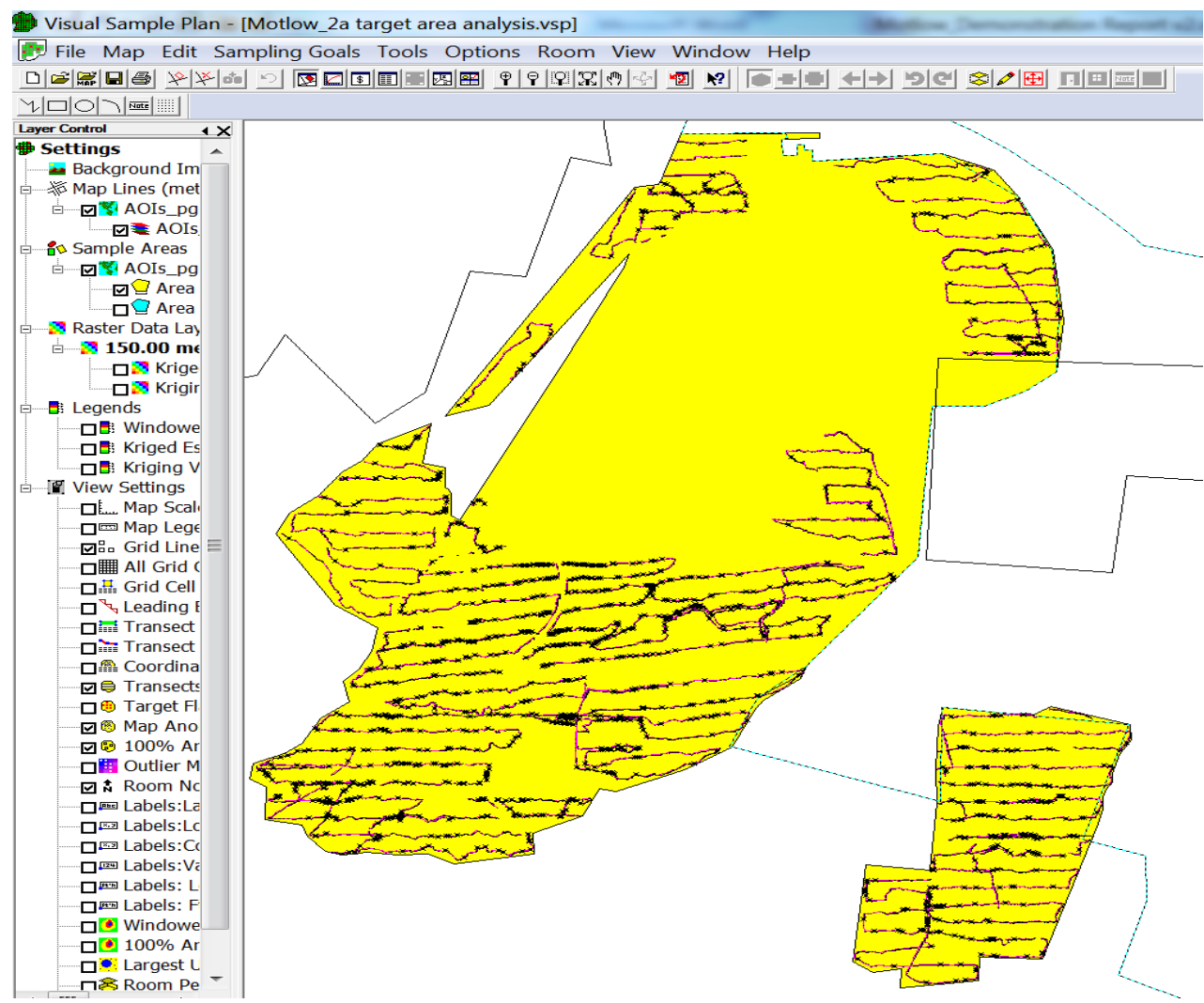

Figure 10. Area 2a Transects and Anomaly Locations 
The VSP target area flagging and geostatisical mapping methods were employed using the actual course-over-ground and anomaly location survey results. Several potential target areas were identified and delineated. Figure 11 shows the results of the geostatistical analysis and delineates 13 possible target areas where the anomaly density appears to be significantly higher than background densities. Any area where the average kriged anomaly density was above 225/acre and at least 2 acres in size was identified and delineated. Several of these are clustered in the center of the larger portion of Area 2 a south of the large unsampled area and may represent one large high-density area. Table 5 summarizes the attributes of the delineated areas.

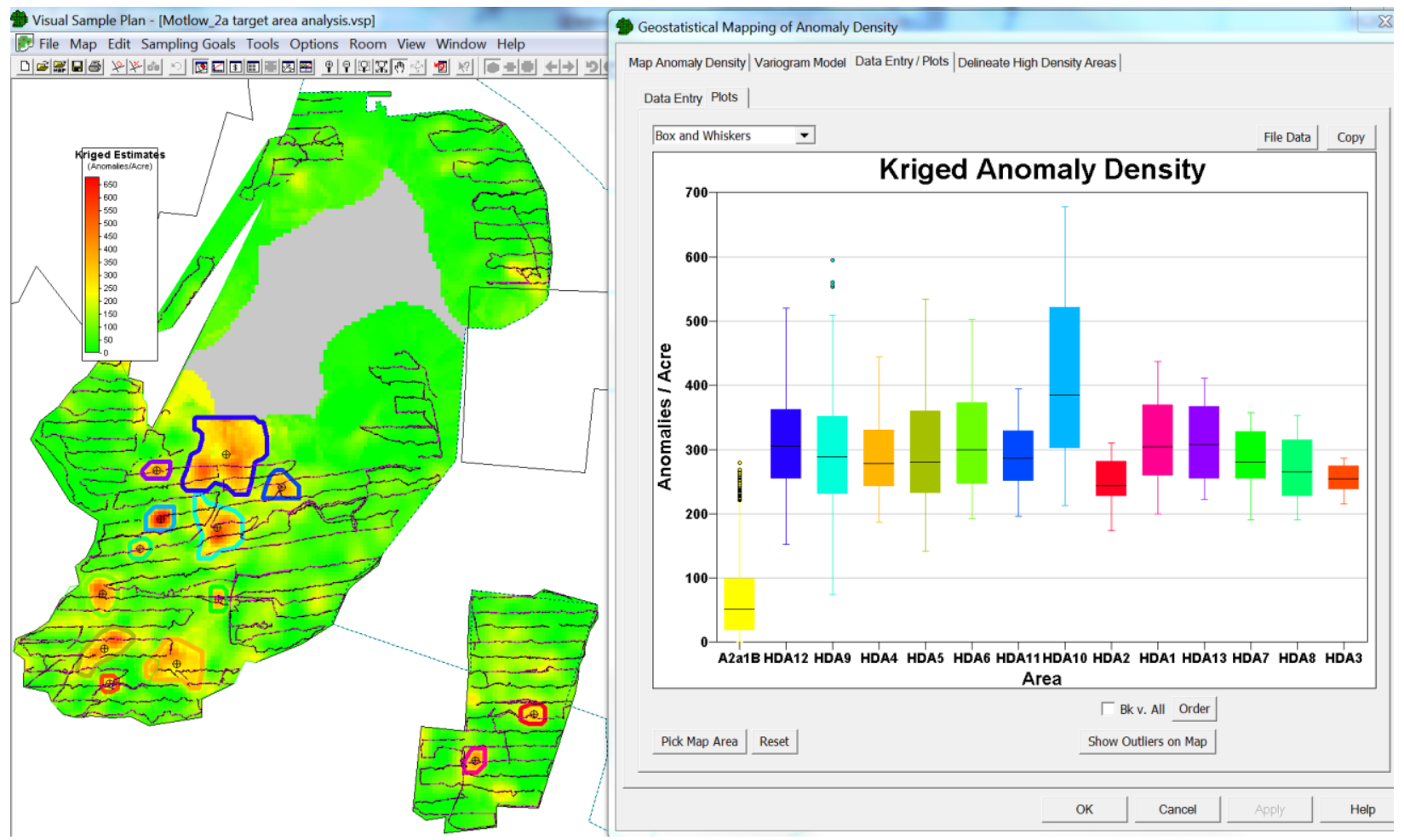

Figure 11. Geostatistical Mapping and Target Area Delineation for Area 2a

Table 5. Summary of delineated areas in Area 2a

\begin{tabular}{|l|l|l|l|l|l|l|}
\hline Name & $\begin{array}{l}\text { Creation } \\
\text { Parameters }\end{array}$ & $\begin{array}{l}\text { Size } \\
\text { (acres) }\end{array}$ & $\begin{array}{l}\text { Transect } \\
\text { Area } \\
\text { (acres) }\end{array}$ & Anomalies & $\begin{array}{l}\text { Kriged Density } \\
\text { (per acre) }\end{array}$ & $\begin{array}{l}\text { Potential } \\
\text { Anomalies }\end{array}$ \\
\hline High-Density Area 1 & $\begin{array}{l}\text { Auto Krig: 225 / acre, 2 } \\
\text { acres min }\end{array}$ & 3.94 & 0.04 & 19 & 310.85 & 1224 \\
\hline High-Density Area 2 & $\begin{array}{l}\text { Auto Krig: 225 / acre, 2 } \\
\text { acres min }\end{array}$ & 4.17 & 0.04 & 10 & 252.54 & 1053 \\
\hline High-Density Area 3 & $\begin{array}{l}\text { Auto Krig: 225 / acre, 2 } \\
\text { acres min }\end{array}$ & 2.16 & 0.09 & 33 & 254.86 & 551 \\
\hline High-Density Area 4 & $\begin{array}{l}\text { Auto Krig: 225 / acre, 2 } \\
\text { acres min }\end{array}$ & 18.46 & 0.16 & 49 & 288.43 & 5323 \\
\hline High-Density Area 5 & $\begin{array}{l}\text { Auto Krig: 225 / acre, 2 } \\
\text { acres min }\end{array}$ & 13.05 & 0.13 & 46 & 302.09 & 3942 \\
\hline High-Density Area 6 & $\begin{array}{l}\text { Auto Krig: 225 / acre, 2 } \\
\text { acres min }\end{array}$ & 9.73 & 0.13 & 46 & 315.98 & 3074 \\
\hline High-Density Area 7 & Auto Krig: 225 / acre, 2 & 3.55 & 0.08 & 32 & 286.38 & 1017 \\
\hline
\end{tabular}




\begin{tabular}{|l|l|l|l|l|l|l|}
\hline & acres min & & & & & \\
\hline High-Density Area 8 & $\begin{array}{l}\text { Auto Krig: 225 / acre, 2 } \\
\text { acres min }\end{array}$ & 3.24 & 0.03 & 11 & 268.86 & 872 \\
\hline High-Density Area 9 & $\begin{array}{l}\text { Auto Krig: 225 / acre, 2 } \\
\text { acres min }\end{array}$ & 19.69 & 0.28 & 85 & 300.68 & 5921 \\
\hline High-Density Area 10 & $\begin{array}{l}\text { Auto Krig: 225 / acre, 2 } \\
\text { acres min }\end{array}$ & 6.02 & 0.04 & 18 & 419.87 & 2529 \\
\hline High-Density Area 11 & $\begin{array}{l}\text { Auto Krig: 225 / acre, 2 } \\
\text { acres min }\end{array}$ & 7.41 & 0.12 & 37 & 288.33 & 2137 \\
\hline High-Density Area 12 & $\begin{array}{l}\text { Auto Krig: 225 / acre, 2 } \\
\text { acres min }\end{array}$ & 46.18 & 0.23 & 82 & 314.20 & 14509 \\
\hline High-Density Area 13 & $\begin{array}{l}\text { Auto Krig: 225 / acre, 2 } \\
\text { acres min }\end{array}$ & 3.78 & 0.02 & 8 & 310.61 & 1175 \\
\hline
\end{tabular}

This methodology in VSP for the objective of target-area detection and delineation within the RI stage performed as expected. The demonstration on Area 2a provides a good illustration of how this VSP module can be used to support this particular RI objective.

\subsection{Evaluation of Type-2 Area (Area 3a)}

In Section 4.3 we defined Area 3a, a set of buffer areas and small arms ranges not investigated in depth previously. Based on known historical use and available data, this area was considered unlikely to contain residual MEC and presents a minimal risk of exposure to UXO.

Sections 5.1.2.1 and 5.1.2.2 outlined initial transect survey schemes requested by PNNL. Because the option for north-south transects that traversed the entire site was operationally most feasible for the project team, they chose that option. Some portions of Area 3a could not be surveyed because of right of entry issues, and these areas were excluded from the total area acreage, which resulted in approximately 1610 acres in Area 3a. Unfortunately, because of unexpected difficulties and expenses encountered, the contractor was only able to perform every other transect that was proposed, resulting in 2.7 transect acres, $0.17 \%$ coverage, and 6.8 miles of transects. The original design called for 4.8 transect acres, $0.28 \%$ coverage, and 12.1 miles of transects. The actual course-over-ground transects and anomaly locations are shown in Figure 12 


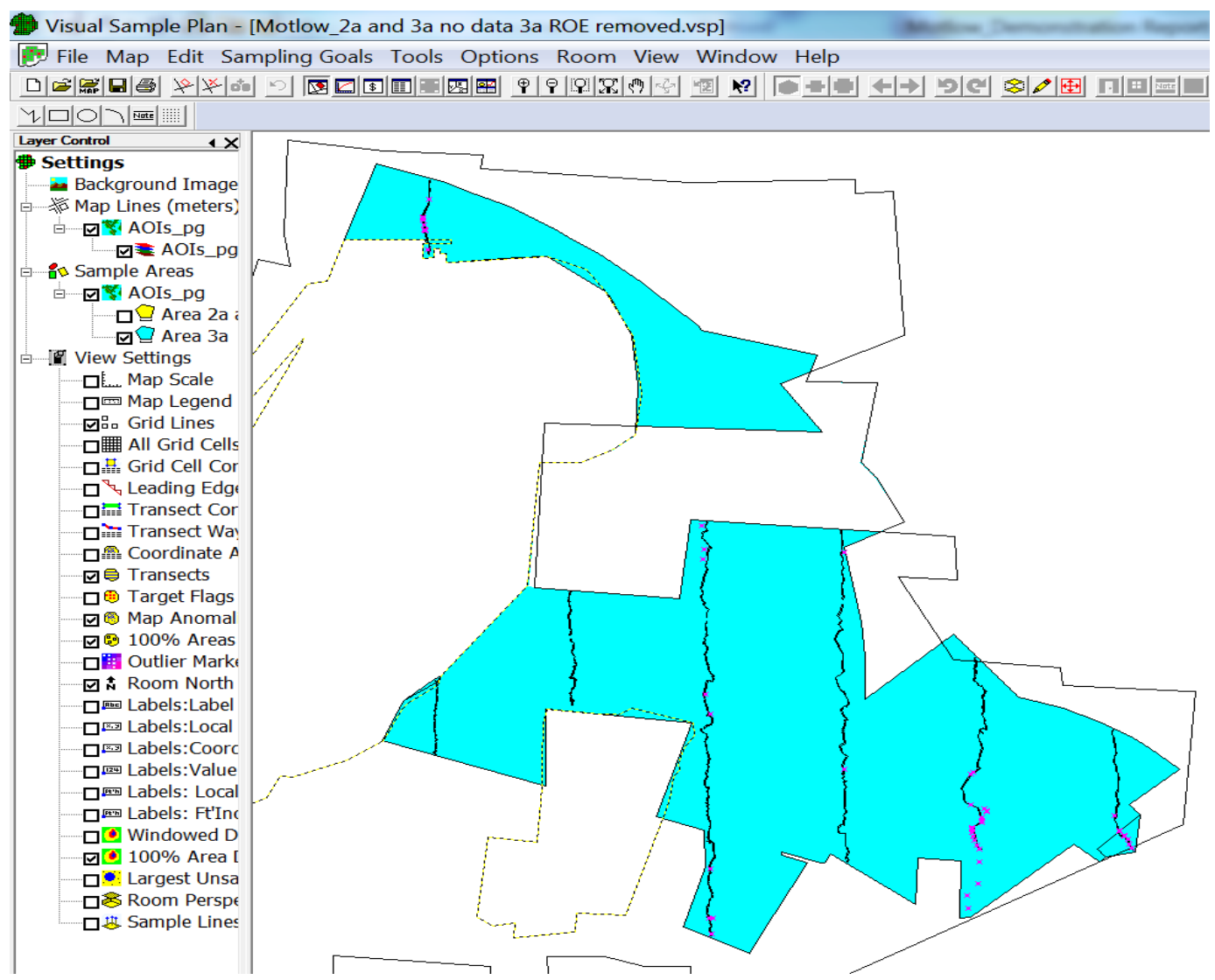

Figure 12. Actual Transects Performed and Anomalies Identified on Area 3a

\subsubsection{Anomaly Dig Results and Estimation of TOI Per Acre}

The primary objective of the RI for this Type- 2 area was to estimate the TOI/acre and demonstrate with high confidence that it is less than $0.5 /$ acre. Fifty-three anomalies were identified with the transect survey. Of these, the contractor was able to reacquire 43 , which were dug and investigated to determine whether they were TOI. The investigation results for the 43 dug anomalies are shown in Appendix B. None of the dug anomalies from the limited number of transects in Area-3a were TOI.

As outlined in Section 2.1.2, within the VSP TOI/acre estimation and testing module, there are three possible options for whether and how to account for prior information: 1) Non-Bayesian, 2) Bayesian with an uninformed prior, or 3) Bayesian with an informed prior. In practice, there is usually little difference between the Non-Bayesian and uninformed Bayesian options, and the uninformed Bayesian method is equivalent to the UXO Estimator solution. The original design that required 4.8 transect acres and covered $0.28 \%$ of the site was devised using the uninformed Bayesian approach. However, as shown in Figure 13, using a reasonable informed prior allows the desired confidence to be achieved with only 2.37 transect acres and $0.147 \%$ coverage (ignore the transect length). This assumes that before surveying and digging one has at least $75 \%$ confidence that there are no more than 1000 TOI on this site and that there is equal likelihood of having greater or less than 499 TOI. Given the fact that from $100 \%$ surveys and anomaly digs within Area 1 where there were known target areas less than 800 TOI were found, this prior assumption seems very defensible for Area 3a. 
Target of Interest (TOI) Estimation/Comparison

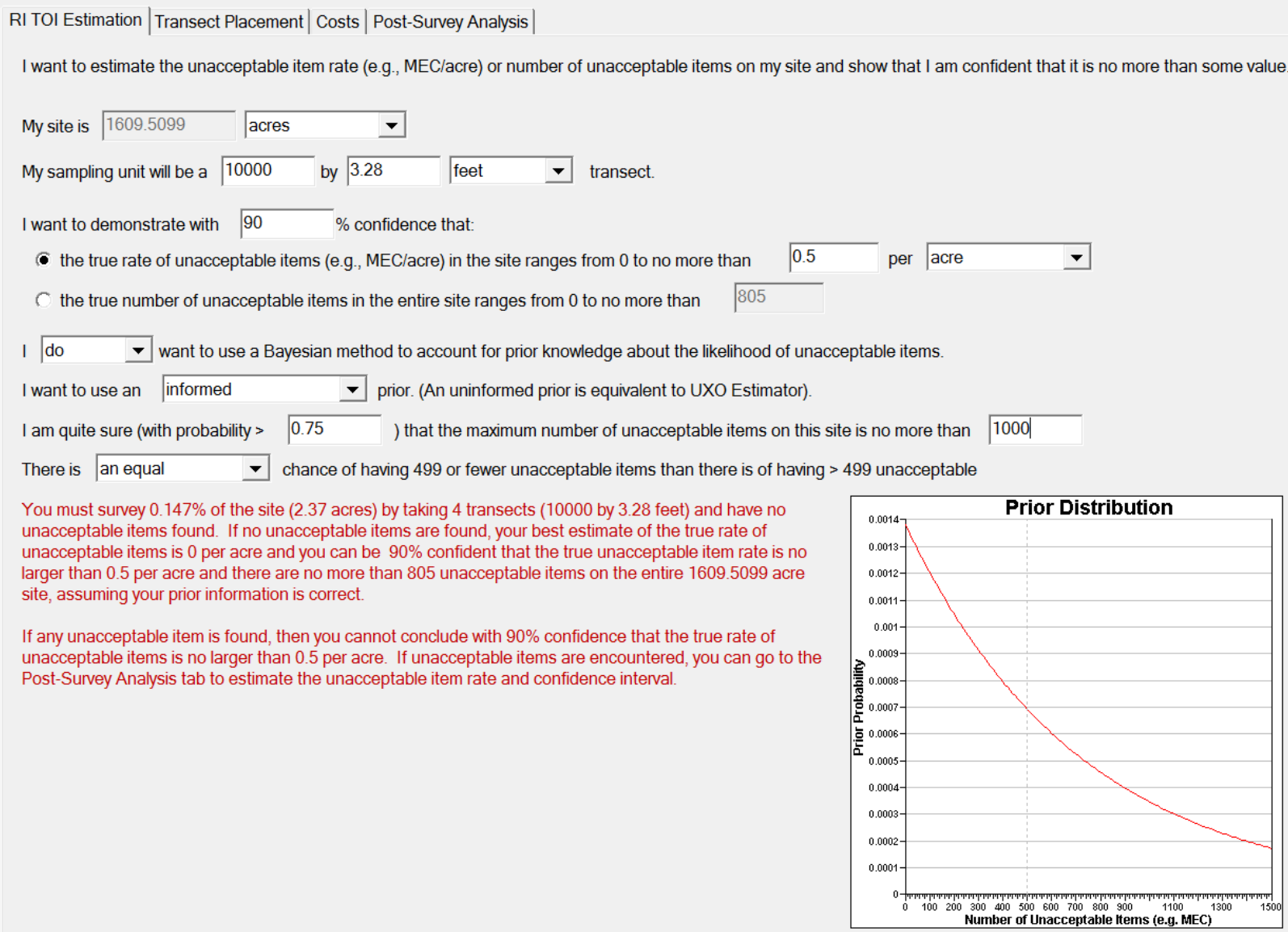

Figure 13. VSP Design Using a Conservative Informed Prior

Therefore, although the contractor could not perform all of the originally requested transects for Area 3a, they were able to perform a sufficient amount of surveying and digging to meet data quality objective requirements if the VSP informed prior approach is used. This demonstrates the benefits of reduced required survey acreage when the informed prior approach can be justified.

Using the VSP TOI/acre estimation and comparison module, the actual survey acreage can be input for Area 3a to determine whether using the informed Bayesian approach, one can be $90 \%$ confident that the true TOI/acre rate is less than 0.5/acre. Figure 14 shows that, with no TOI found for the 2.7 acreage surveyed $(0.168 \%$ coverage), one can be $90 \%$ confident that the true rate is less than $0.466 /$ acre. Alternatively, one can be $91.6 \%$ confident that the true rate is less than 0.5/acre. Based on this finding, the desired confidence goals were achieved for Area $3 \mathrm{a}$ by using the Bayesian model with defensible priors. 


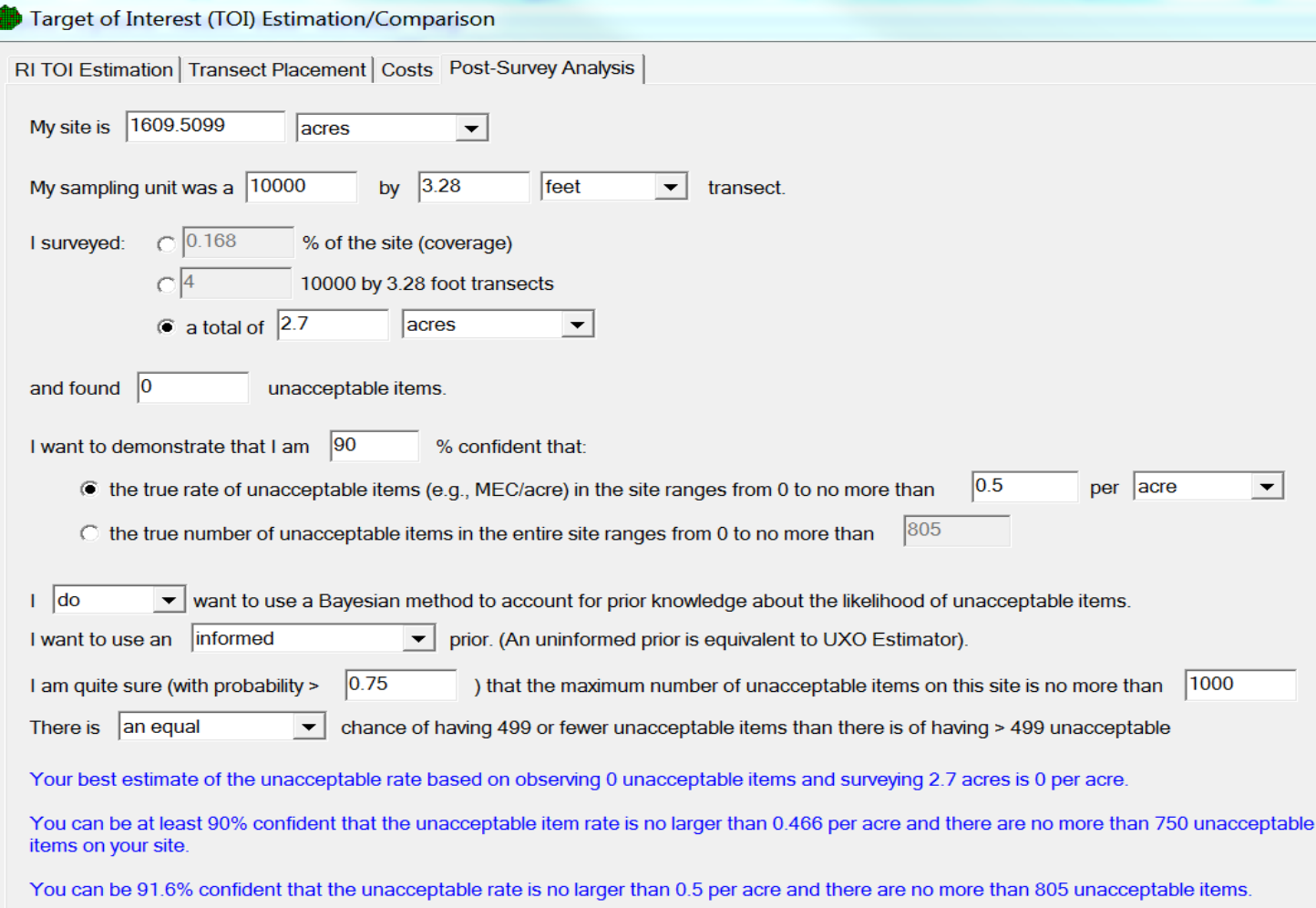

Figure 14. VSP Screenshot Showing Calculated Confidence for Achieved Survey Acreage

\subsection{Evaluation of Type-3 Area (Area 3a revisited)}

Although there was no area within this Motlow site that was designated as a presumptively clean site, Area 3a was considered as such for purposes of this demonstration report. Some stakeholders may want to make a different statement about the likelihood of TOI presence than that shown in Section 6.2 (TOI/acre is less than 0.5/acre). Another VSP module allows one to state that they are $\mathrm{X} \%$ confident that at least $\mathrm{Y} \%$ of all parcels of a specified size do not contain TOI if no TOI is found (see Section 2.1.3). Depending on the desired X\% and Y\% values, this module may require more survey acreage than the TOI/acre estimation/comparison module.

Suppose the stakeholders desired to develop a transect survey design for Area 3a that would allow them to state that they are $90 \%$ confident that no more than $3 \%$ of all possible $1 / 4$-acre parcels contain TOI. Assume they want to take use 4000-foot x 1-meter transects and are quite sure that there are not going to be more than 150 of the parcels that will contain TOI. Figure 15 shows that approximately 8.5 survey acres would be needed ( $0.53 \%$ coverage) and no TOI found in order to be $90 \%$ confident that no more than $3 \%$ of all possible parcels of concern contain TOI. Table 6 shows the survey acreage required for various input parameters. 


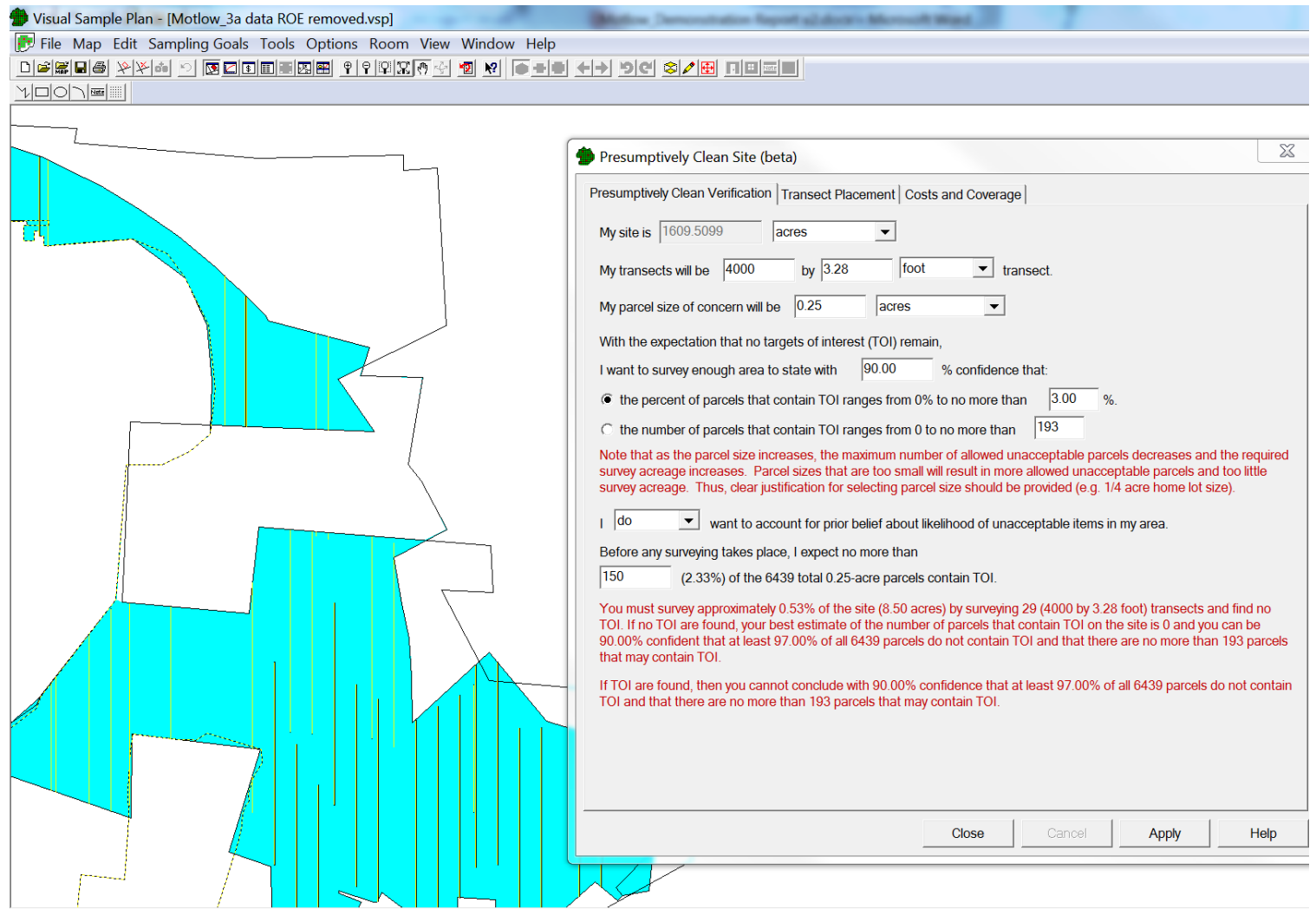

Figure 15. Example of VSP-RI Presumptively Clean Module Applied to Area 3a

Table 6. VSP Presumptively Clean Module Survey Requirements for Area 3a Assuming Various Input Parameters for a 1/4 Acre Parcel Size

$\begin{array}{lllll}\begin{array}{l}\text { Percent } \\ \text { Confidence }\end{array} & \begin{array}{l}\text { Maximum Percent } \\ \text { Parcels that May } \\ \text { Contain TOI }\end{array} & \begin{array}{l}\text { Prior on } \\ \text { Maximum } \\ \text { Parcels w/ TOI }\end{array} & \begin{array}{l}\text { Required } \\ \text { Survey } \\ \text { Acreage }\end{array} & \begin{array}{l}\text { Percent } \\ \text { Coverage }\end{array} \\ 90 \% & 5 \% & \text { Unknown } & 11.25 & 0.70 \% \\ 90 \% & 5 \% & 250 & 5.25 & 0.33 \% \\ 90 \% & 5 \% & 200 & 3.50 & 0.22 \% \\ 90 \% & 3 \% & \text { Unknown } & 19.0 & 1.18 \% \\ 90 \% & 3 \% & 200 & 11.0 & 0.68 \% \\ 90 \% & 3 \% & 150 & 8.5 & 0.53 \% \\ 90 \% & 1 \% & \text { Unknown } & 56.5 & 3.51 \% \\ 90 \% & 1 \% & 150 & 45.5 & 2.83 \% \\ 90 \% & 1 \% & 50 & 24.75 & 1.54 \% \\ 95 \% & 5 \% & \text { Unknown } & 14.75 & 0.92 \% \\ 95 \% & 5 \% & 250 & 8.5 & 0.53 \% \\ 95 \% & 5 \% & 200 & 7.0 & 0.43 \% \\ 95 \% & 3 \% & \text { Unknown } & 24.5 & 1.52 \% \\ 95 \% & 3 \% & 200 & 16.75 & 1.04 \% \\ 95 \% & 3 \% & 150 & 14.0 & 0.87 \% \\ 95 \% & 1 \% & \text { Unknown } & 73.0 & 4.54 \% \\ 95 \% & 1 \% & 150 & 61.75 & 3.84 \% \\ 95 \% & 1 \% & 50 & 41.25 & 2.56 \%\end{array}$

Bayesian Prior Used is the before surveying expected maximum number of $1 / 4$-acre parcels that could contain TOI in Area 3a. 
Given the fact that the actual transect survey acreage on Area 3a was 2.7 acres and no TOI were found, one can determine the statistical statements that can be made for this $\mathrm{X} \% / \mathrm{Y} \%$ objective. If no prior information is available, one can be $90 \%$ confident that no more than $20 \%$ of all $1 / 4$-acre parcels contain TOI, given the 2.7 acres surveyed. Because there were only approximately 700 TOI found on an adjacent area that contained target areas, it may not be unreasonable to assume that for Area 3a, no more than 700 of the 1/4-acre parcels could contain TOI. Moreover, because no target areas are suspected in Area 3a, it may even be reasonable to assume that very few (say <200) of the parcels could contain TOI. Given the 2.7 acres surveyed, the achieved confidence and maximum percentages of the parcels that may contain TOI accounting for the prior information on the maximum number of TOI containing $1 / 4$-acre parcels $(<700$ or $<200)$, are shown in Table 7.

Table 7. Achieved Confidence Given Actual Survey Results (2.7 acres surveyed and no TOI found) for Area 3a for a 1/4 Acre Parcel Size of Concern

\begin{tabular}{|lrl|}
\hline Achieved Percent & Maximum Percent Parcels that May Contain TOI & Prior on Maximum Parcels w/ TOI \\
Confidence & & \\
$90 \%$ & $20 \%$ & Unknown \\
$90 \%$ & $11.8 \%$ & 700 \\
$90 \%$ & $5.4 \%$ & 200 \\
$<50 \%$ & $5 \%$ & Unknown \\
$62 \%$ & $5 \%$ & 700 \\
$88 \%$ & $5 \%$ & 200 \\
\hline
\end{tabular}

\subsection{Evaluation of Effects of Varied Dimension Transect Surveys and Grid Surveys on Confidence and Spatial Representation}

The two designs performed in Area 3a do not provide enough information to validate the appropriateness of grids or varied transect dimensions. This evaluation is performed using simulated data in Section 7.6.

\section{PERFORMANCE ASSESSMENT}

The performance objectives for this demonstration are reiterated in Table 8 along with a brief performance assessment summary. All of the objectives of this demonstration were achieved except for the enhanced boundary delineation tools demonstration. Because of the unforeseen complexity of these new boundary delineation methods, these new tools in VSP were still under development when this demonstration was completed. It is anticipated that they will be illustrated in a future demonstration. Each of the performance objectives is discussed below. 
Table 8. Performance Objectives and Evaluation Summary

\begin{tabular}{|c|c|c|c|}
\hline $\begin{array}{l}\text { Performance } \\
\text { Objective }\end{array}$ & Metric & Success Criteria & Performance Assessment \\
\hline $\begin{array}{l}\text { 1. Show application of } \\
\text { VSP-RI modules for } \\
3 \text { types of areas }\end{array}$ & $\begin{array}{l}\text { Application of the VSP-RI } \\
\text { modules to three different } \\
\text { types of areas within Motlow } \\
\text { site. }\end{array}$ & $\begin{array}{l}\text { - Well delineated target } \\
\text { areas (see description) } \\
\text { - Estimate an upper } \\
\text { bound on TOI/acre } \\
\text { - Acceptance of transect } \\
\text { design input parameters. }\end{array}$ & $\begin{array}{l}\text { VSP-RI Modules used } \\
\text { successfully; target areas } \\
\text { identified on Area 2a; } \\
\text { TOI/acre shown to be }<0.5 \\
\text { on Area 3a; Concurrence } \\
\text { on transect design input } \\
\text { parameters. }\end{array}$ \\
\hline $\begin{array}{l}\text { 2. Experience for } \\
\text { developing VSP-RI } \\
\text { workflow process } \\
\text { guidance. }\end{array}$ & $\begin{array}{l}\text { Agreement within VSP-RI } \\
\text { advisory committee of } \\
\text { general workflow process. }\end{array}$ & $\begin{array}{l}\text { Draft of VSP-RI workflow } \\
\text { process developed. }\end{array}$ & $\begin{array}{l}\text { Motlow Demo guided } \\
\text { development of new VSP- } \\
\text { UXO Expert Guide; Vetted } \\
\text { with Advisory group. }\end{array}$ \\
\hline $\begin{array}{l}\text { 3. Demonstrate } \\
\text { usability of VSP-RI } \\
\text { modules and } \\
\text { identify needed } \\
\text { improvements. } \\
\end{array}$ & $\begin{array}{l}\text { Contractor understanding/use } \\
\text { of VSP-RI and list of } \\
\text { recommended improvements. }\end{array}$ & $\begin{array}{l}\text { Successful application of } \\
\text { VSP-RI modules and } \\
\text { minimal list of needed } \\
\text { improvements. }\end{array}$ & $\begin{array}{l}\text { VSP-RI modules } \\
\text { successfully applied; } \\
\text { Several improvements } \\
\text { spawned by Motlow Demo. }\end{array}$ \\
\hline $\begin{array}{l}\text { 4. VSP-RI module } \\
\text { comparison with } \\
\text { UXO Estimator }\end{array}$ & $\begin{array}{l}\text { Cost of transects and } \\
\text { simplicity of use. } \\
\text { Demonstrate that VSP and } \\
\text { UXO Estimator answers are } \\
\text { same when same assumption } \\
\text { is used. }\end{array}$ & $\begin{array}{l}\text { VSP-RI survey acreage } \\
\text { required is same as UXO } \\
\text { estimator under certain } \\
\text { conditions. VSP-RI shown } \\
\text { to require less acreage } \\
\text { under alternative } \\
\text { assumptions. }\end{array}$ & $\begin{array}{l}\text { VSP-RI TOI/Acre } \\
\text { estimation/delineation } \\
\text { module with unknown } \\
\text { Bayesian prior shown } \\
\text { equivalent to UXO } \\
\text { Estimator; With informed } \\
\text { prior, achieved desired } \\
\text { confidence with reduced } \\
\text { surveying. }\end{array}$ \\
\hline $\begin{array}{l}\text { 5. Evaluate } \\
\text { performance of } \\
\text { transects vs. grids for } \\
\text { UXO/acre estimation } \\
\text { objective and spatial } \\
\text { coverage index. }\end{array}$ & $\begin{array}{l}\text { Desired confidence equals } \\
\text { achieved confidences for } \\
\text { simulations where UXO } \\
\text { spatial density patterns and } \\
\text { number of UXO are varied }\end{array}$ & $\begin{array}{l}\text { Guidance to provide VSP- } \\
\text { RI user help on selecting } \\
\text { transect length and width. }\end{array}$ & $\begin{array}{l}1 \mathrm{~m} \text { and } 3 \mathrm{~m} \text { wide transect } \\
\text { consistently meet } \\
\text { confidence objectives and } \\
\text { are the most robust to TOI } \\
\text { clustering. Grid surveying } \\
\text { often did not meet desired } \\
\text { confidence. }\end{array}$ \\
\hline $\begin{array}{l}\text { 6. Compare the utility } \\
\text { of different possible } \\
\text { target area boundary } \\
\text { delineation methods. }\end{array}$ & $\begin{array}{ll}- & \text { Ease of use } \\
\text { - Are boundaries, based } \\
\text { on systematic transects, } \\
\text { sufficiently bounding } \\
\text { high-density areas for } \\
\text { future remediation } \\
\text { efforts? }\end{array}$ & $\begin{array}{l}\text { Boundary tools support } \\
\text { cost estimation and } \\
\text { associated uncertainty of } \\
\text { remediation needs. } \\
\text { Boundary delineation } \\
\text { results on synthesized } \\
\text { sites are conservative } \\
\text { (meet or exceed specified } \\
\text { delineation objectives). } \\
\end{array}$ & $\begin{array}{l}\text { Complexity of new } \\
\text { boundary delineation tools } \\
\text { delayed availability for this } \\
\text { demonstration; unachieved. }\end{array}$ \\
\hline
\end{tabular}

\subsection{Objective 1 Assessment: Show Application of VSP-RI Modules for 3 Types Of Areas}

As shown in Section 6, the VSP-RI modules were applied to Motlow areas and demonstrated to be effective in achieving the goals of the Motlow RI. For Area 2a (Type-1 area) where the objective was to identify and delineate any potential target areas, the application of the VSP generated transect survey design resulted in the identification and delineation of several potential target areas. This finding was consistent with the analysis performed by the Motlow RI contractor. 
For Area 3a (Type-2 area), where the objective was to estimate TOI/acre and demonstrate that one can be $90 \%$ confident that the true TOI/acre rate was less than 0.5, the VSP generated transect survey design was developed. Because of funding and practical constraints, only about half of the as-designed transects were performed. Yet, using the VSP-RI modules and reasonable Bayesian priors, the reduced survey acreage was sufficient to demonstrate that one can be $90 \%$ confident that the true TOI/acre rate is less than $0.5 /$ acre.

Although the Motlow RI did not have a presumptively clean area (Type-3 area), Area 3a was used to demonstrate how one could have developed a transect survey design that allowed one to conclude that with X\% confidence no more than $\mathrm{Y} \%$ of all possible $1 / 4$-acre parcels contain TOI. This demonstration effectively showed how all three relevant VSP-RI modules can be applied during an RI process.

\subsection{Objective 2 Assessment: Gain Experience for Developing VSP-RI Workflow Process}

Guidance

This Motlow demonstration provided real-world application experience for the VSP development team as we interacted with the project team at Parsons. This helped us formulate the content of a new VSP-UXO guide that any VSP user can launch. Figure 16 shows one of many screens within this VSP-UXO guide. The purpose of this guide is to help the user determine which VSP modules are most appropriate for their particular use. This new expert guide will be publicly available in VSP 7.0 that will be released in March 2014.

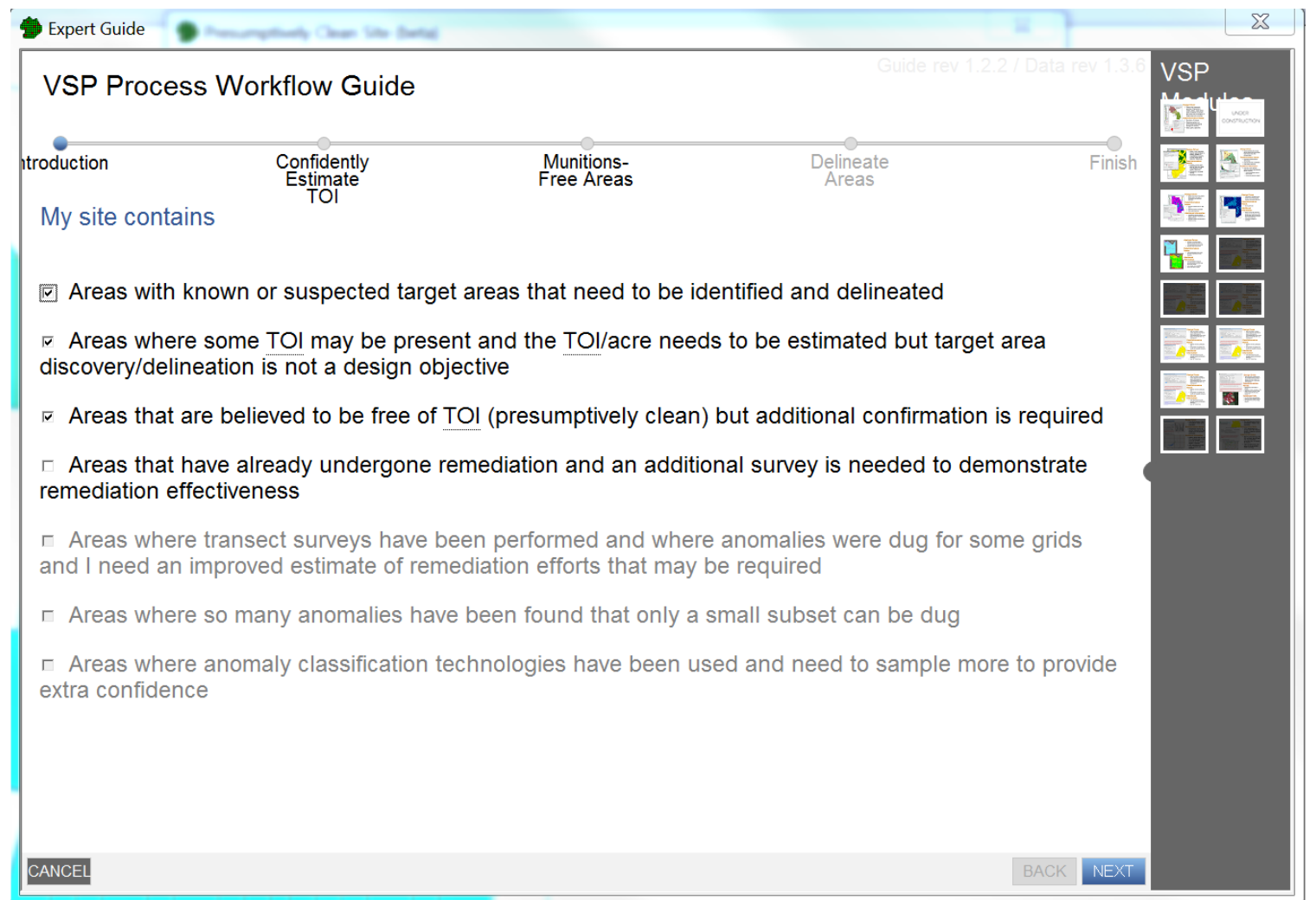

Figure 16. VSP-UXO Expert Guide Initial Page 


\subsection{Objective 3 Assessment: Evaluate Usability of VSP and Identify Needed Improvements}

As we began this demonstration, the contractor had already used VSP to develop a transect survey design for Area 2a. They had no issues with using that module appropriately. For Area 3a, they used UXO Estimator to determine the required survey acreage and had already reached agreement with the stakeholders that they would perform grid surveys instead of transect surveys. However, they easily understood the VSP-RI module for estimating TOI/acre.

As we proceeded with this demonstration, although the VSP modules were easy to use and readily understood, the need for several modifications were identified and those were implemented to improve the modules. The major improvements are listed below.

- Transect placement options - Methods are being added to ensure unbiased spatial coverage of transects and deal with transects of a given length that would go beyond the boundaries of the area. Options for equally spaced transects that go the entire length of the areas also are being added to address practical constraints and operational efficiency of transect clearing and access issues.

- Parcel sizes for Presumptively Clean module - To avoid misuse and standardize the presumptively clean module (Type-3 area), we now force the user to specify a parcel size of concern and all statistical statements, and survey requirements are based on parcel size equivalent survey acreage.

- VSP-RI module organization - All the VSP modules that may be pertinent for an RI process were coupled together under one Sampling Goal in VSP called "Remedial Investigation (UXO)."

- Post-Survey TOI/Acre Estimation - A post survey analysis tab was added under the TOI/Acre Estimation and Comparison user dialog to calculate the estimated TOI/acre and upper confidence limit that was achieved based on actual survey acreage and number of TOI found which included the uninformed and informed Bayesian options.

- User dialog wording - Some of the wording on the user dialogs was changed to better ensure that user inputs would be correct and design/analysis outputs would be readily understood.

- Online help and automatic reports - The online help and automatically generated VSP reports were developed and added.

\subsection{Objective 4 Assessment: VSP-RI Module Comparison with UXO Estimator}

For the VSP-RI TOI/acre estimation and comparison module, when using uninformed priors, the required survey acreage from VSP is equivalent to the required survey acreage from UXO Estimator. Specific examples of VSP output compared to UXO output are shown in Table 9. The VSP output is rounded but as can be seen, these results are equivalent. 
Table 9. VSP-RI Module Output Compared with UXO Estimator

$\begin{array}{ccccc}\begin{array}{l}\text { Required Percent } \\ \text { Confidence }\end{array} & \begin{array}{l}\text { Maximum True TOI/Acre } \\ \text { Rate }\end{array} & \text { Site Acreage } & \begin{array}{l}\text { UXO Estimator } \\ \text { Required Survey } \\ \text { Acreage } \\ \text { Output }\end{array} & \begin{array}{l}\text { VSP-RI } \\ \text { Uninformed Prior } \\ \text { Required Survey } \\ \text { Acreage }\end{array} \\ 90 \% & 1 / \text { acre } & 1000 & 2.298 & 2.3 \\ 90 \% & 0.5 / \text { acre } & 1000 & 4.586 & 4.59 \\ 90 \% & 0.1 / \text { acre } & 1000 & 22.540 & 22.5 \\ 90 \% & 1 / \text { acre } & 100 & 2.254 & 2.25 \\ 90 \% & 0.5 / \text { acre } & 100 & 4.415 & 4.41 \\ 90 \% & 0.1 / \text { acre } & 100 & 18.887 & 18.9 \\ 95 \% & 1 / \text { acre } & 1000 & 2.989 & 2.99 \\ 95 \% & 0.5 / \text { acre } & 1000 & 5.962 & 5.96 \\ 95 \% & 0.1 / \text { acre } & 1000 & 29.226 & 29.2 \\ 95 \% & 1 / \text { acre } & 100 & 2.923 & 2.92 \\ 95 \% & 0.5 / \text { acre } & 100 & 5.705 & 5.7 \\ 95 \% & 0.1 / \text { acre } & 100 & 23.841 & 23.8\end{array}$

\subsection{Objective 5 Assessment: Evaluate Performance of Transects Vs. Grids for UXO/Acre}

\section{Estimation Objective and Spatial Coverage Index}

Sampling designs are always built on model assumptions, and it is often valuable to test the robustness of the designs to departures from their respective assumptions. In two previous documents, we have performed similar validations (Hathaway 2009, Pulsipher 2012). The previous two studies were developed to validate the verification sampling modules in VSP. For this study, we validate the RI TOI rate estimation and comparison sampling design. The primary difference between these two designs is the resulting confidence statements. For verification designs, the confidence statements answer questions about the percent of transects that do not contain TOI by calculating a fixed number of transects that must be surveyed. The RI TOI rate estimation and comparison sampling design provides confidence statements on the rate of TOI within the sample area and calculates an amount of area that must be surveyed.

When performing spatial sampling the two primary model assumptions that are generally evaluated are the spatial point (TOI) patterns and the sampling unit size. If there is no spatial TOI pattern (uniform TOI distribution throughout the sample area), any size and placement of sampling units is acceptable (see Figure 17). If the sampling unit is small enough, the confidence statements are quite robust to extreme spatial TOI patterns (few clusters with TOI tightly spaced around those clusters). In application, remedial investigation projects want each survey location (sampling unit or transect) to be as large as possible as it makes the survey work easier to complete. This work examines the sensitivity of the prescribed VSP confidence statements to variations in the spatial point patterns and sampling unit size. 


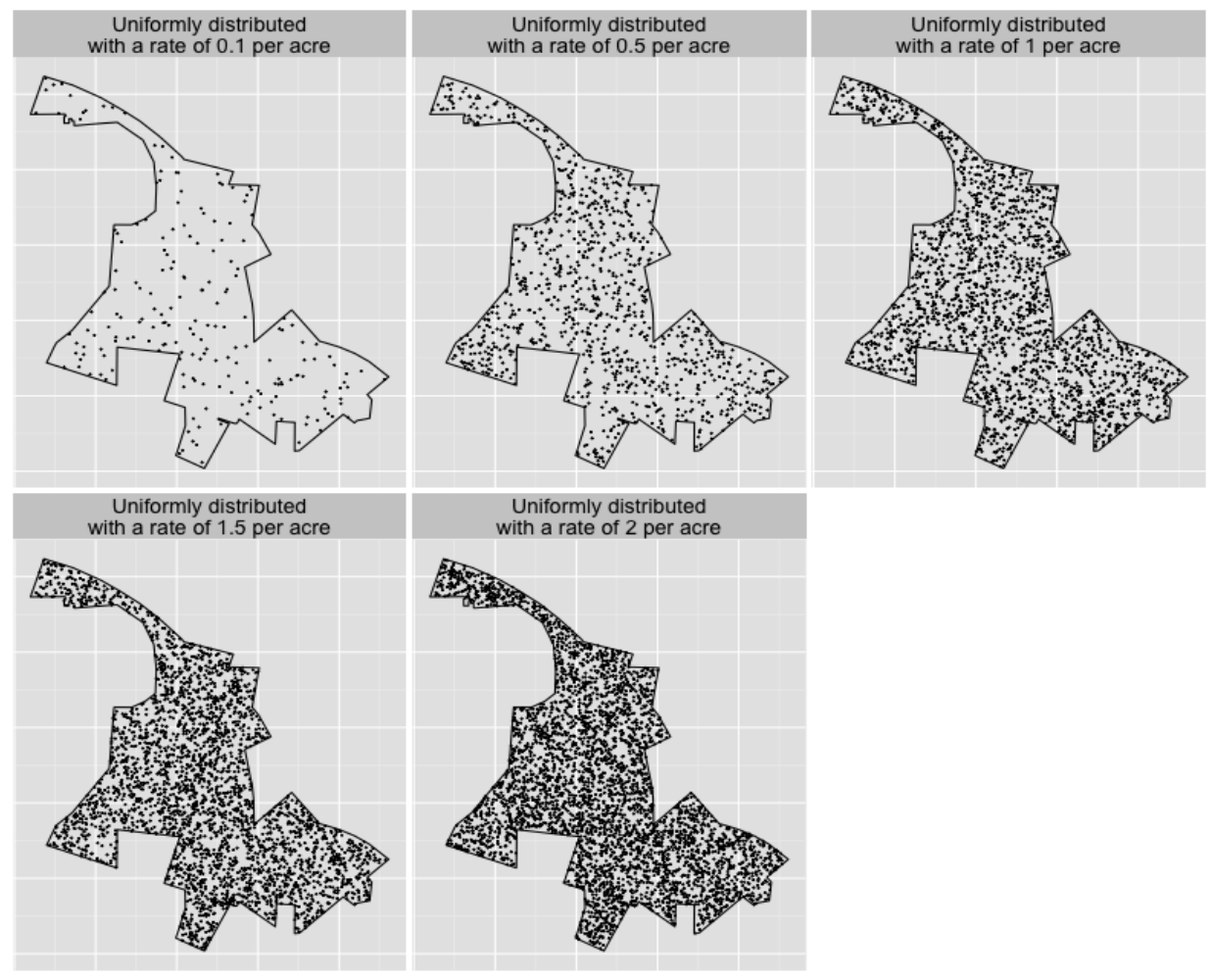

Figure 17. Uniform Point Patterns for the Five Different TOI per Acre Rates

We created 85 different TOI point patterns within the Motlow site boundaries. These 85 TOI patterns are a result of a combination of the TOI rate $(0.1,0.5,1,1.5$, and 2 TOI/acre) and the type of clustering. The number of center points and the distance at which the points grouped around those center points defined the clustering. We used four different levels for the number of center points - 10,30,60,120, with four different levels for clustering around the center points - within $60 \times 60$ meters ( 0.9 acres), $125 \times 125$ meters (3.9 acres), 250 x 250 meters (15.4 acres), and 500 x 500 meters (62.8 acres) square area. Finally, a uniform distribution of TOI was generated for each TOI rate (see Figure 18).

The 16 different clustering patterns are also described by the max percent of area within the Motlow boundary where TOI points could be placed. For example, if there are 10 cluster locations where all points for each cluster are within a 0.9 acre footprint, then of the 1989 acres at Motlow at most $0.45 \%$ ( 9 acres) of the area has potential for TOI placement. Figure 18 and 19 show examples of the varied spatial TOI patterns for the 0.1 and 1 TOI rate per acre respectively with each spatial map labeled as to the max percent of area where TOI could be placed.

These 85 different TOI patterns were then used to validate the robustness of varied sampling unit dimensions on the confidence statements $(90 \%, 95 \%, 99 \%$, and $99.9 \%)$. We allowed the sampling unit to have dimensions of $50 \times 50,100 \times 100$, and $50 \times 100$ meters to represent grids. We also simulated transects with widths of 1, 3, and 6 meters with varied lengths of 50, 100, 500, 1000, and 3000 meters to make 18 different sampling unit dimensions. Additionally, we placed the transects using simple random sampling or systematic random sampling. The required survey acreages for the varied confidence and TOI rates are shown in Table 10. The 
largest acreage is required from the 99.9/0.1 designs at 67.9 acres. The least required acreage results from the $90 / 2$ designs at 1.2 acres.

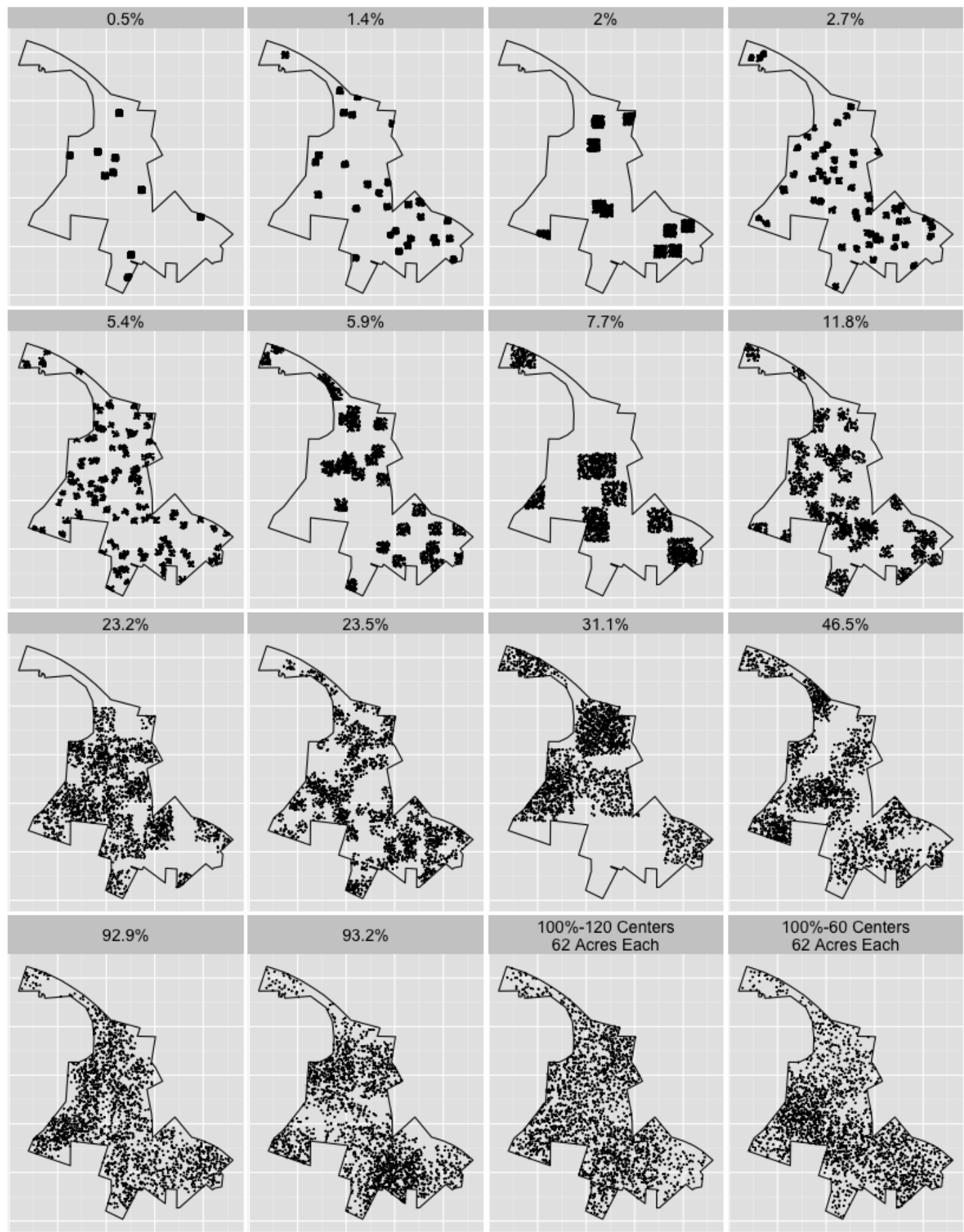

Figure 18. The 16 TOI Spatial Point Patterns Using a Rate of 1 TOI Per Acre Used to Evaluate the Confidence Performance for Different Sampling Unit Dimensions 


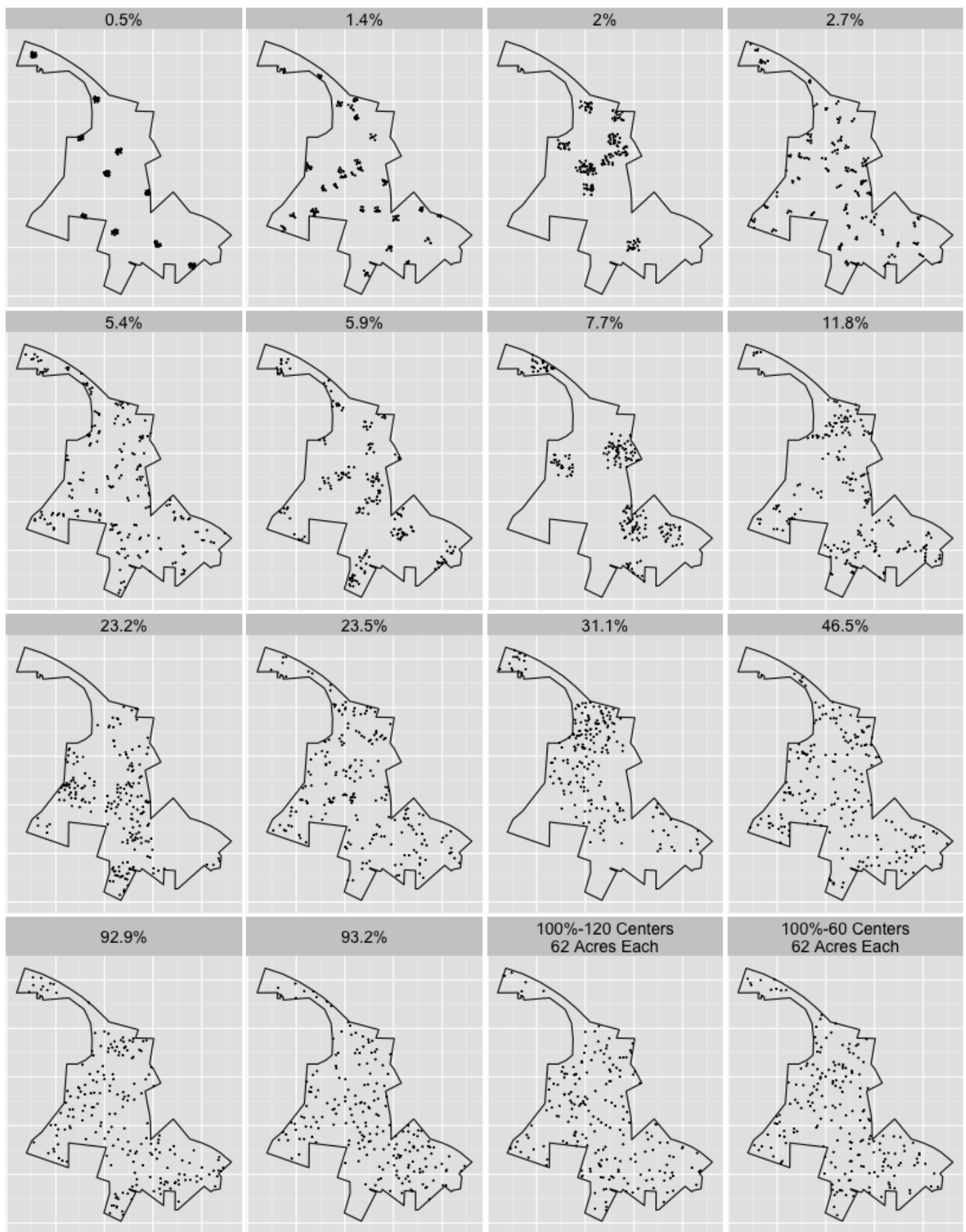

Figure 19. The 16 TOI Spatial Point Patterns Using a Rate of 0.1 TOI Per Acre Used to Evaluate the Confidence Performance for Different Sampling Unit Dimensions 
Table 10. Summary of the Calculated Number of Acres Required for Each Confidence Design Case Used in this Simulation Study

\begin{tabular}{|c|c|c|c|}
\hline $\begin{array}{c}\text { Area } \\
\text { Required } \\
\text { Case }\end{array}$ & Confidence & TOI/acre & $\begin{array}{c}\text { Number of acres calculated by } \\
\text { confidence design }\end{array}$ \\
\hline 1 & 90 & 0.1 & 22.9 \\
\hline 2 & 90 & 0.5 & 4.6 \\
\hline 3 & 90 & 1.0 & 2.3 \\
\hline 4 & 90 & 1.5 & 1.5 \\
\hline 5 & 90 & 2.0 & 1.2 \\
\hline 6 & 95 & 0.1 & 29.0 \\
\hline 7 & 95 & 0.5 & 6.0 \\
\hline 8 & 95 & 1.0 & 3.0 \\
\hline 9 & 95 & 1.5 & 2.0 \\
\hline 10 & 95 & 2.0 & 1.5 \\
\hline 11 & 99 & 0.1 & 45.5 \\
\hline 12 & 99 & 0.5 & 9.2 \\
\hline 13 & 99 & 1.0 & 4.6 \\
\hline 14 & 99 & 1.5 & 3.1 \\
\hline 15 & 99 & 2.0 & 2.3 \\
\hline 16 & 99.9 & 0.1 & 67.9 \\
\hline 17 & 99.9 & 0.5 & 13.8 \\
\hline 18 & 99.9 & 1.0 & 6.9 \\
\hline 19 & 99.9 & 1.5 & 4.6 \\
\hline 20 & 99.9 & 2.0 & 3.4 \\
\hline
\end{tabular}

For each design type (transect dimension, confidence, and TOI rate) the achieved confidence is calculated by finding the percentage of the 2300 iterations (random transect selections) that had at least one TOI within a transect from that sample. The TOI rate upon which the design type was built is placed within the Motlow boundary area using one of the 17 TOI point patterns described previously (16 TOI clustering patterns and the one uniform TOI pattern). If a transect design (calculated survey area) is devised to detect a specified TOI rate with $90 \%$ confidence and the true TOI rate upon which the design is applied is equal to the design rate and uniformly distributed within the sample area, repeated sampling would result in $10 \%$ of the repeated transect samples not containing TOI. We show the results for random sampling in this report as the results from systematic and random had no observable differences in performance.

Figure 20 shows the achieved confidence results (y-axis) for the varied designs from the 2300 iterations as applied to the TOI point patterns shown in Figure 17. Each panel of Figure 20 shows the achieved results with the as-designed confidence listed at the top of the panel (y-axis scale varies in each panel). The horizontal solid black line is the approximately 3 standard deviation lower bound on the as-designed (horizontal dotted line) confidence. Most of the cases fall within the 3 standard deviation boundary as expected. As we have only run 2300 simulations for each design type, we would expect a few of the cases to fall outside the boundaries as shown in Figure 20. These results validate that the simulation is performing correctly and allow us to examine the robustness in confidence as the TOI point pattern deviates from a uniform distribution. 


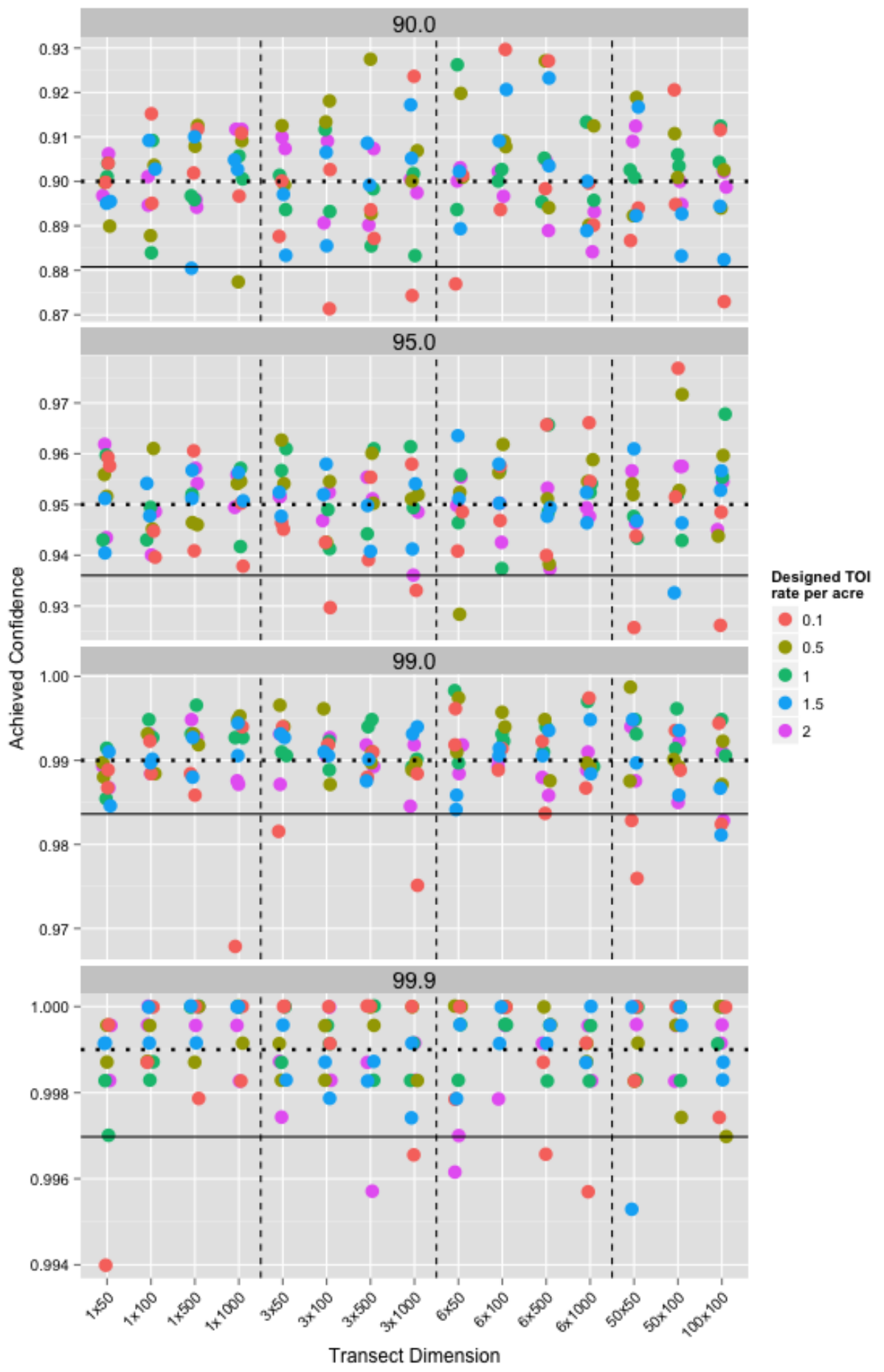

Figure 20. Achieved confidence (y-axis) for the varied confidence (panel), TOI rates (color of points) and sampling unit dimension ( $\mathrm{x}$-axis) for the uniformly distributed points as shown in Figure 20. 
Figure 21, Figure 22, and Figure 23 provide the achieved confidence results for the varied sampling unit dimensions and type of clustering as categorized by the maximum percent of the area where TOI could be placed. We grouped results into TOI placement that is extremely clustered, has some clustering, and little to no clustering. These groupings were defined below:

- Extremely clustered - Less than $12 \%$ of the sample area having the potential to contain TOI

- Some clustering - Between $23 \%$ and $50 \%$ of the sample area having the potential to contain TOI

- Little to no clustering - Greater than $90 \%$ of the sample area having the potential to contain TOI.

For the extreme clustering cases (Figure 21), the results show that if the TOI rate is above $0.5 /$ acre, the desired confidence is not achieved except for perhaps the narrower, shorter transects. For the some clustering cases (Figure 22), all the 1 meter and 3 meter wide transects meet the designed confidence with exception of a few of the 2 TOI/acre designs (which would most likely be very unexpected on this type of site area). None of the grid survey options met the as-designed confidence and generally perform poorly when there is some clustering. Finally, for the little to no clustering cases (Figure 23), all transect sampling units meet the designed confidence. The grid-sized transects $(50 \times 50,100 \times 100$, and $50 \times 100$ meter $)$ did not perform well. The very low TOI rate design of $0.1 \mathrm{TOI} / \mathrm{acre}$ met confidence designs for the grids in some cases and all transect sampling unit cases.

Similar to the conclusions reported in the previous simulation studies on appropriate transect dimensions, transect sampling is always recommended over grid sampling to attain a representative sample that is robust to clustered TOI point patterns. The shorter and narrower transects are more robust to strong clustering in TOI locations. The typically used 1 meter and 3 meter wide transects perform well in most cases and can be expected to perform well for TOI rates below $0.5 /$ acre even with extreme clustering of TOI. 


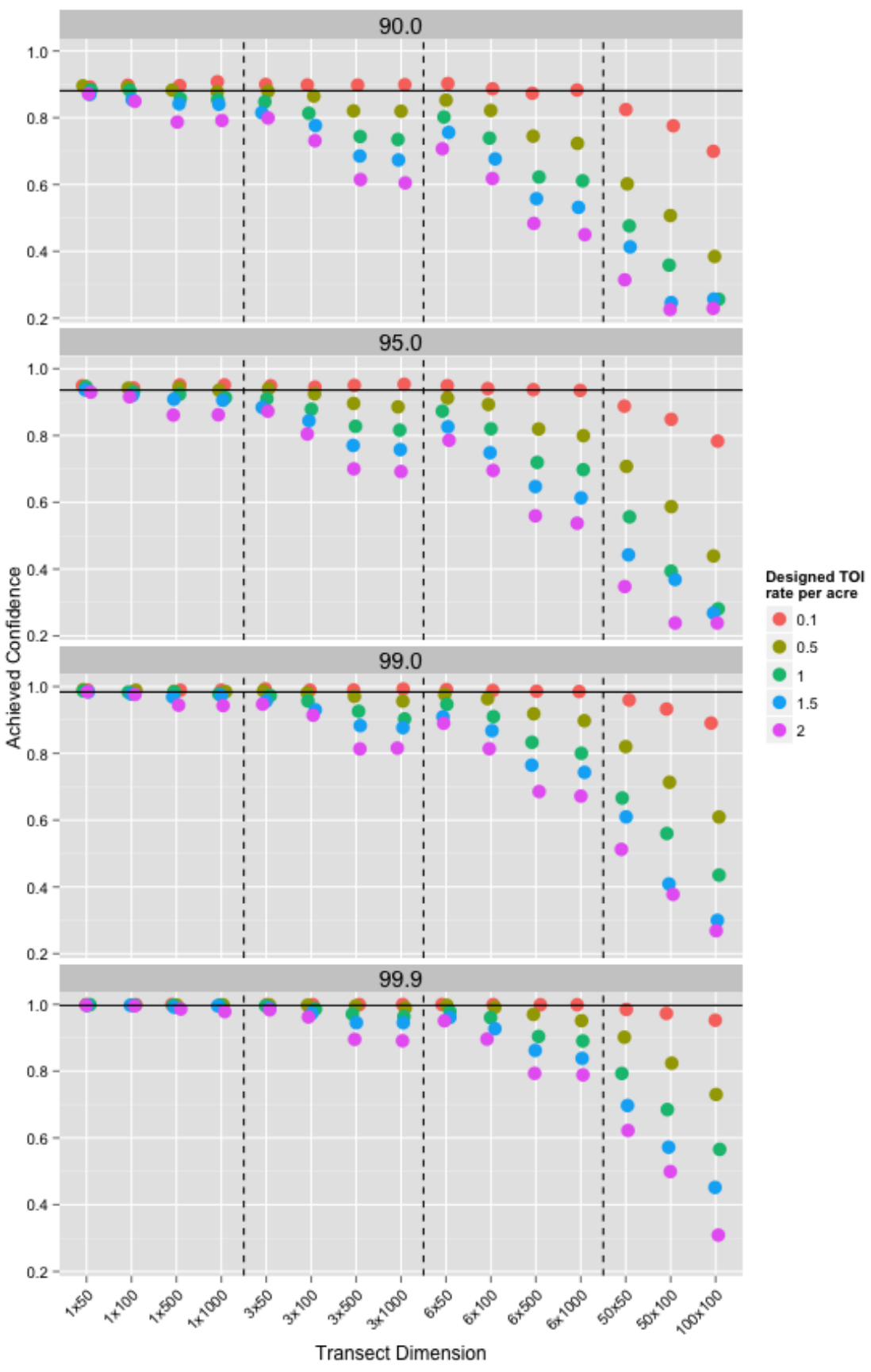

Figure 21. Achieved confidence (y-axis) for the varied confidence (panel), TOI rates (color of points) and sampling unit dimension ( $\mathrm{x}$-axis) for the TOI point patterns that restrain points to fall in no more than $12 \%$ of the sample area. The solid horizontal line is the 3 standard deviation lower bound of confidence performance from a simulation study using 2300 simulations to evaluate confidence. The vertical dashed lines separate the three transect widths and the grid based sampling units. 


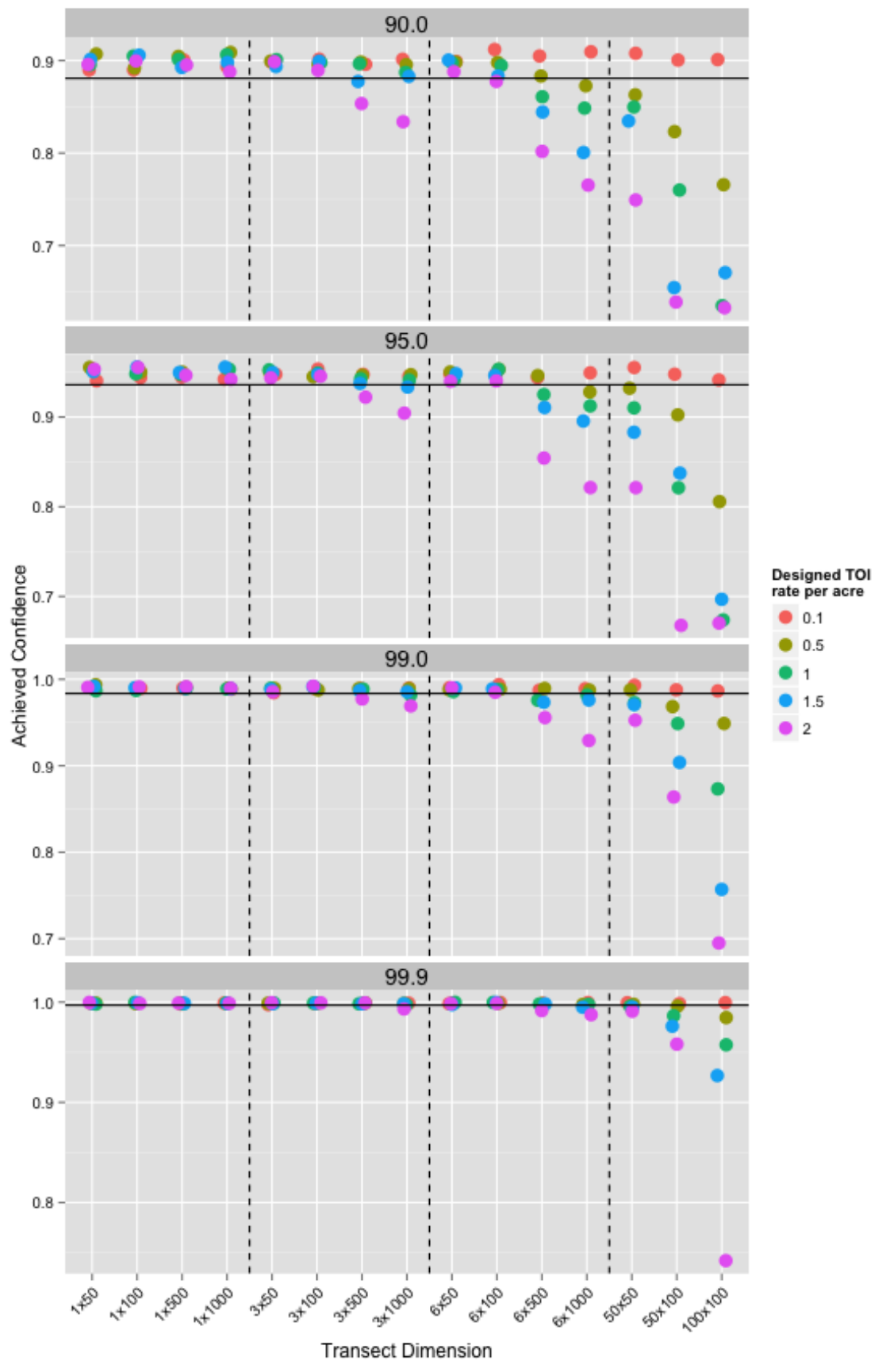

Figure 22. Achieved confidence (y-axis) for the varied confidence (panel), TOI rates (color of points) and sampling unit dimension (x-axis) for the TOI point patterns that restrain points to fall in no more than $50 \%$ but greater than $23 \%$ of the sample area. The solid horizontal line is the 3 standard deviation lower bound of confidence performance from a simulation study using 2300 simulations to evaluate confidence. The vertical lines separate the three transect widths and the grid based sampling units. 


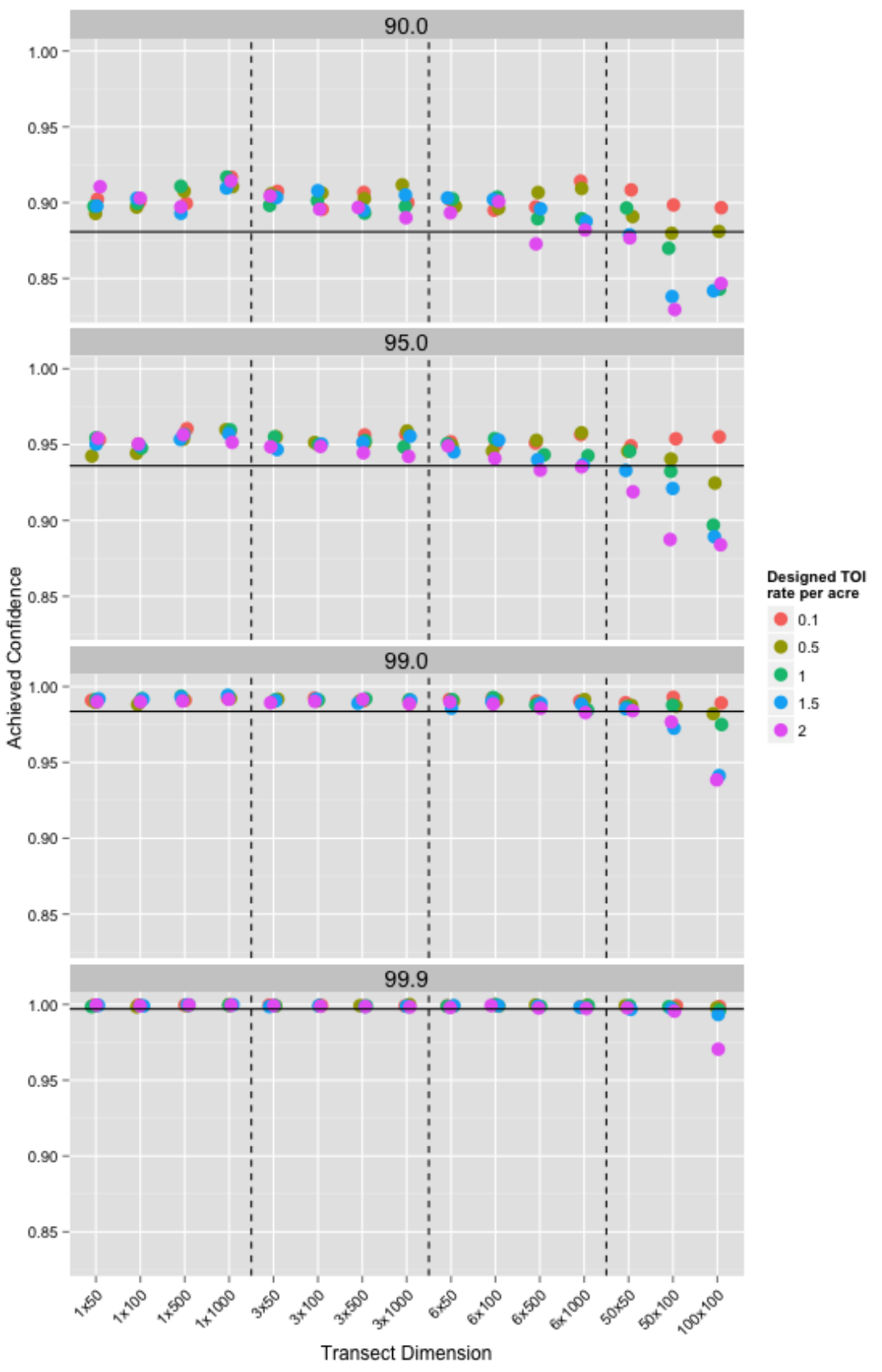

Figure 23. Achieved confidence (y-axis) for the varied confidence (panel), TOI rates (color of points) and sampling unit dimension ( $\mathrm{x}$-axis) for the TOI point patterns that restrain points to fall in greater than $90 \%$ of the sample area. The solid horizontal line is the 3 standard deviation lower bound of confidence performance from a simulation study using 2300 simulations to evaluate confidence. The vertical lines separate the three transect widths and the grid based sampling units. 


\subsection{Objective 6 Assessment: Compare the Utility of Different Possible Target Area Boundary Delineation Methods}

Because of the complexity of these methods, they were not fully developed in time for this demonstration. They are nearing completion and will be included in a future VSP release and tested/demonstrated on a site in the future.

\section{COST ASSESSMENT}

PNNL's VSP software is freely available at no cost to the user. Costs for conducting transect surveys are borne by the geophysical survey contractors. VSP can help minimize these costs by helping develop an optimal transect survey design. The following table (Table 11) does identify some potential costs that are primarily in the form of man hours. However, the benefit of having an acceptable data quality objective-based design can potentially reduce the overall man hours cost of the remediation process. Obtaining sufficiently precise estimates of anomaly density, target area spatial extent, or TOI/acre will be important in accurately costing out any potential remediation.

Table 11. Potential Costs of Using VSP-RI Modules

\begin{tabular}{|c|c|}
\hline Cost Element & Data \\
\hline Use of VSP & $\begin{array}{l}\text { Obtaining the software and learning how to use it } \\
\text { - VSP Training hours } \\
\text { - VSP Training costs } \\
\text { - VSP Software - no cost }\end{array}$ \\
\hline Transect Designs & $\begin{array}{l}\text { Using VSP to develop the implemented surveyed } \\
\text { transects for each type of area. } \\
\text { - Could change originally planned survey costs } \\
\text { required for VSP design }\end{array}$ \\
\hline Geophysical Survey Costs & $\begin{array}{l}\text { Cost per linear foot for conducting geophysical surveys } \\
\text { can be factored in to the overall costs and any cost } \\
\text { comparisons. Provided by survey contractor. }\end{array}$ \\
\hline Interpretation/Analysis of Geophysical Survey Data & $\begin{array}{l}\text { Average cost per identified anomaly of evaluating the } \\
\text { geophysical surveys can be factored into the overall } \\
\text { costs and any cost comparisons. Provided by survey } \\
\text { contractor. }\end{array}$ \\
\hline Digging and Anomaly Identification Costs & $\begin{array}{l}\text { Cost of digging and identifying each anomaly can be } \\
\text { factored into overall costs and any cost comparisons. } \\
\text { Provided by contractor. }\end{array}$ \\
\hline
\end{tabular}




\section{REFERENCES}

Bowen W and Bennett C. (1987). Statistical Methods for Nuclear Material Management. Washington: Nuclear Regulatory Commission.

Department of the Navy. (2009). Explosives Safety Submission: Non-Time Critical Removal Action, Navy/Denver Research Institute. Silverdale, WA: Department of the Navy, Naval Facilities Engineering Command Northwest.

Gilbert R, J Wilson, R O'Brien, D Carlson, B Pulsipher, and D Bates. (2003). Version 2.0 Visual Sample Plan (VSP): UXO Module Code Description and Verification. Richland: Pacific Northwest National Laboratory.

Hahn GJ and WQ Meeker. (1991). Statistical Intervals: A Guide for Practitioners, New York: Jonh Wiley and Sons, Inc.

Hathaway J, R Gilbert, and JP Wilson. (2009). Evaluation of spatially clustered ordnance when using compliance sampling surveys after clean-up at military training sites. Stochastic Environmental Research and Risk Assessment , 23 (2), 253-261.

Intergovernmental Data Quality Task Force. (2005). Uniform Federal Policy for Quality Assurance Project Plans: Part 2B, Quality Assurance/Quality Control Compendium: Minimum QA/QC Activities. DoD. Washington, D.C.: DoD.

ITRC Unexploded Ordnance Team. (2008). Quality Consideration for Munitions Response Projects. Washington, D.C.: Interstate Technology and Regulatory Council.

Jaech J. (1973). Statistical Methods in Nuclear Material Control. Oakridge: Technical Information Center, Office of Information Services, U.S. Atomic Energy Commission.

Malcom Pirnie, Inc. (2008). Final Preliminary Assessment / Site Inspection Report: Navy /Denver Research Institute (DRI) Site Former Lowry Training Annex, Colorado. Sliverdale, Washington: Naval Facilities Engineering Command Northwest.

Matzke B, J Wilson, L Nuffer, S Dowson, J Hathaway, N Hassig, L Sego, C Murray, B Pulsipher, B Roberts, and McKenna S. (2010). Visual Sample Plan Version 6.0 User's Guide. PNNL-19915, Pacific Northwest National Laboratory, Richland, Washington.

MIL-STD-1916. (1996). DOD Test Method Standard: DOD prefereed Methods for acceptance of product.

Pulsipher BA, JE Hathaway, KK Anderson, and JE Wilson. (2012). Demonstration Report for Visual Sample Plan (VSP) Verification Sampling Methods at the Navy/DRI Site. PNNL-20654, Pacific Northwest National Laboratory, Richland, Washington. 
Pulsipher B, J Hathaway, L Newburn, and J Wilson. (2012). Visual Sample Plan Remedial Investigation (VSP-RI) Module Demonstration Plan - Motlow Tennessee Site. PNNL-23169, Pacific Northwest National Laboratory, Richland, Washington.

Shilling E. (1978). A Lot Sensitive Sampling Plan for Compliance Testing and Acceptance Inspection. Journal of Quality Technology, 10 (2), 47-51.

Shilling E. (1982). Acceptance Sampling in Quality Control. New York: Marcel Dekker.

Sky Research. (2009). Final Former Lowry Training Annex - East Extension Area Post Removal Verification Report. U.S. Army Corps of Engineers Omaha District, Omaha, Nebraska.

Squeglia N. (1994). Zero Acceptance Number Sampling Plans. Milwakee: American Society for Quality Press.

Tetra Tech EC, Inc. (2010a). Explosives Safety Submission, Non-Time Critical Removal Action Navy/Denver Research Institute, Former Lowry Training Annex, Aurora, Colorado. Washington: Naval Facilities Engineering Command Northwest.

Tetra Tech EC, Inc. (2010). Non-Time Critical Removal Action Work Plan. Navy/Denver Research Institute, Former Lowry Training Annex, Aurora, Colorado. Washington: Naval Facilities Engineering Command Northwest.

U.S. Department of Defense. (1996). U.S. Department of Defense Test Methods Standard, DoD Preferred Methods for Acceptance of Product, MIL-STD 1916. Washington: U.S. Department of Defense, U.S. Printing Office.

Williams G. (2003). Echo/Foxtrot Sector Completion Report, Beacon Point Ordnance Clearance. Lakewood: Fostwer Wheeler Environmental Corporation.

Woolford JE. (2001). Interim Guidance on the Use of SiteStat/GridStats and Other Army Corps of Engineers Statistical Techniques to Characterize Military Ranges. Washington, D.C.: United States Environmental Protection Agency. 


\section{Appendix A: Points of Contact}

\begin{tabular}{|c|c|c|c|}
\hline $\begin{array}{c}\text { POINT OF CONTACT } \\
\text { Name }\end{array}$ & $\begin{array}{c}\text { ORGANIZATION } \\
\text { Name } \\
\text { Address }\end{array}$ & Phone & Role in Project \\
\hline Brent Pulsipher & PNNL & $(509) 375-3989$ & Principal Investigator \\
\hline John Hathaway & PNNL & $(509) 372-4970$ & Demonstration Lead \\
\hline John Wilson & PNNL & $(970) 270-2998$ & VSP Lead Programmer \\
\hline Chris Cochrane & USACE & $(256) 895-1696$ & USACE Project Lead \\
\hline Elise Goggin & USACE & $(256) 895-1635$ & USACE Project Geophysicist \\
\hline Karl Blankinship & USACE, Mobile Office & $(256) 682-7546$ & USACE District Project Manager \\
\hline John Hoffelt & $\begin{array}{c}\text { Tennessee Department of } \\
\text { Environmental and } \\
\text { Conservation (TDEC) }\end{array}$ & $(615) 687-7067$ & Contractor Project Manager \\
\hline Christian tenBraak & Parsons & $(303) 764-1923$ & Contractor Deputy Project Manager \\
\hline Carrie Ross & Parsons & $(303) 764-8736$ & Contractor Geophysicist \\
\hline Craig Murray & Parsons & $(303) 764-8868$ & Rer \\
\hline
\end{tabular}




\section{Appendix B: Area 3a Dig Results}

\begin{tabular}{|c|c|c|c|c|c|c|c|c|c|c|c|c|c|c|c|c|c|c|c|}
\hline $\begin{array}{l}\text { Proj } \\
\text { ect }\end{array}$ & $\begin{array}{l}\text { Locati } \\
\text { on }\end{array}$ & $\begin{array}{l}\text { Unique } \\
\text { Target ID }\end{array}$ & $\begin{array}{l}\text { Eastin } \\
g \\
\text { (UTM } \\
\text { meter } \\
\text { s) }\end{array}$ & $\begin{array}{l}\text { Northin } \\
g(U T M \\
\text { meters } \\
\quad\end{array}$ & $\begin{array}{l}\text { Fidu } \\
\text { cial } \\
\text { (Yes } \\
\text { or } \\
\text { No) } \\
\end{array}$ & $\begin{array}{l}\mathrm{CH} 2( \\
\mathrm{mV})\end{array}$ & Date & $\begin{array}{c}\mathrm{Pre} \\
\mathrm{mV}\end{array}$ & $\begin{array}{l}\text { Post } \\
\mathrm{mV}^{-}\end{array}$ & $\begin{array}{c}\text { Anomaly } \\
\text { Type } \\
\end{array}$ & $\begin{array}{c}\text { \# of } \\
\text { contacts }\end{array}$ & $\begin{array}{l}\text { Depth } \\
\text { (cm) }\end{array}$ & $\begin{array}{c}\text { Descrip } \\
\text { tion }\end{array}$ & $\begin{array}{l}\text { Item_le } \\
\text { ngth } \\
(\mathrm{cm})\end{array}$ & Grid & Photo ID & $\begin{array}{c}\text { Agreeme } \\
\text { nt } \\
\text { between } \\
\text { Dig } \\
\text { Results \& } \\
\text { GEO } \\
\text { Data } \\
\text { (G=good, } \\
\text { P=poor, } \\
U= \\
\text { unaccept } \\
\text { able) }\end{array}$ & $\begin{array}{c}\text { GE } \\
O \\
\text { QC } \\
\text { Initi } \\
\text { als }\end{array}$ & $\begin{array}{c}\text { Comme } \\
\text { nts }\end{array}$ \\
\hline $\begin{array}{l}\text { PNN } \\
L\end{array}$ & $\begin{array}{l}\text { Site } \\
3 a\end{array}$ & $\begin{array}{c}\text { Site } \\
\text { 3aTransect } \\
\text { 10A-001 }\end{array}$ & $\begin{array}{c}56749 \\
6.0\end{array}$ & $\begin{array}{c}391133 \\
6.8\end{array}$ & Yes & 7.79 & $\begin{array}{c}7 / 10 / 2 \\
013\end{array}$ & 8 & 0 & OD & 1 & 2 & Scrap & 11 & $\begin{array}{c}\text { Site } \\
\text { 3aTransec } \\
\text { t10A }\end{array}$ & $\begin{array}{c}\text { Site3AGridT10A } \\
0001\end{array}$ & G & SS & \\
\hline $\begin{array}{l}\text { PNN } \\
\text { L }\end{array}$ & $\begin{array}{l}\text { Site } \\
3 a\end{array}$ & $\begin{array}{c}\text { Site } \\
\text { 3aTransect } \\
\text { 10A-002 }\end{array}$ & $\begin{array}{c}56748 \\
9.0\end{array}$ & $\begin{array}{c}391142 \\
0.3\end{array}$ & Yes & 13.97 & $\begin{array}{c}7 / 10 / 2 \\
013\end{array}$ & 40 & 0 & OD & 1 & 0 & $\begin{array}{l}\text { Scrap } \\
\text { Chain }\end{array}$ & 50 & $\begin{array}{c}\text { Site } \\
\text { 3aTransec } \\
\text { t10A }\end{array}$ & $\begin{array}{c}\text { Site3AGridT10A } \\
0002\end{array}$ & G & SS & \\
\hline $\begin{array}{l}\mathrm{PNN} \\
\mathrm{L}\end{array}$ & $\begin{array}{l}\text { Site } \\
3 a\end{array}$ & $\begin{array}{c}\text { Site } \\
\text { 3aTransect } \\
\text { 10A-003 }\end{array}$ & $\begin{array}{c}56754 \\
8.7\end{array}$ & $\begin{array}{c}391149 \\
7.2\end{array}$ & Yes & 6.08 & $\begin{array}{c}7 / 10 / 2 \\
013\end{array}$ & 11 & 0 & OD & 1 & 5 & Scrap & 10 & $\begin{array}{c}\text { Site } \\
\text { 3aTransec } \\
\text { t10A }\end{array}$ & $\begin{array}{c}\text { Site3AGridT10A_ } \\
0003\end{array}$ & G & SS & \\
\hline $\begin{array}{l}\text { PNN } \\
\text { L }\end{array}$ & $\begin{array}{l}\text { Site } \\
3 a\end{array}$ & $\begin{array}{c}\text { Site } \\
\text { 3aTransect } \\
\text { 10A-004 }\end{array}$ & $\begin{array}{c}56755 \\
2.5\end{array}$ & $\begin{array}{c}391163 \\
7.8\end{array}$ & Yes & 74.25 & $\begin{array}{c}7 / 10 / 2 \\
013\end{array}$ & 75 & 0 & OD & 1 & 5 & Scrap & 20 & $\begin{array}{l}\text { Site } \\
\text { 3aTransec } \\
\text { t10A }\end{array}$ & $\begin{array}{c}\text { Site3AGridT10A } \\
0004\end{array}$ & G & SS & \\
\hline $\begin{array}{l}\mathrm{PNN} \\
\mathrm{L}\end{array}$ & $\begin{array}{l}\text { Site } \\
3 a\end{array}$ & $\begin{array}{c}\text { Site } \\
\text { 3aTransect } \\
\text { 10A-005 }\end{array}$ & $\begin{array}{c}56755 \\
2.5\end{array}$ & $\begin{array}{c}391172 \\
1.1\end{array}$ & Yes & 6.03 & $\begin{array}{c}7 / 10 / 2 \\
013\end{array}$ & 6 & 0 & OD & 1 & 5 & $\begin{array}{l}\text { Scrap } \\
\text { Wire }\end{array}$ & 4 & $\begin{array}{c}\text { Site } \\
\text { 3aTransec } \\
\text { t10A }\end{array}$ & $\begin{array}{l}\text { Site3AGridT10A_ } \\
0005\end{array}$ & G & SS & \\
\hline $\begin{array}{l}\text { PNN } \\
\mathrm{L}\end{array}$ & $\begin{array}{l}\text { Site } \\
3 a\end{array}$ & $\begin{array}{c}\text { Site } \\
\text { 3aTransect } \\
\text { 10A-006 }\end{array}$ & $\begin{array}{c}56754 \\
0.5\end{array}$ & $\begin{array}{c}391175 \\
2.3\end{array}$ & Yes & 9.96 & $\begin{array}{c}7 / 10 / 2 \\
013\end{array}$ & 36 & 0 & OD & 1 & 3 & Scrap & 10 & $\begin{array}{c}\text { Site } \\
\text { 3aTransec } \\
\text { t10A }\end{array}$ & $\begin{array}{c}\text { Site3AGridT10A } \\
0006\end{array}$ & G & SS & \\
\hline $\begin{array}{l}\text { PNN } \\
\mathrm{L}\end{array}$ & $\begin{array}{l}\text { Site } \\
3 a\end{array}$ & $\begin{array}{c}\text { Site } \\
\text { 3aTransect } \\
\text { 10A-007 }\end{array}$ & $\begin{array}{c}56752 \\
5.6\end{array}$ & $\begin{array}{c}391178 \\
1.0\end{array}$ & Yes & $\begin{array}{c}171.2 \\
3\end{array}$ & $\begin{array}{c}7 / 10 / 2 \\
013\end{array}$ & 180 & 30 & OD & 1 & 20 & Scrap & 40 & $\begin{array}{c}\text { Site } \\
\text { 3aTransec } \\
\text { t10A }\end{array}$ & $\begin{array}{c}\text { Site3AGridT10A } \\
0007\end{array}$ & G & SS & \\
\hline $\begin{array}{l}\text { PNN } \\
L\end{array}$ & $\begin{array}{l}\text { Site } \\
3 a\end{array}$ & $\begin{array}{c}\text { Site } \\
\text { 3aTransect } \\
\text { 10A-008 }\end{array}$ & $\begin{array}{c}56751 \\
9.2\end{array}$ & $\begin{array}{c}391180 \\
4.9\end{array}$ & Yes & 6.67 & $\begin{array}{c}7 / 10 / 2 \\
013\end{array}$ & 8 & 4 & OD & 1 & 15 & $\begin{array}{c}\text { Rust in } \\
\text { dirt }\end{array}$ & 1 & $\begin{array}{c}\text { Site } \\
\text { 3aTransec } \\
\text { t10A }\end{array}$ & $\begin{array}{l}\text { Site3AGridT10A } \\
0008\end{array}$ & G & SS & \\
\hline
\end{tabular}




\begin{tabular}{|c|c|c|c|c|c|c|c|c|c|c|c|c|c|c|c|c|c|c|}
\hline $\begin{array}{l}\text { PNN } \\
L\end{array}$ & $\begin{array}{l}\text { Site } \\
3 a\end{array}$ & $\begin{array}{c}\text { Site } \\
\text { 3aTransect } \\
\text { 10A-009 }\end{array}$ & $\begin{array}{c}56751 \\
6.3\end{array}$ & $\begin{array}{c}391183 \\
1.5\end{array}$ & Yes & 4.97 & $\begin{array}{c}7 / 10 / 2 \\
013\end{array}$ & 0 & 0 & NC & 0 & & No Find & & $\begin{array}{c}\text { Site } \\
\text { 3aTransec } \\
\text { t10A }\end{array}$ & $\begin{array}{c}\text { Site3AGridT10A_ } \\
0009\end{array}$ & G & SS \\
\hline $\begin{array}{l}\text { PNN } \\
L\end{array}$ & $\begin{array}{l}\text { Site } \\
3 a\end{array}$ & $\begin{array}{c}\text { Site } \\
\text { 3aTransect } \\
\text { 10A-010 }\end{array}$ & $\begin{array}{l}56751 \\
6.6\end{array}$ & $\begin{array}{c}391185 \\
1.6\end{array}$ & Yes & 7.94 & $\begin{array}{c}7 / 10 / 2 \\
013\end{array}$ & 3 & 0 & NC & 0 & & No Find & & $\begin{array}{c}\text { Site } \\
\text { 3aTransec } \\
\text { t10A }\end{array}$ & $\begin{array}{l}\text { Site3AGridT10A } \\
0010\end{array}$ & G & SS \\
\hline $\begin{array}{l}\text { PNN } \\
\text { L }\end{array}$ & $\begin{array}{l}\text { Site } \\
3 a\end{array}$ & $\begin{array}{c}\text { Site } \\
\text { 3aTransect } \\
\text { 10A-011 }\end{array}$ & $\begin{array}{c}56751 \\
6.6\end{array}$ & $\begin{array}{c}391185 \\
6.8\end{array}$ & Yes & $\begin{array}{c}6414 . \\
62\end{array}$ & $\begin{array}{c}7 / 10 / 2 \\
013\end{array}$ & 6400 & 6400 & OD & 1 & 61 & Culvert & 914 & $\begin{array}{c}\text { Site } \\
\text { 3aTransec } \\
\text { t10A }\end{array}$ & $\begin{array}{c}\text { Site3AGridT10A } \\
0011\end{array}$ & G & SS \\
\hline $\begin{array}{l}\text { PNN } \\
L\end{array}$ & $\begin{array}{l}\text { Site } \\
3 a\end{array}$ & $\begin{array}{c}\text { Site } \\
\text { 3aTransect } \\
\text { 10A-012 }\end{array}$ & $\begin{array}{l}56751 \\
6.6\end{array}$ & $\begin{array}{c}391186 \\
4.3\end{array}$ & Yes & 11.84 & $\begin{array}{c}7 / 10 / 2 \\
013\end{array}$ & 20 & 0 & OD & 1 & 10 & Scrap & 17 & $\begin{array}{c}\text { Site } \\
\text { 3aTransec } \\
\text { t10A }\end{array}$ & $\begin{array}{l}\text { Site3AGridT10A_ } \\
0012\end{array}$ & G & SS \\
\hline $\begin{array}{l}\text { PNN } \\
\text { L }\end{array}$ & $\begin{array}{l}\text { Site } \\
3 a\end{array}$ & $\begin{array}{c}\text { Site } \\
\text { 3aTransect } \\
\text { 10A-013 }\end{array}$ & $\begin{array}{l}56756 \\
4.0\end{array}$ & $\begin{array}{c}391190 \\
0.6\end{array}$ & Yes & 6.32 & $\begin{array}{l}7 / 10 / 2 \\
013\end{array}$ & 8 & 0 & OD & 1 & 2 & Scrap & 11 & $\begin{array}{c}\text { Site } \\
\text { 3aTransec } \\
\text { t10A }\end{array}$ & $\begin{array}{l}\text { Site3AGridT10A } \\
0013\end{array}$ & G & SS \\
\hline $\begin{array}{l}\text { PNN } \\
\text { L }\end{array}$ & $\begin{array}{l}\text { Site } \\
3 a\end{array}$ & $\begin{array}{c}\text { Site } \\
\text { 3aTransect } \\
\text { 10A-014 }\end{array}$ & $\begin{array}{c}56756 \\
6.6\end{array}$ & $\begin{array}{c}391191 \\
1.3\end{array}$ & Yes & 41.06 & $\begin{array}{l}7 / 10 / 2 \\
013\end{array}$ & 44 & 0 & OD & 1 & 15 & Scrap & 10 & $\begin{array}{c}\text { Site } \\
\text { 3aTransec } \\
\text { t10A }\end{array}$ & $\begin{array}{c}\text { Site3AGridT10A } \\
0014\end{array}$ & G & SS \\
\hline $\begin{array}{l}\text { PNN } \\
\text { L }\end{array}$ & $\begin{array}{l}\text { Site } \\
3 a\end{array}$ & $\begin{array}{c}\text { Site } \\
\text { 3aTransect } \\
\text { 10A-015 }\end{array}$ & $\begin{array}{c}56756 \\
6.6\end{array}$ & $\begin{array}{c}391192 \\
9.1\end{array}$ & Yes & 22.73 & $\begin{array}{l}7 / 10 / 2 \\
013\end{array}$ & 17 & 0 & OD & 1 & 4 & $\begin{array}{l}\text { Horse } \\
\text { shoe }\end{array}$ & 15 & $\begin{array}{c}\text { Site } \\
\text { 3aTransec } \\
\text { t10A }\end{array}$ & $\begin{array}{l}\text { Site3AGridT10A } \\
0015\end{array}$ & G & SS \\
\hline $\begin{array}{l}\text { PNN } \\
\text { L }\end{array}$ & $\begin{array}{l}\text { Site } \\
3 a\end{array}$ & $\begin{array}{c}\text { Site } \\
\text { 3aTransect } \\
\text { 10A-016 }\end{array}$ & $\begin{array}{c}56759 \\
2.1\end{array}$ & $\begin{array}{c}391196 \\
7.9\end{array}$ & Yes & 7.68 & $\begin{array}{c}7 / 10 / 2 \\
013\end{array}$ & 14 & 0 & OD & 1 & 5 & $\begin{array}{l}\text { Horse } \\
\text { shoe }\end{array}$ & 12 & $\begin{array}{c}\text { Site } \\
\text { 3aTransec } \\
\text { t10A }\end{array}$ & $\begin{array}{l}\text { Site3AGridT10A } \\
0016\end{array}$ & G & SS \\
\hline $\begin{array}{l}\text { PNN } \\
\mathrm{L}\end{array}$ & $\begin{array}{l}\text { Site } \\
3 a\end{array}$ & $\begin{array}{c}\text { Site } \\
\text { 3aTransect } \\
\text { 10A-017 }\end{array}$ & $\begin{array}{c}56759 \\
2.1\end{array}$ & $\begin{array}{c}391197 \\
3.4\end{array}$ & Yes & 8.34 & $\begin{array}{c}7 / 10 / 2 \\
013\end{array}$ & 6 & 0 & OD & 1 & 5 & Scrap & 10 & $\begin{array}{c}\text { Site } \\
\text { 3aTransec } \\
\text { t10A }\end{array}$ & $\begin{array}{c}\text { Site3AGridT10A_ } \\
0017\end{array}$ & G & SS \\
\hline $\begin{array}{l}\text { PNN } \\
\text { L }\end{array}$ & $\begin{array}{l}\text { Site } \\
3 a\end{array}$ & $\begin{array}{c}\text { Site } \\
\text { 3aTransect } \\
\text { 10A-018 }\end{array}$ & $\begin{array}{c}56759 \\
2.1\end{array}$ & $\begin{array}{c}391197 \\
7.2\end{array}$ & Yes & 14.52 & $\begin{array}{l}7 / 10 / 2 \\
013\end{array}$ & 20 & 0 & OD & 1 & 7 & $\begin{array}{l}\text { Horse } \\
\text { shoe }\end{array}$ & 12 & $\begin{array}{c}\text { Site } \\
\text { 3aTransec } \\
\text { t10A }\end{array}$ & $\begin{array}{l}\text { Site3AGridT10A } \\
0018\end{array}$ & G & SS \\
\hline $\begin{array}{l}\text { PNN } \\
\text { L }\end{array}$ & $\begin{array}{l}\text { Site } \\
3 a\end{array}$ & $\begin{array}{c}\text { Site } \\
\text { 3aTransect } \\
\text { 10A-019 }\end{array}$ & $\begin{array}{c}56758 \\
1.4\end{array}$ & $\begin{array}{c}391199 \\
0.4\end{array}$ & Yes & 6.12 & $\begin{array}{c}7 / 10 / 2 \\
013\end{array}$ & 12 & 0 & OD & 1 & 4 & Scrap & 2 & $\begin{array}{c}\text { Site } \\
\text { 3aTransec } \\
\text { t10A }\end{array}$ & $\begin{array}{l}\text { Site3AGridT10A_ } \\
0019\end{array}$ & G & SS \\
\hline $\begin{array}{l}\text { PNN } \\
L\end{array}$ & $\begin{array}{l}\text { Site } \\
3 a\end{array}$ & $\begin{array}{c}\text { Site } \\
\text { 3aTransect } \\
\text { 10A-020 }\end{array}$ & $\begin{array}{l}56750 \\
5.8\end{array}$ & $\begin{array}{c}391201 \\
5.7\end{array}$ & Yes & 35.87 & $\begin{array}{l}7 / 10 / 2 \\
013\end{array}$ & 42 & 0 & OD & 1 & 15 & $\begin{array}{l}\text { Horse } \\
\text { shoe }\end{array}$ & 15 & $\begin{array}{c}\text { Site } \\
\text { 3aTransec } \\
\text { t10A }\end{array}$ & $\begin{array}{l}\text { Site3AGridT10A } \\
0020\end{array}$ & G & SS \\
\hline
\end{tabular}

Demonstration Report for VSP-RI Methods on the Motlow TN Site 


\begin{tabular}{|c|c|c|c|c|c|c|c|c|c|c|c|c|c|c|c|c|c|c|}
\hline $\begin{array}{l}\text { PNN } \\
L\end{array}$ & $\begin{array}{l}\text { Site } \\
3 a\end{array}$ & $\begin{array}{c}\text { Site } \\
\text { 3aTransect } \\
\text { 10A-021 }\end{array}$ & $\begin{array}{c}56750 \\
5.8\end{array}$ & $\begin{array}{c}391201 \\
6.3\end{array}$ & Yes & 49.52 & $\begin{array}{c}7 / 10 / 2 \\
013\end{array}$ & 42 & 0 & OD & 1 & 15 & $\begin{array}{l}\text { Horse } \\
\text { shoe }\end{array}$ & 15 & $\begin{array}{c}\text { Site } \\
\text { 3aTransec } \\
\text { t10A }\end{array}$ & $\begin{array}{c}\text { Site3AGridT10A_ } \\
0021\end{array}$ & G & SS \\
\hline $\begin{array}{l}\mathrm{PNN} \\
\mathrm{L}\end{array}$ & $\begin{array}{l}\text { Site } \\
3 a\end{array}$ & $\begin{array}{c}\text { Site } \\
\text { 3aTransect } \\
\text { 10A-022 }\end{array}$ & $\begin{array}{c}56751 \\
1.1\end{array}$ & $\begin{array}{l}391221 \\
8.4\end{array}$ & Yes & 6.35 & $\begin{array}{c}7 / 10 / 2 \\
013\end{array}$ & 8 & 0 & OD & 1 & 5 & Scrap & 35 & $\begin{array}{c}\text { Site } \\
\text { 3aTransec } \\
\text { t10A }\end{array}$ & $\begin{array}{c}\text { Site3AGridT10A } \\
0022\end{array}$ & G & SS \\
\hline $\begin{array}{l}\text { PNN } \\
L\end{array}$ & $\begin{array}{l}\text { Site } \\
3 a\end{array}$ & $\begin{array}{c}\text { Site } \\
\text { 3aTransect } \\
\text { 10A-023 }\end{array}$ & $\begin{array}{c}56752 \\
4.0\end{array}$ & $\begin{array}{c}391223 \\
1.4\end{array}$ & Yes & 64.59 & $\begin{array}{c}7 / 10 / 2 \\
013\end{array}$ & 100 & 0 & OD & 1 & 18 & Scrap & 35 & $\begin{array}{c}\text { Site } \\
\text { 3aTransec } \\
\text { t10A }\end{array}$ & $\begin{array}{c}\text { Site3AGridT10A_ } \\
0023\end{array}$ & G & SS \\
\hline $\begin{array}{l}\text { PNN } \\
\mathrm{L}\end{array}$ & $\begin{array}{l}\text { Site } \\
\text { 3a }\end{array}$ & $\begin{array}{c}\text { Site } \\
\text { 3aTransect } \\
12 \mathrm{~A}-001\end{array}$ & $\begin{array}{l}56835 \\
9.3\end{array}$ & $\begin{array}{l}391172 \\
9.2\end{array}$ & Yes & 91.63 & $\begin{array}{c}7 / 10 / 2 \\
013\end{array}$ & 1300 & 0 & OD & 1 & 1 & $\begin{array}{l}\text { Sheet } \\
\text { Metal }\end{array}$ & 20 & $\begin{array}{c}\text { Site } \\
\text { 3aTransec } \\
\text { t12A }\end{array}$ & $\begin{array}{c}\text { Site3aGridT12A_0 } \\
001\end{array}$ & G & SS \\
\hline $\begin{array}{l}\text { PNN } \\
\text { L }\end{array}$ & $\begin{array}{l}\text { Site } \\
3 a\end{array}$ & $\begin{array}{c}\text { Site } \\
\text { 3aTransect } \\
\text { 12A-003 }\end{array}$ & $\begin{array}{c}56834 \\
6.2\end{array}$ & $\begin{array}{c}391175 \\
5.7\end{array}$ & Yes & 8.29 & $\begin{array}{l}7 / 10 / 2 \\
013\end{array}$ & 8 & 0 & OD & 1 & 5 & Nail & 10 & $\begin{array}{c}\text { Site } \\
\text { 3aTransec } \\
\text { t12A }\end{array}$ & $\begin{array}{c}\text { Site3aGridT12A_0 } \\
003\end{array}$ & G & SS \\
\hline $\begin{array}{l}\text { PNN } \\
\text { L }\end{array}$ & $\begin{array}{l}\text { Site } \\
3 a\end{array}$ & $\begin{array}{c}\text { Site } \\
\text { 3aTransect } \\
\text { 12A-004 }\end{array}$ & $\begin{array}{c}56833 \\
9.5\end{array}$ & $\begin{array}{c}391178 \\
9.0\end{array}$ & Yes & 14.76 & $\begin{array}{c}7 / 10 / 2 \\
013\end{array}$ & 7 & 5 & OD & 1 & 6 & Nail Pit & 5 & $\begin{array}{c}\text { Site } \\
\text { 3aTransec } \\
\text { t12A }\end{array}$ & $\begin{array}{c}\text { Site3aGridT12A_0 } \\
004\end{array}$ & G & SS \\
\hline $\begin{array}{l}\text { PNN } \\
L\end{array}$ & $\begin{array}{l}\text { Site } \\
3 a\end{array}$ & $\begin{array}{c}\text { Site } \\
\text { 3aTransect } \\
\text { 12A-005 }\end{array}$ & $\begin{array}{c}56832 \\
2.4\end{array}$ & $\begin{array}{c}391180 \\
8.3\end{array}$ & Yes & 9.31 & $\begin{array}{l}7 / 10 / 2 \\
013\end{array}$ & 12 & 2 & OD & 1 & 5 & Nail & 10 & $\begin{array}{c}\text { Site } \\
\text { 3aTransec } \\
\text { t12A }\end{array}$ & $\begin{array}{c}\text { Site3aGridT12A_0 } \\
005\end{array}$ & G & SS \\
\hline $\begin{array}{l}\text { PNN } \\
\text { L }\end{array}$ & $\begin{array}{l}\text { Site } \\
3 a\end{array}$ & $\begin{array}{c}\text { Site } \\
\text { 3aTransect } \\
\text { 12A-006 }\end{array}$ & $\begin{array}{c}56832 \\
2.4\end{array}$ & $\begin{array}{c}391181 \\
5.2\end{array}$ & Yes & 23.43 & $\begin{array}{c}7 / 10 / 2 \\
013\end{array}$ & 33 & 9 & OD & 1 & 5 & Nail Pit & 10 & $\begin{array}{c}\text { Site } \\
\text { 3aTransec } \\
\text { t12A }\end{array}$ & $\begin{array}{c}\text { Site3aGridT12A_0 } \\
006\end{array}$ & G & SS \\
\hline $\begin{array}{l}\text { PNN } \\
\mathrm{L}\end{array}$ & $\begin{array}{l}\text { Site } \\
3 a\end{array}$ & $\begin{array}{c}\text { Site } \\
\text { 3aTransect } \\
12 \mathrm{~A}-007\end{array}$ & $\begin{array}{c}56829 \\
4.3\end{array}$ & $\begin{array}{c}391184 \\
1.2\end{array}$ & Yes & 6.54 & $\begin{array}{l}7 / 10 / 2 \\
013\end{array}$ & 12 & 0 & OD & 1 & 3 & Nail & 13 & $\begin{array}{c}\text { Site } \\
\text { 3aTransec } \\
\text { t12A }\end{array}$ & $\begin{array}{c}\text { Site3aGridT12A_0 } \\
007\end{array}$ & G & SS \\
\hline $\begin{array}{l}\mathrm{PNN} \\
\mathrm{L}\end{array}$ & $\begin{array}{l}\text { Site } \\
\text { 3a }\end{array}$ & $\begin{array}{c}\text { Site } \\
\text { 3aTransect } \\
12 \mathrm{~A}-008\end{array}$ & $\begin{array}{c}56829 \\
4.3\end{array}$ & $\begin{array}{l}391184 \\
3.5\end{array}$ & Yes & 13.53 & $\begin{array}{c}7 / 10 / 2 \\
013\end{array}$ & 15 & 0 & OD & 1 & 5 & Nail Pit & 10 & $\begin{array}{c}\text { Site } \\
\text { 3aTransec } \\
\text { t12A }\end{array}$ & $\begin{array}{c}\text { Site3aGridT12A_0 } \\
008\end{array}$ & G & SS \\
\hline $\begin{array}{l}\text { PNN } \\
\text { L }\end{array}$ & $\begin{array}{l}\text { Site } \\
3 a\end{array}$ & $\begin{array}{c}\text { Site } \\
\text { 3aTransect } \\
12 \mathrm{~A}-010\end{array}$ & $\begin{array}{l}56826 \\
4.6\end{array}$ & $\begin{array}{c}391194 \\
4.5\end{array}$ & Yes & 41.55 & $\begin{array}{l}7 / 10 / 2 \\
013\end{array}$ & 40 & 0 & OD & 1 & 5 & $\begin{array}{l}\text { Scrap } \\
\text { Metal }\end{array}$ & 25 & $\begin{array}{c}\text { Site } \\
\text { 3aTransec } \\
\text { t12A }\end{array}$ & $\begin{array}{c}\text { Site3aGridT12A_0 } \\
010\end{array}$ & G & SS \\
\hline
\end{tabular}




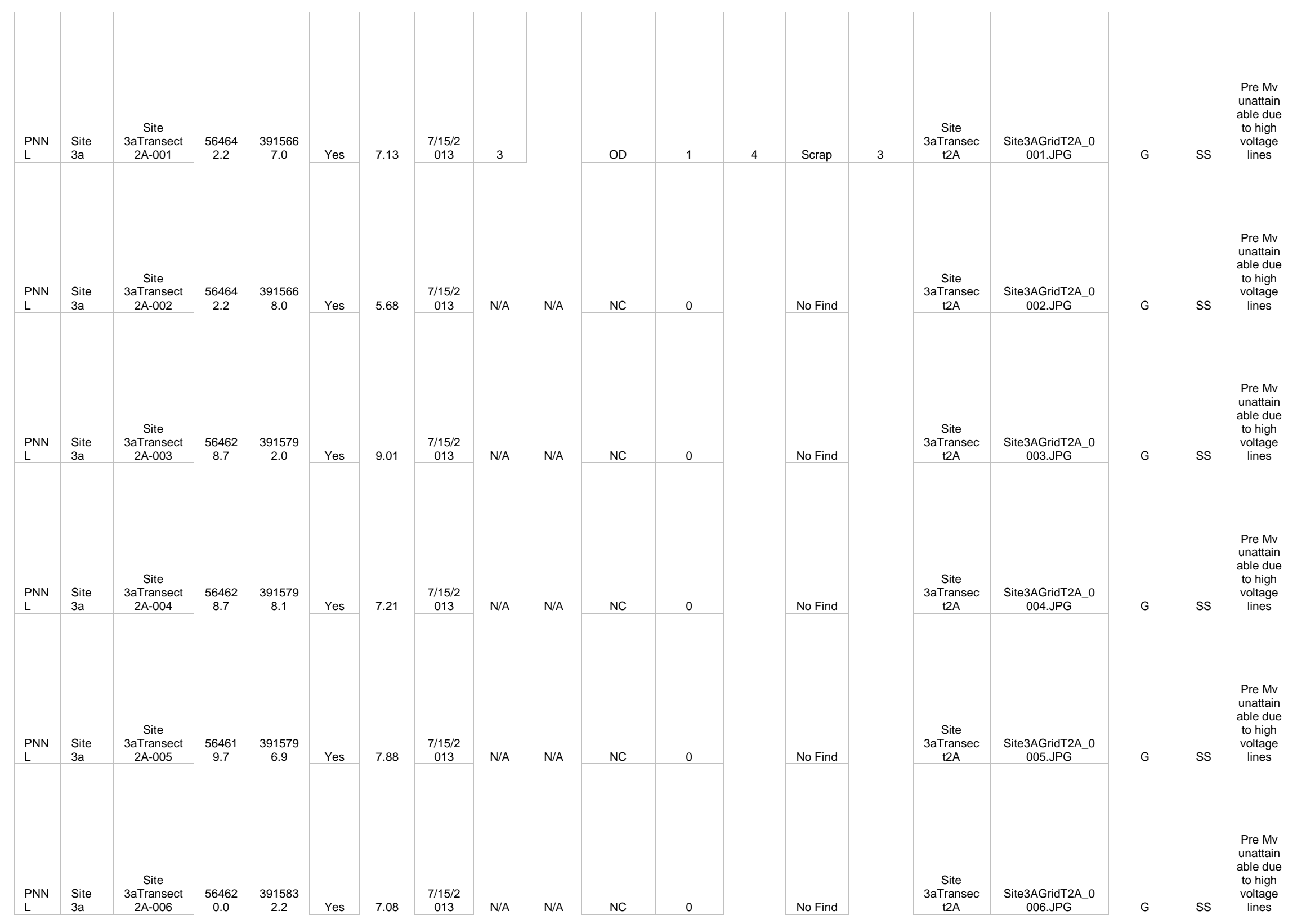

Demonstration Report for VSP-RI Methods on the Motlow TN Site 


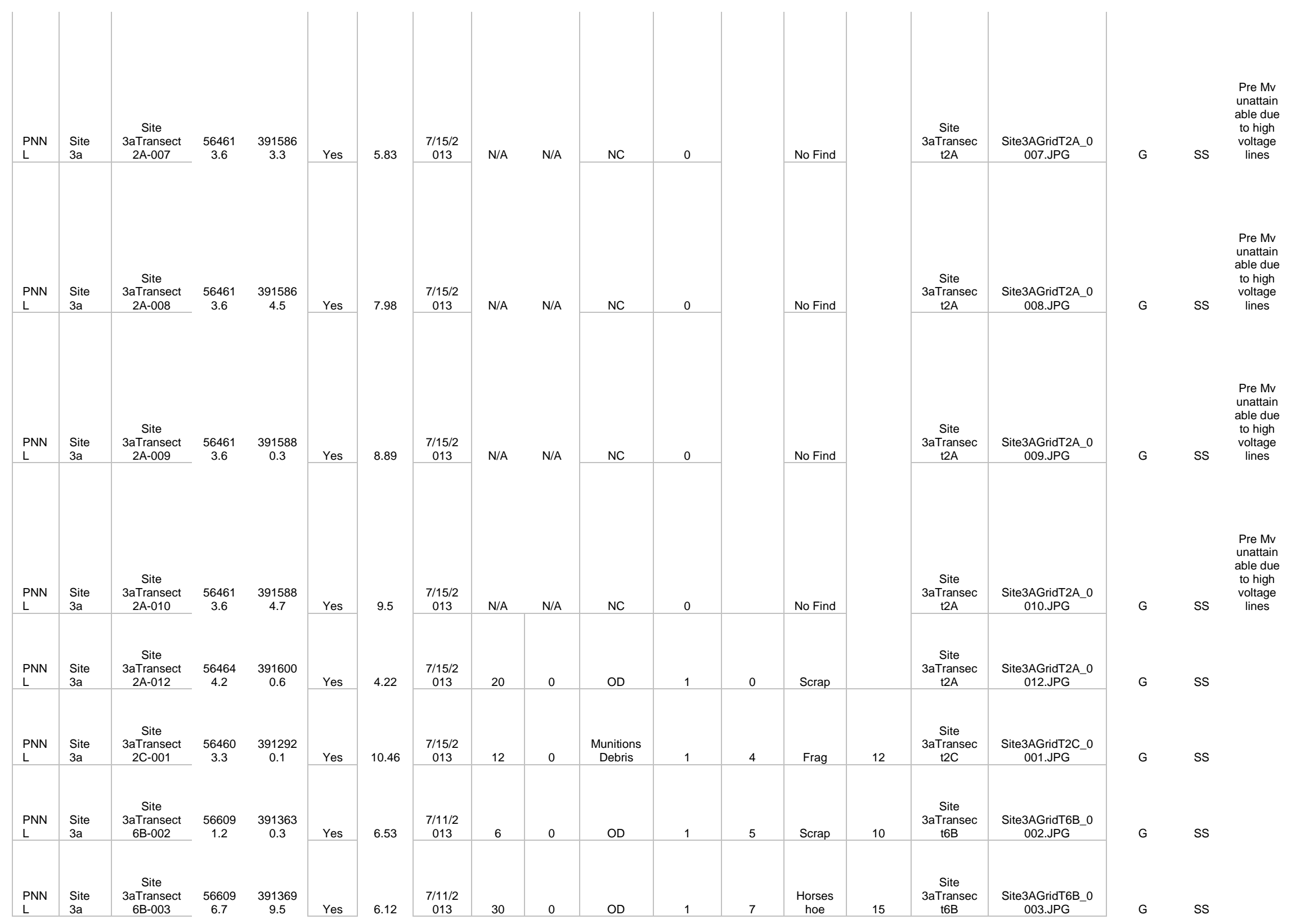

Demonstration Report for VSP-RI Methods on the Motlow TN Site 


\begin{tabular}{|c|c|c|c|c|c|c|c|c|c|c|c|c|c|c|c|c|c|}
\hline $\begin{array}{l}\text { PNN } \\
L\end{array}$ & $\begin{array}{l}\text { Site } \\
3 a\end{array}$ & $\begin{array}{c}\text { Site } \\
\text { 3arransect } \\
\text { 6B-004 }\end{array}$ & $\begin{array}{l}56608 \\
8.4\end{array}$ & $\begin{array}{c}391385 \\
1.2\end{array}$ & Yes & 15.81 & $\begin{array}{c}7 / 11 / 2 \\
013\end{array}$ & 20 & 0 & OD & 1 & 2 & $\begin{array}{l}\text { Barbwir } \\
\text { e }\end{array}$ & 40 & $\begin{array}{c}\text { Site } \\
\text { 3aTransec } \\
\text { t6B }\end{array}$ & $\begin{array}{c}\text { Site3AGridT6B_0 } \\
\text { 004.JPG }\end{array}$ & G \\
\hline $\begin{array}{l}\text { PNN } \\
L\end{array}$ & $\begin{array}{l}\text { Site } \\
3 a\end{array}$ & $\begin{array}{c}\text { Site } \\
\text { 3aTransect } \\
\text { 6C-001 }\end{array}$ & $\begin{array}{l}56613 \\
9.1\end{array}$ & $\begin{array}{c}391116 \\
6.1\end{array}$ & Yes & 8.64 & $\begin{array}{c}7 / 11 / 2 \\
013\end{array}$ & 10 & 5 & OD & 1 & 5 & Nail Pit & 12 & $\begin{array}{c}\text { Site } \\
\text { 3aTransec } \\
\text { t6C }\end{array}$ & $\begin{array}{l}\text { Site3AGridT6C_0 } \\
\text { 001.JPG }\end{array}$ & G \\
\hline $\begin{array}{l}\text { PNN } \\
L\end{array}$ & $\begin{array}{l}\text { Site } \\
3 a\end{array}$ & $\begin{array}{c}\text { Site } \\
\text { 3aTransect } \\
\text { 6C-003 }\end{array}$ & $\begin{array}{l}56614 \\
4.4\end{array}$ & $\begin{array}{c}391127 \\
0.4\end{array}$ & Yes & 35.66 & $\begin{array}{c}7 / 11 / 2 \\
013\end{array}$ & 30 & 0 & OD & 1 & 6 & Wire & 40 & $\begin{array}{c}\text { Site } \\
\text { 3aTransec } \\
\text { t6C }\end{array}$ & $\begin{array}{c}\text { Site3AGridT6C_0 } \\
\text { 003.JPG }\end{array}$ & G \\
\hline $\begin{array}{l}\text { PNN } \\
L\end{array}$ & $\begin{array}{l}\text { Site } \\
3 a\end{array}$ & $\begin{array}{c}\text { Site } \\
\text { 3aTransect } \\
\text { 6C-004 }\end{array}$ & $\begin{array}{l}56612 \\
5.6\end{array}$ & $\begin{array}{c}391127 \\
1.0\end{array}$ & Yes & $\begin{array}{c}107.8 \\
3\end{array}$ & $\begin{array}{l}7 / 11 / 2 \\
013\end{array}$ & 100 & 0 & OD & 1 & 10 & $\begin{array}{l}\text { Horses } \\
\text { hoe }\end{array}$ & 15 & $\begin{array}{c}\text { Site } \\
\text { 3aTransec } \\
\text { t6C }\end{array}$ & $\begin{array}{l}\text { Site3AGridT6C_0 } \\
\text { 004.JPG }\end{array}$ & G \\
\hline $\begin{array}{l}\text { PNN } \\
L\end{array}$ & $\begin{array}{l}\text { Site } \\
3 a\end{array}$ & $\begin{array}{c}\text { Site } \\
\text { 3aTransect } \\
\text { 6C-006 }\end{array}$ & $\begin{array}{l}56613 \\
4.5\end{array}$ & $\begin{array}{c}391159 \\
2.1\end{array}$ & Yes & 6.45 & $\begin{array}{c}7 / 15 / 2 \\
013\end{array}$ & 10 & 0 & OD & 1 & 3 & Nails & 12 & $\begin{array}{c}\text { Site } \\
\text { 3aTransec } \\
\text { t6C }\end{array}$ & $\begin{array}{c}\text { Site3AGridT6C_0 } \\
\text { 006.JPG }\end{array}$ & G \\
\hline $\begin{array}{l}\text { PNN } \\
\text { L }\end{array}$ & $\begin{array}{l}\text { Site } \\
3 a\end{array}$ & $\begin{array}{c}\text { Site } \\
\text { 3aTransect } \\
\text { 6C-007 }\end{array}$ & $\begin{array}{c}56613 \\
1.1\end{array}$ & $\begin{array}{c}391261 \\
0.4\end{array}$ & Yes & 38.36 & $\begin{array}{c}7 / 15 / 2 \\
013\end{array}$ & 40 & 0 & OD & 1 & 7 & $\begin{array}{l}\text { Horses } \\
\text { hoe }\end{array}$ & 21 & $\begin{array}{c}\text { Site } \\
\text { 3aTransec } \\
\text { t6C }\end{array}$ & $\begin{array}{c}\text { Site3AGridT6C_0 } \\
\text { 007.JPG }\end{array}$ & $\mathrm{G}$ \\
\hline $\begin{array}{l}\text { PNN } \\
L\end{array}$ & $\begin{array}{l}\text { Site } \\
3 a\end{array}$ & $\begin{array}{c}\text { Site } \\
\text { 3aTransect } \\
\text { 6C-008 }\end{array}$ & $\begin{array}{c}56610 \\
6.4\end{array}$ & $\begin{array}{c}391274 \\
1.7\end{array}$ & Yes & 6.89 & $\begin{array}{l}7 / 15 / 2 \\
013\end{array}$ & 18 & 0 & OD & 1 & 4 & $\begin{array}{l}\text { Horses } \\
\text { hoe }\end{array}$ & 10 & $\begin{array}{c}\text { Site } \\
\text { 3aTransec } \\
\text { t6C }\end{array}$ & $\begin{array}{l}\text { Site3AGridT6C_0 } \\
\text { 008.JPG }\end{array}$ & G \\
\hline $\begin{array}{l}\text { PNN } \\
\mathrm{L}\end{array}$ & $\begin{array}{l}\text { Site } \\
3 a\end{array}$ & $\begin{array}{c}\text { Site } \\
\text { 3aTransect } \\
\text { 8B-001 }\end{array}$ & $\begin{array}{c}56683 \\
7.8\end{array}$ & $\begin{array}{c}391367 \\
8.9\end{array}$ & Yes & 10.94 & $\begin{array}{c}7 / 15 / 2 \\
013\end{array}$ & 11 & 0 & OD & 1 & 0 & Nails & 8 & $\begin{array}{c}\text { Site } \\
\text { 3aTransec } \\
\text { t8B }\end{array}$ & $\begin{array}{c}\text { Site3AGridT8B_0 } \\
\text { 001.JPG }\end{array}$ & G \\
\hline $\begin{array}{l}\text { PNN } \\
L\end{array}$ & $\begin{array}{l}\text { Site } \\
3 a\end{array}$ & $\begin{array}{c}\text { Site } \\
\text { 3aTransect } \\
\text { 8C-001 }\end{array}$ & $\begin{array}{l}56684 \\
1.5\end{array}$ & $\begin{array}{c}391225 \\
1.0\end{array}$ & Yes & 35.35 & $\begin{array}{l}7 / 15 / 2 \\
013\end{array}$ & 40 & 0 & OD & 1 & 0 & $\begin{array}{l}\text { Barbwir } \\
\text { e }\end{array}$ & 5 & $\begin{array}{c}\text { Site } \\
\text { 3aTransec } \\
\text { t8C }\end{array}$ & $\begin{array}{l}\text { Site3AGridT8C_0 } \\
\text { 001.JPG }\end{array}$ & G \\
\hline
\end{tabular}


Appendix C: Additional Cluster Pattern Plots and Achieved Confidence for Many of the Simulation Variations

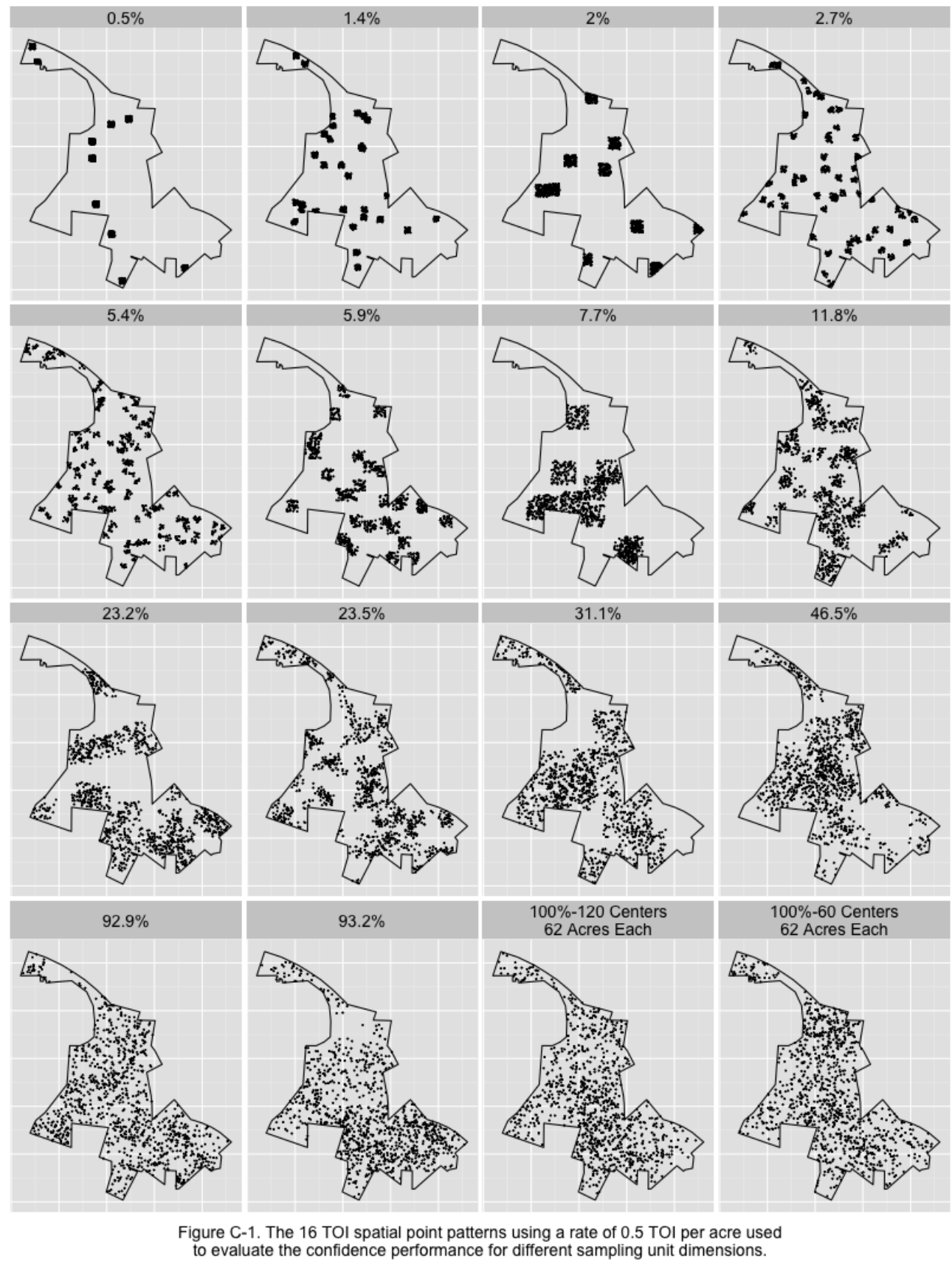

Demonstration Report for VSP-RI Methods on the Motlow TN Site 


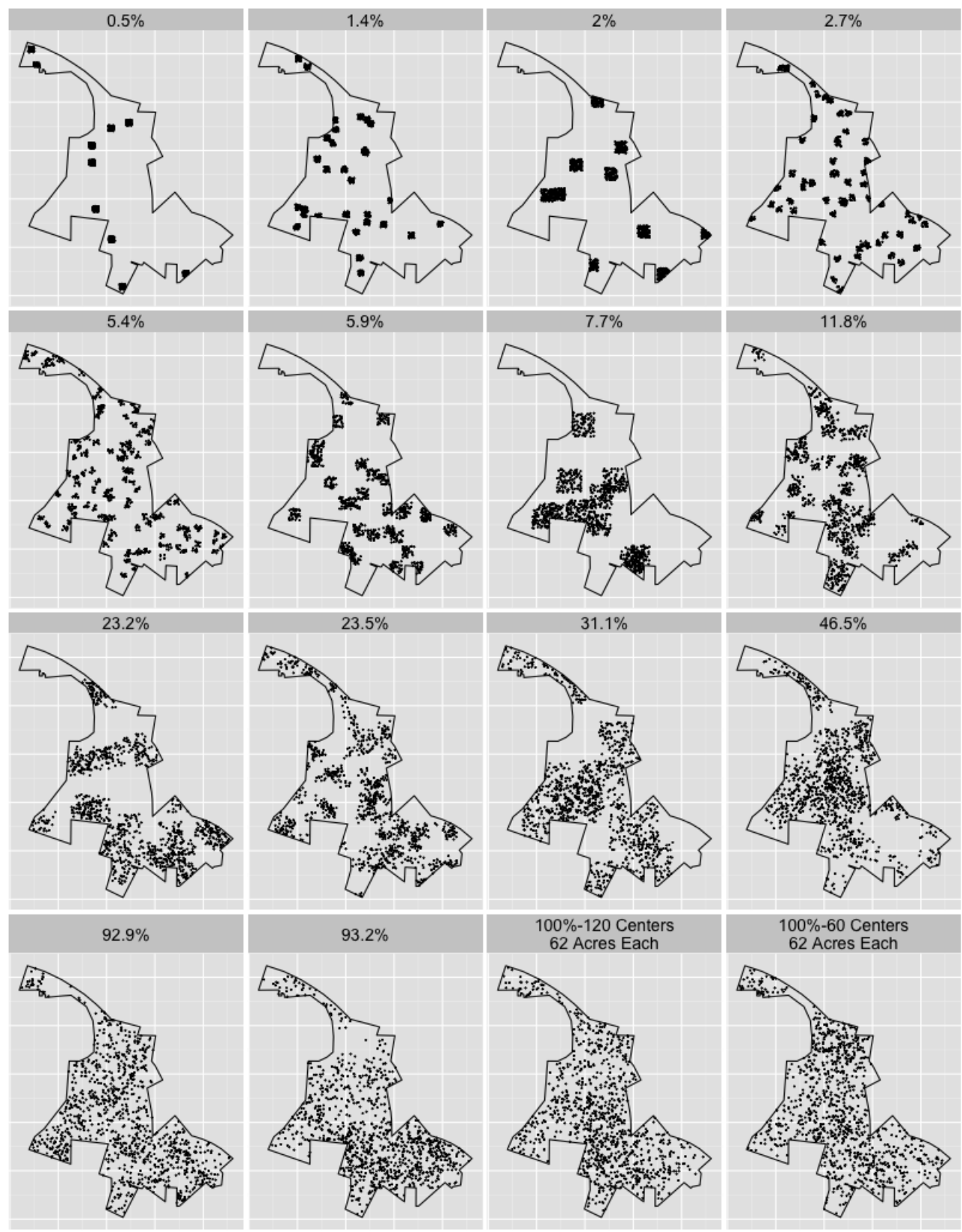

Figure $\mathrm{C}-2$. The $16 \mathrm{TOI}$ spatial point patterns using a rate of $1.5 \mathrm{TOI}$ per acre used to evaluate the confidence performance for different sampling unit dimensions. 


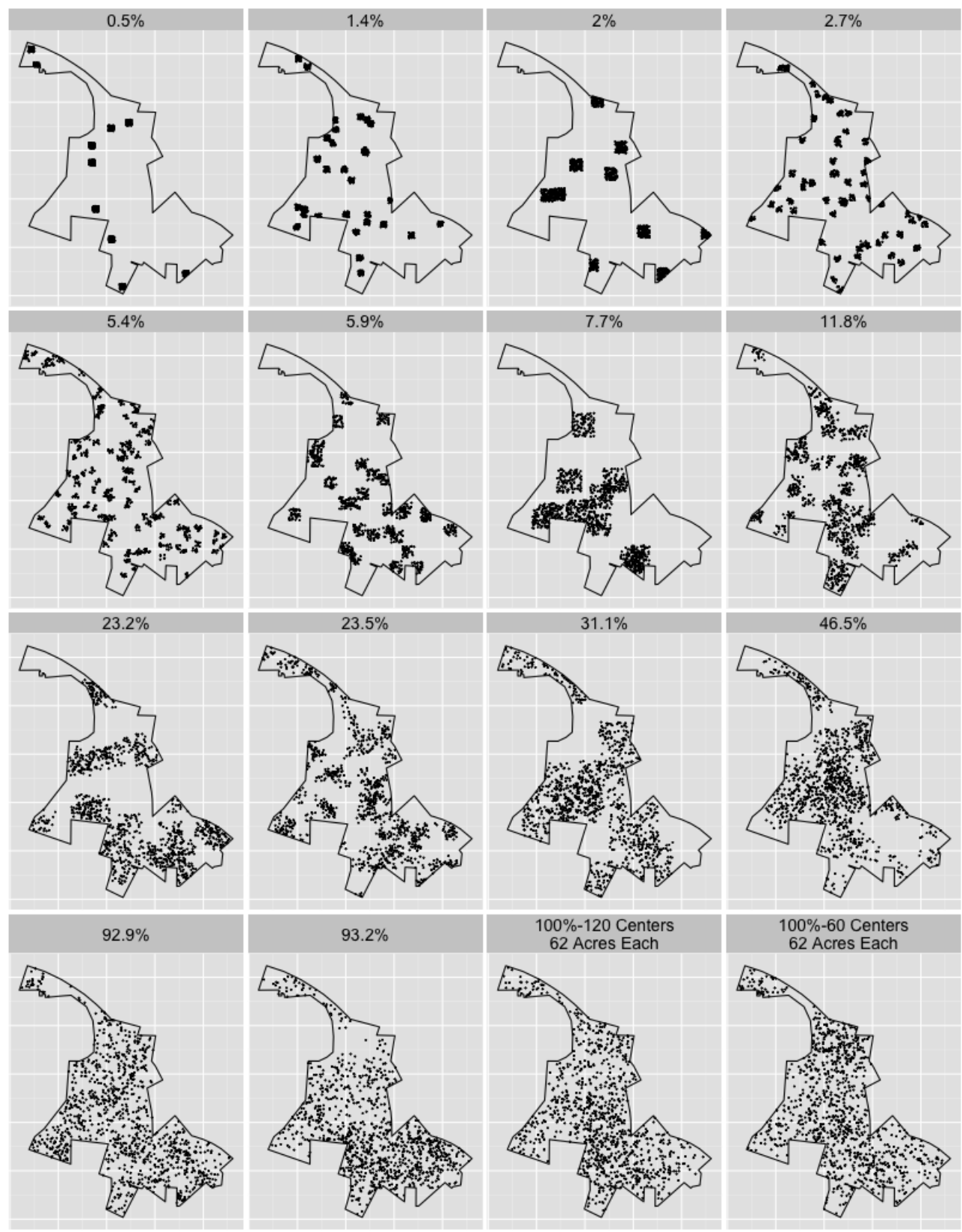

Figure C-3. The 16 TOI spatial point patterns using a rate of 2 TOI per acre used to evaluate the confidence performance for different sampling unit dimensions. 
10 random cluster centers with a maximum of $1.9 \%$ of the area available for TOI placement

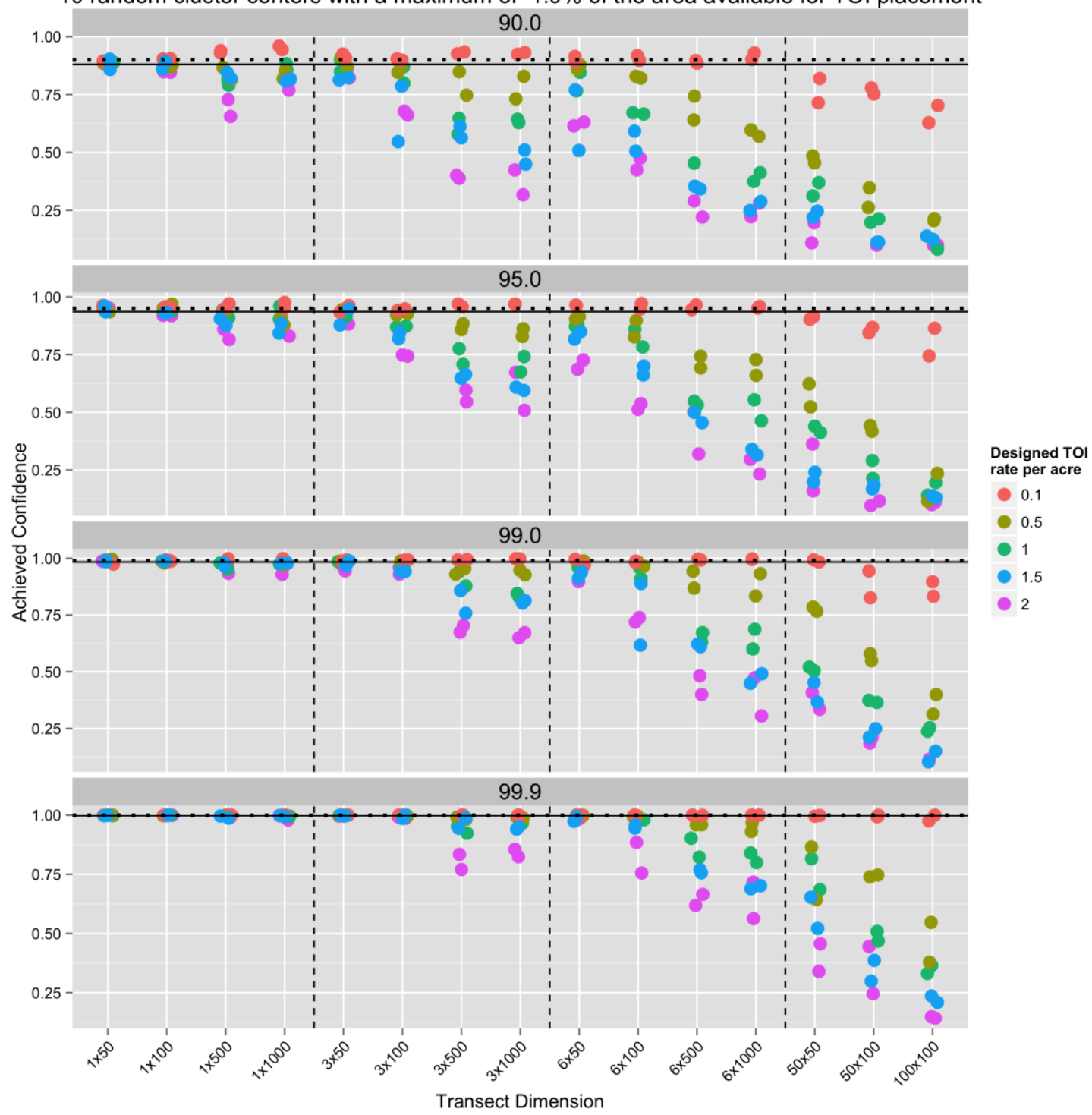

Figure C-4. Achieved confidence performance (y-axis) plots for 10 random cluster centers with all points within a square area of 3.9 acres around each grid center, which results in a maximum of $1.9 \%$ of the

Motlow boundary area of 1989 acres having potential for TOI placement. The sampling unit dimensions are shown on the x-axis. The horizontal dotted line marks the designed confidenceand the solid horizontal line is the 3 standard deviation lower bound for confidence performance of a simulation study using 2300 simulations to evaluate confidence. The vertical lines separate the three transect widths and the grid based sampling units. 
10 random cluster centers with a maximum of $7.8 \%$ of the area available for TOI placement

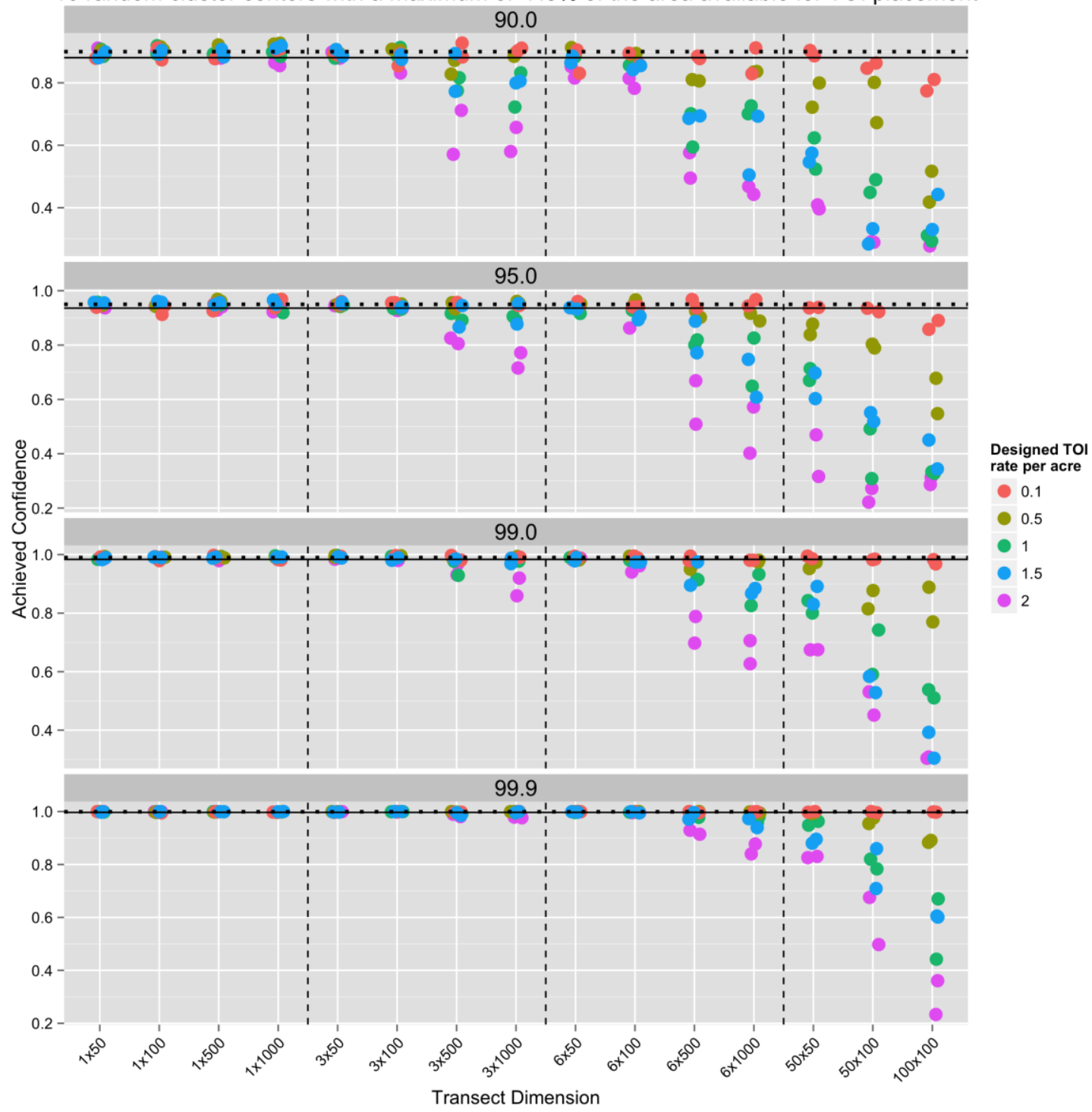

Figure C-5. Achieved confidence performance ( $y$-axis) plots for 10 random cluster centers with all points within a square area of 15.4 acres around each grid center, which results in a maximum of $7.8 \%$ of the Motlow boundary area of 1989 acres having potential for TOI placement. The sampling unit dimensions are shown on the $\mathrm{x}$-axis. The horizontal dotted line marks the designed confidenceand the solid horizontal line is the 3 standard deviation lower bound for confidence performance of a simulation study using 2300 simulations to evaluate confidence. The vertical lines separate the three transect widths and the grid based sampling units. 
10 random cluster centers with a maximum of $31.1 \%$ of the area available for TOI placement

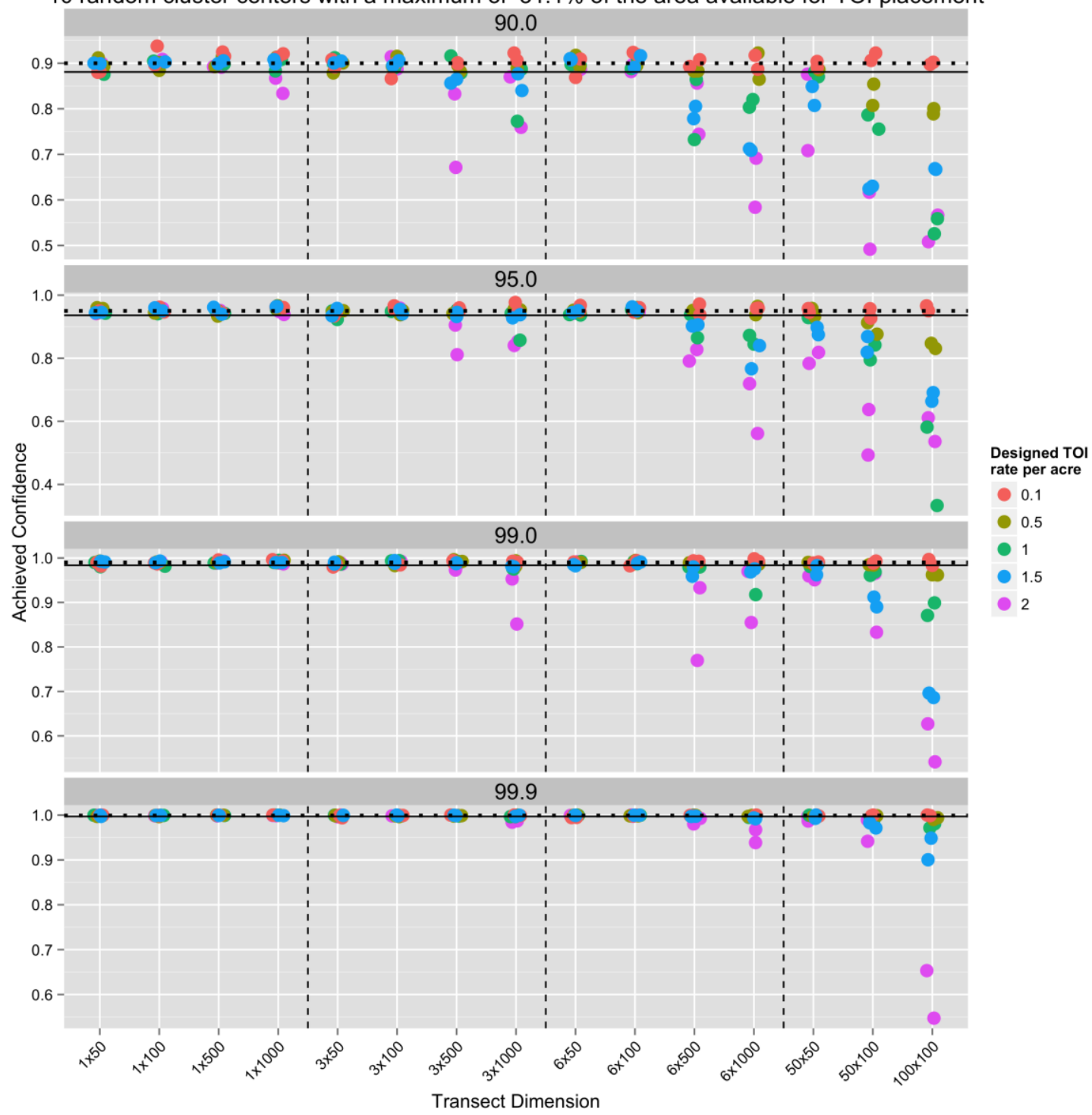

Figure C-6. Achieved confidence performance (y-axis) plots for 10 random cluster centers with all points within a square area of 61.8 acres around each grid center, which results in a maximum of $31.1 \%$ of the Motlow boundary area of 1989 acres having potential for TOI placement. The sampling unit dimensions are shown on the $\mathrm{x}$-axis. The horizontal dotted line marks the designed confidenceand the solid horizontal line is the 3 standard deviation lower bound for confidence performance of a simulation study using 2300 simulations to evaluate confidence. The vertical lines separate the three transect widths and the grid based sampling units. 
10 random cluster centers with a maximum of $0.4 \%$ of the area available for TOI placement

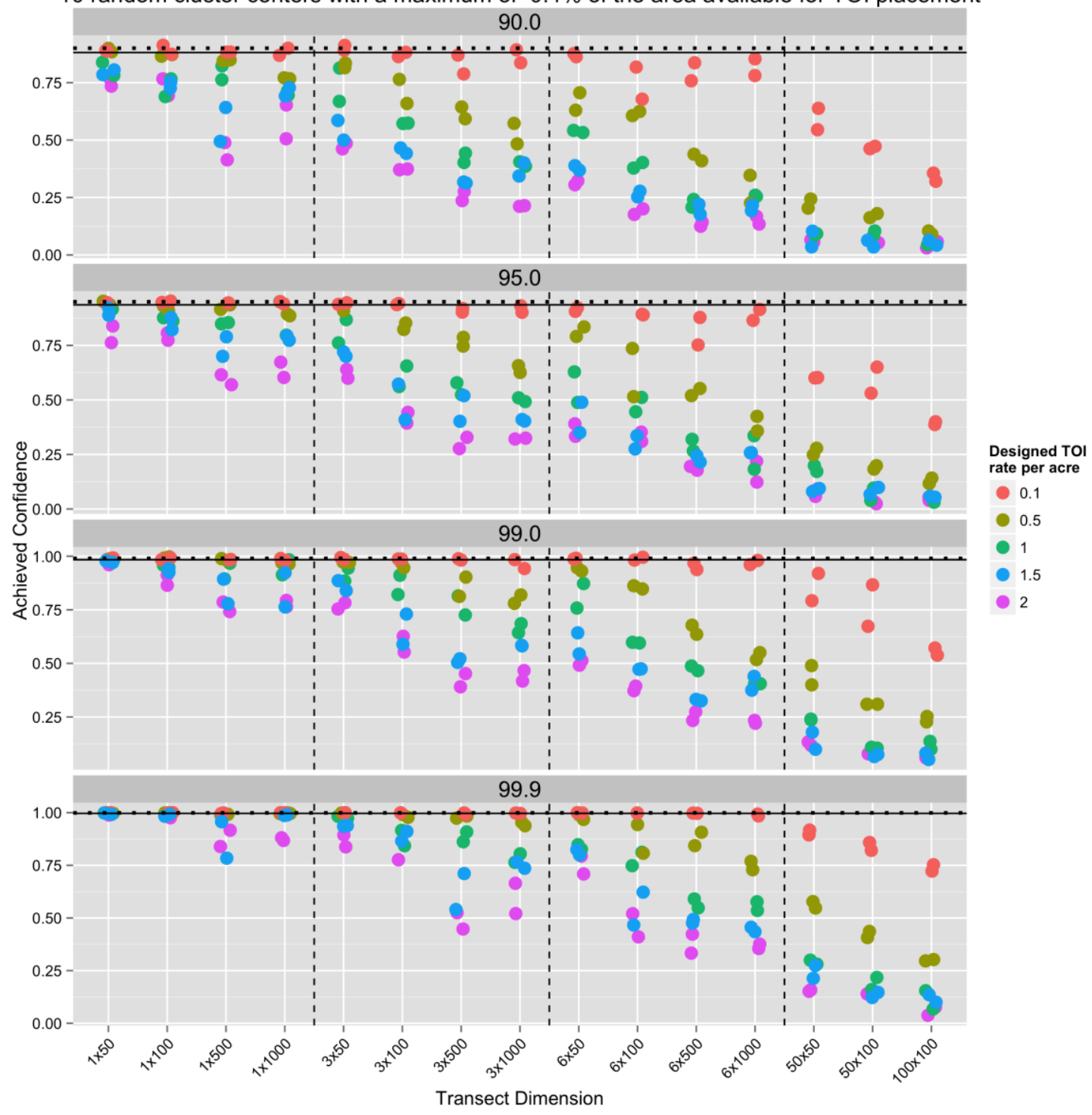

Figure C-7. Achieved confidence performance (y-axis) plots for 10 random cluster centers with all points within a square area of 0.9 acres around each grid center, which results in a maximum of $0.4 \%$ of the

Motlow boundary area of 1989 acres having potential for TOI placement. The sampling unit dimensions are shown on the $\mathrm{x}$-axis. The horizontal dotted line marks the designed confidenceand the solid horizontal line is the 3 standard deviation lower bound for confidence performance of a simulation study using 2300 simulations to evaluate confidence. The vertical lines separate the three transect widths and the grid based sampling units. 
120 random cluster centers with a maximum of $23.3 \%$ of the area available for TOI placement

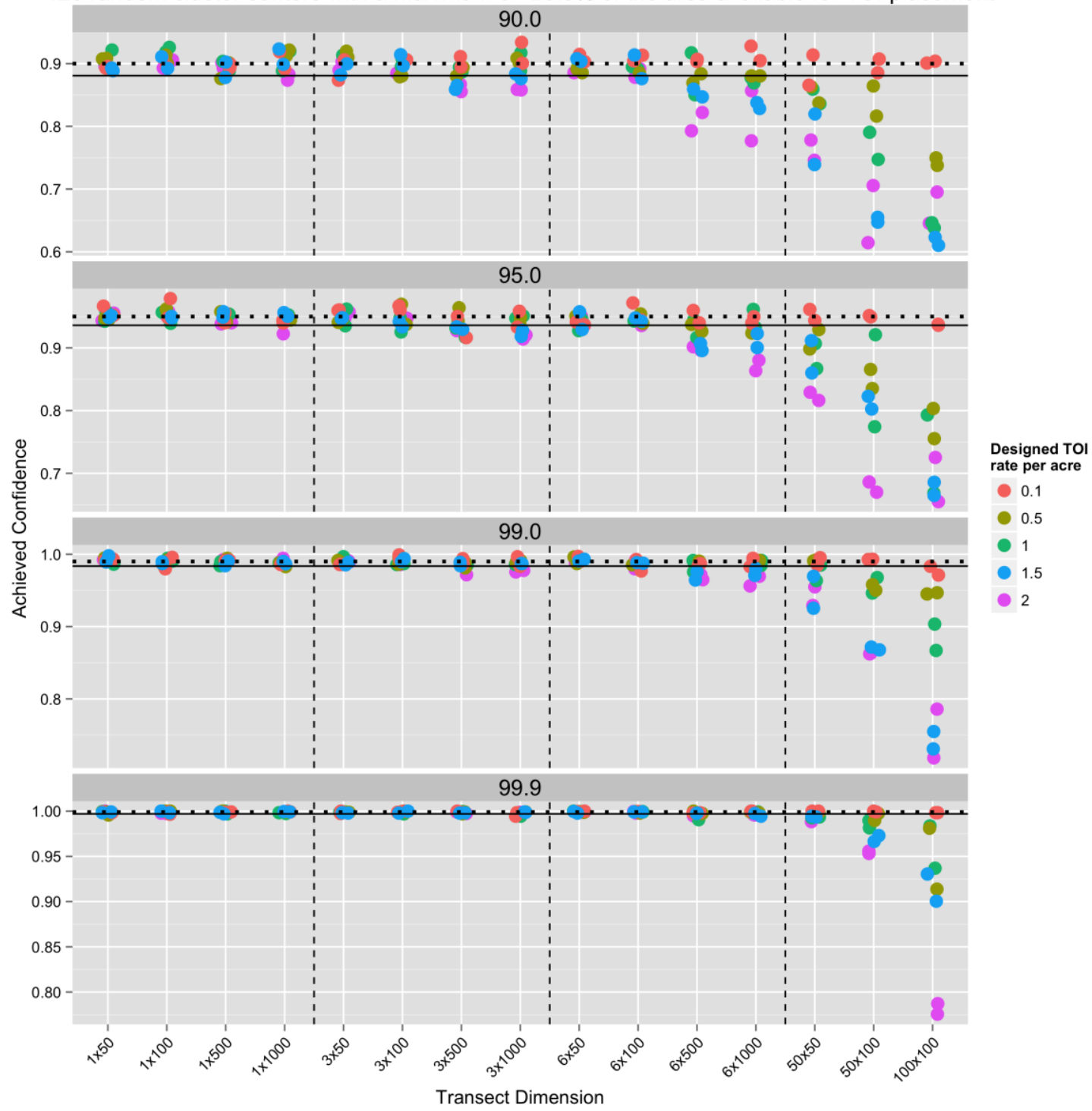

Figure C-8. Achieved confidence performance (y-axis) plots for 120 random cluster centers with all points within a square area of 3.9 acres around each grid center, which results in a maximum of $23.3 \%$ of the

Motlow boundary area of 1989 acres having potential for TOI placement. The sampling unit dimensions are shown on the x-axis. The horizontal dotted line marks the designed confidenceand the solid horizontal line is the 3 standard deviation lower bound for confidence performance of a simulation study using 2300 simulations to evaluate confidence. The vertical lines separate the three transect widths and the grid based sampling units. 
120 random cluster centers with a maximum of $93.2 \%$ of the area available for TOI placement

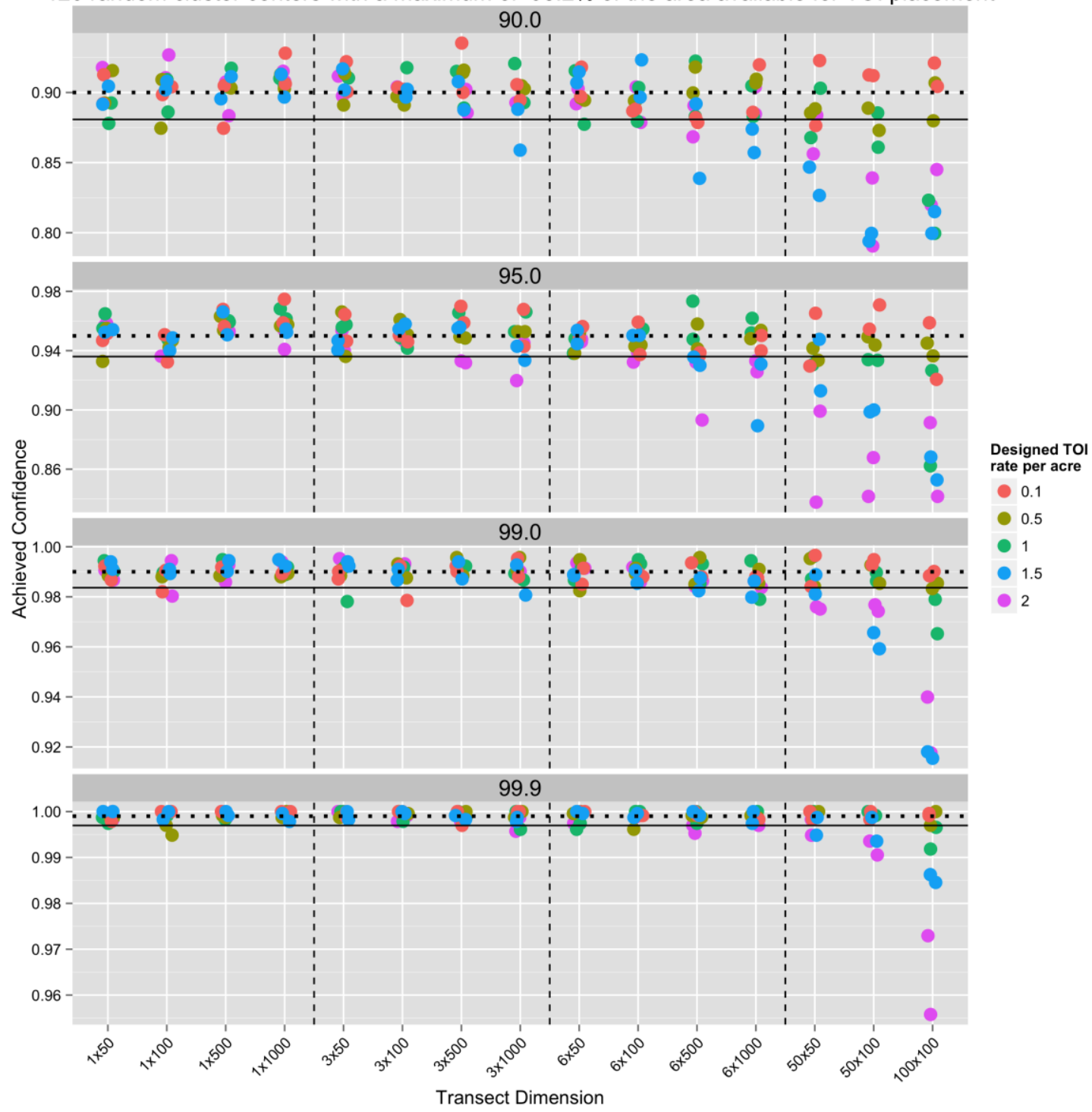

Figure C-9. Achieved confidence performance ( $y$-axis) plots for 120 random cluster centers with all points within a square area of 15.4 acres around each grid center, which results in a maximum of $93.2 \%$ of the Motlow boundary area of 1989 acres having potential for TOI placement. The sampling unit dimensions are shown on the x-axis. The horizontal dotted line marks the designed confidenceand the solid horizontal line is the 3 standard deviation lower bound for confidence performance of a simulation study using 2300 simulations to evaluate confidence. The vertical lines separate the three transect widths and the grid based sampling units. 
120 random cluster centers with a maximum of $100 \%$ of the area available for TOI placement

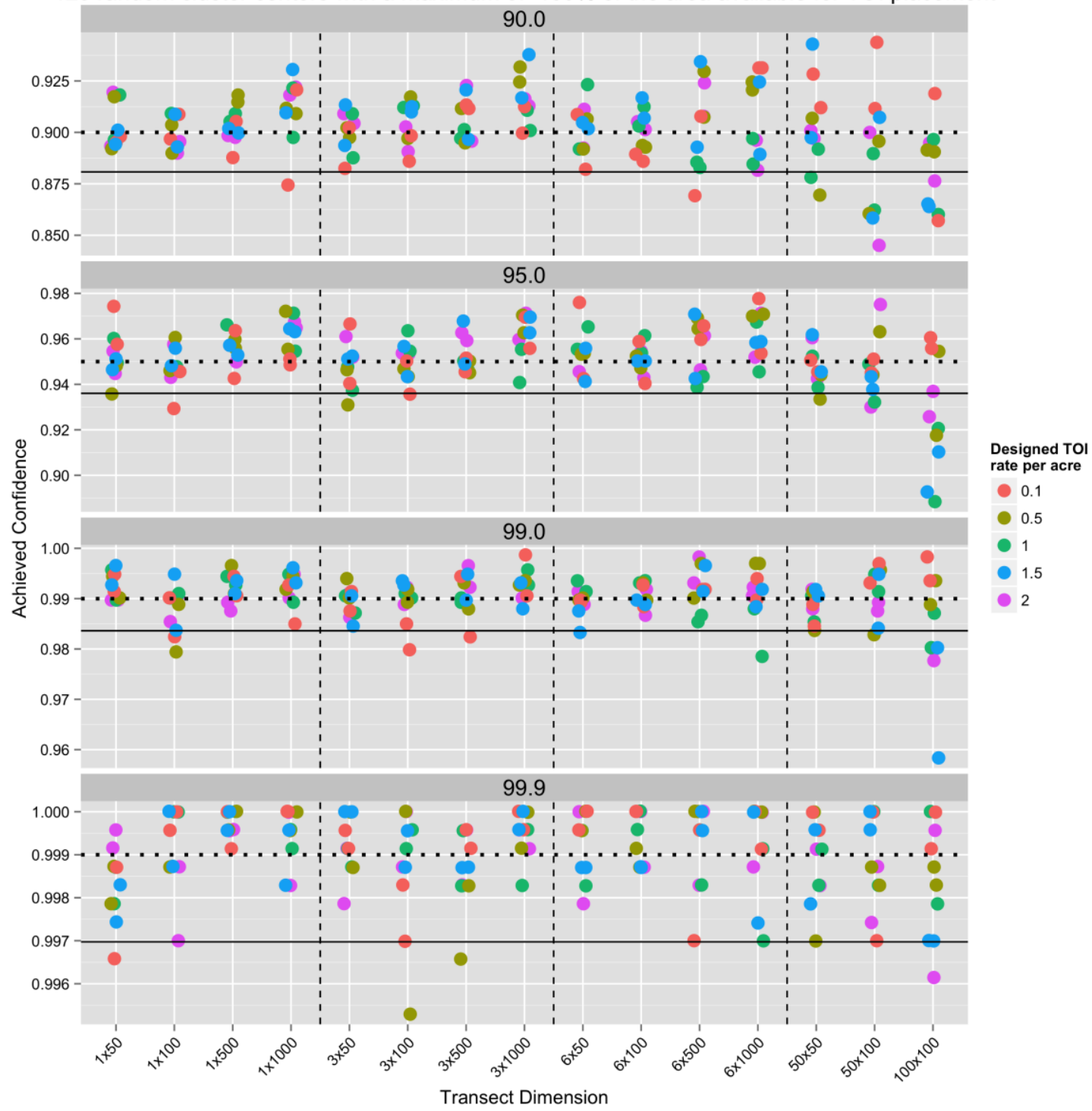

Figure $\mathrm{C}-10$. Achieved confidence performance (y-axis) plots for 120 random cluster centers with all points within a square area of 61.8 acres around each grid center, which results in a maximum of $100 \%$ of the

Motlow boundary area of 1989 acres having potential for TOI placement. The sampling unit dimensions are shown on the x-axis. The horizontal dotted line marks the designed confidenceand the solid horizontal line is the 3 standard deviation lower bound for confidence performance of a simulation study using 2300 simulations to evaluate confidence. The vertical lines separate the three transect widths and the grid based sampling units. 
120 random cluster centers with a maximum of $5.4 \%$ of the area available for TOI placement

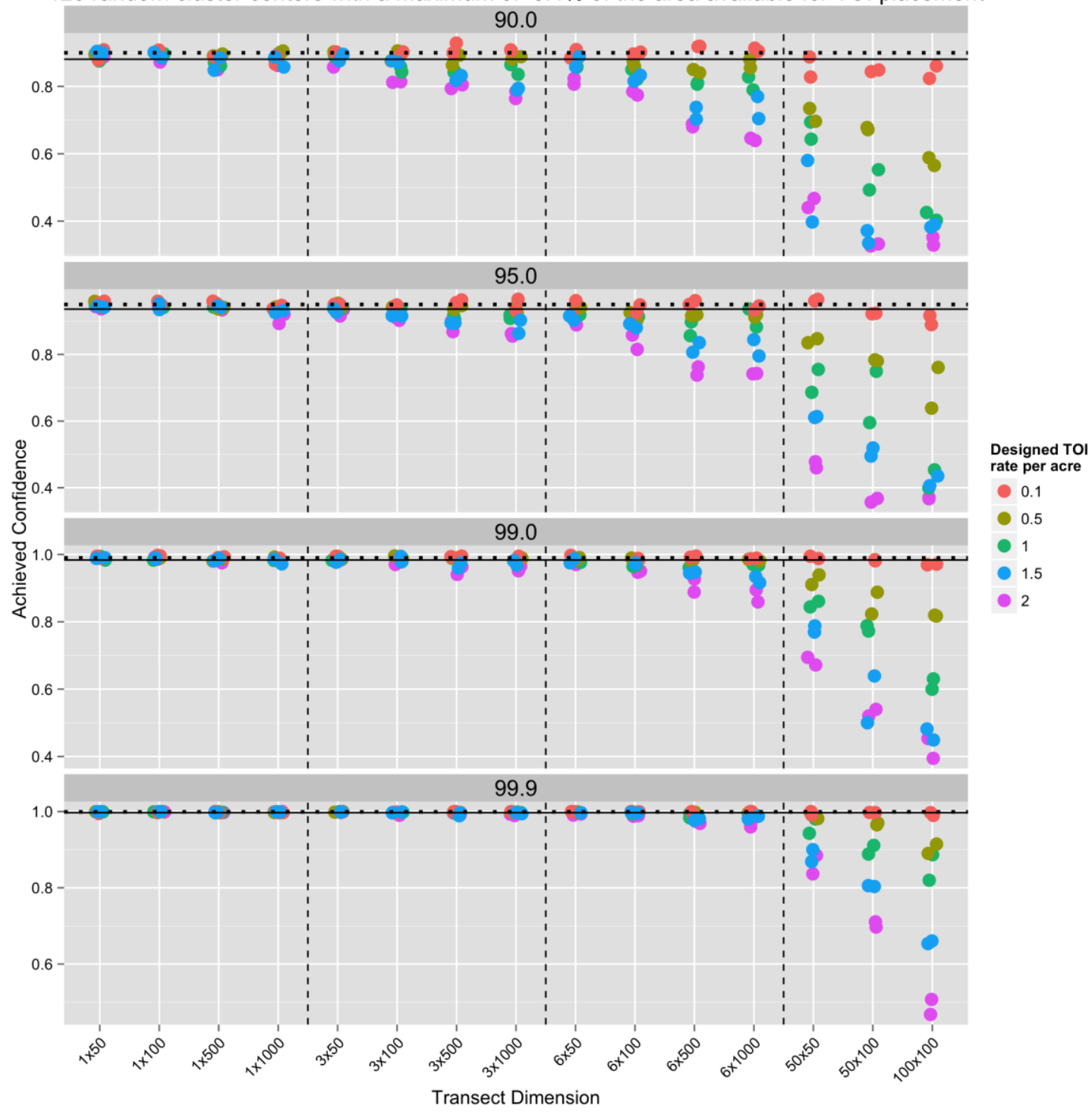

Figure C-11. Achieved confidence performance (y-axis) plots for 120 random cluster centers with all points within a square area of 0.9 acres around each grid center, which results in a maximum of $5.4 \%$ of the

Motlow boundary area of 1989 acres having potential for TOI placement. The sampling unit dimensions are shown on the $x$-axis. The horizontal dotted line marks the designed confidenceand the solid horizontal line is the 3 standard deviation lower bound for confidence performance of a simulation study using 2300 simulations to evaluate confidence. The vertical lines separate the three transect widths and the grid based sampling units. 
30 random cluster centers with a maximum of $5.8 \%$ of the area available for TOI placement

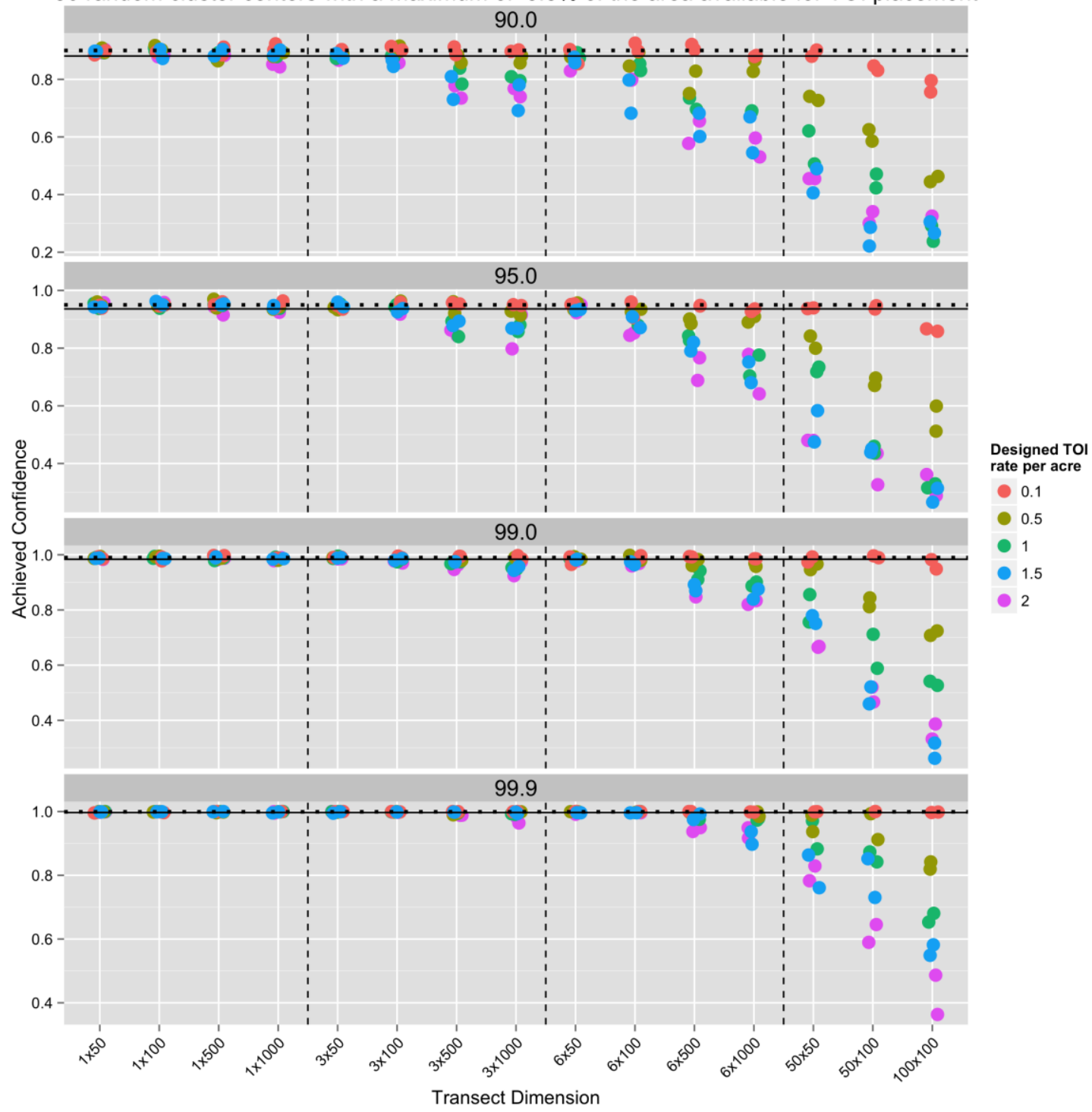

Figure C-12. Achieved confidence performance (y-axis) plots for 30 random cluster centers with all points within a square area of 3.9 acres around each grid center, which results in a maximum of $5.8 \%$ of the

Motlow boundary area of 1989 acres having potential for TOI placement. The sampling unit dimensions are shown on the $x$-axis. The horizontal dotted line marks the designed confidenceand the solid horizontal line is the 3 standard deviation lower bound for confidence performance of a simulation study using 2300 simulations to evaluate confidence. The vertical lines separate the three transect widths and the grid based sampling units. 
30 random cluster centers with a maximum of $23.3 \%$ of the area available for TOI placement

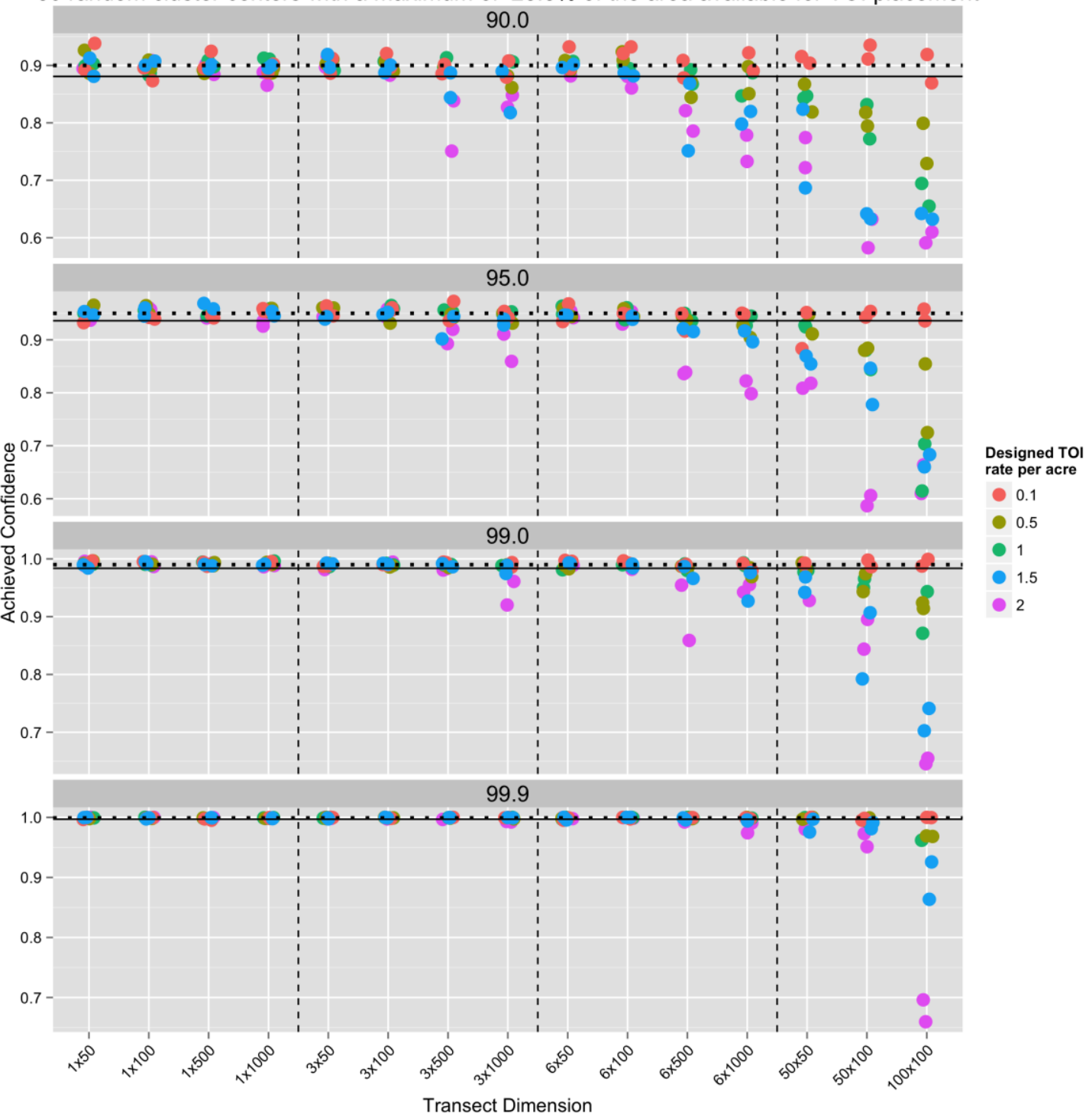

Figure C-13. Achieved confidence performance (y-axis) plots for 30 random cluster centers with all points within a square area of 15.4 acres around each grid center, which results in a maximum of $23.3 \%$ of the Motlow boundary area of 1989 acres having potential for TOI placement. The sampling unit dimensions are shown on the $\mathrm{x}$-axis. The horizontal dotted line marks the designed confidenceand the solid horizontal line is the 3 standard deviation lower bound for confidence performance of a simulation study using 2300 simulations to evaluate confidence. The vertical lines separate the three transect widths and the grid based sampling units. 
30 random cluster centers with a maximum of $93.2 \%$ of the area available for TOI placement

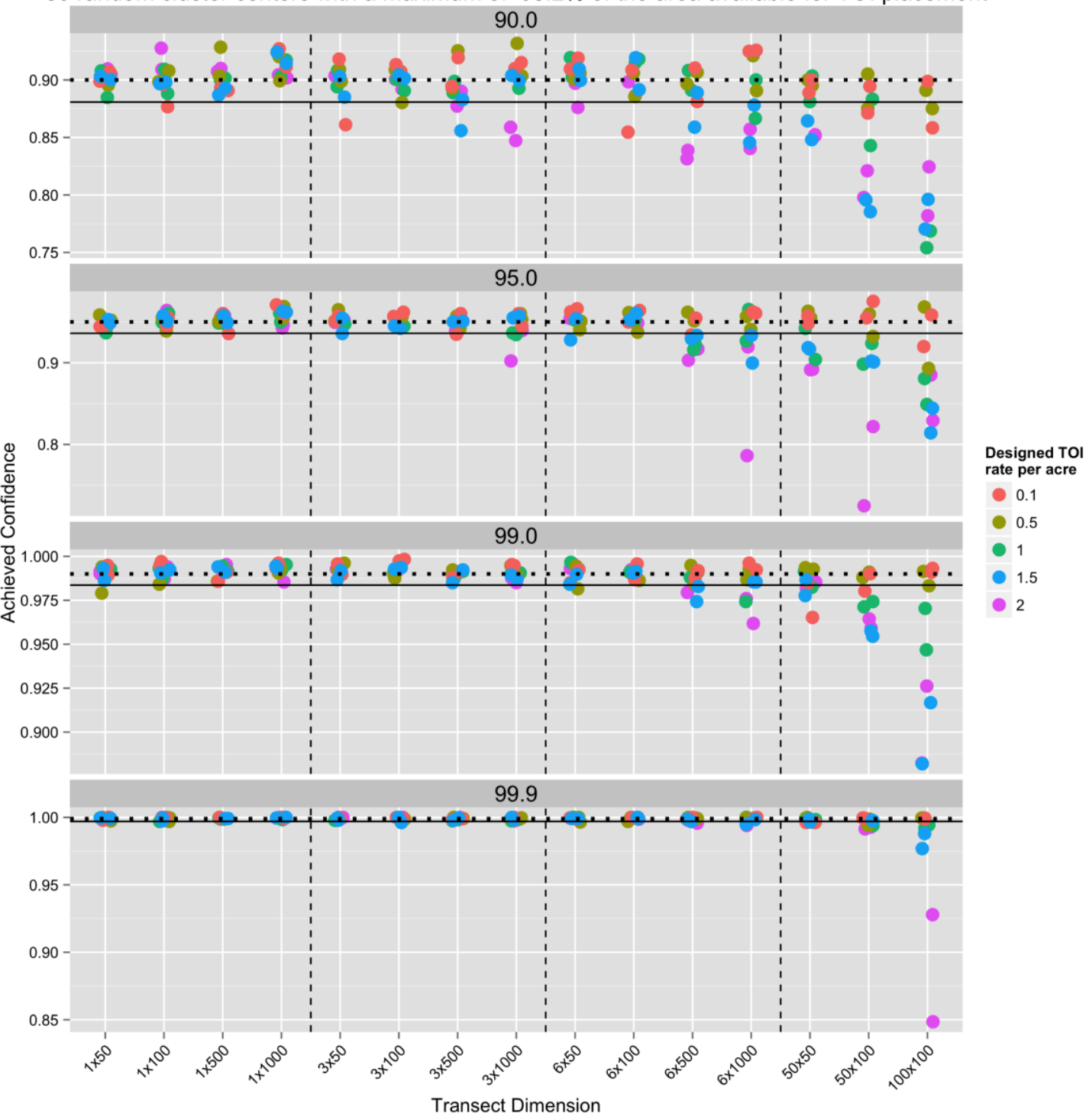

Figure $\mathrm{C}-14$. Achieved confidence performance (y-axis) plots for 30 random cluster centers with all points within a square area of 61.8 acres around each grid center, which results in a maximum of $93.2 \%$ of the

Motlow boundary area of 1989 acres having potential for TOI placement. The sampling unit dimensions are shown on the x-axis. The horizontal dotted line marks the designed confidenceand the solid horizontal line is the 3 standard deviation lower bound for confidence performance of a simulation study using 2300 simulations to evaluate confidence. The vertical lines separate the three transect widths and the grid based sampling units. 
30 random cluster centers with a maximum of $1.3 \%$ of the area available for TOI placement

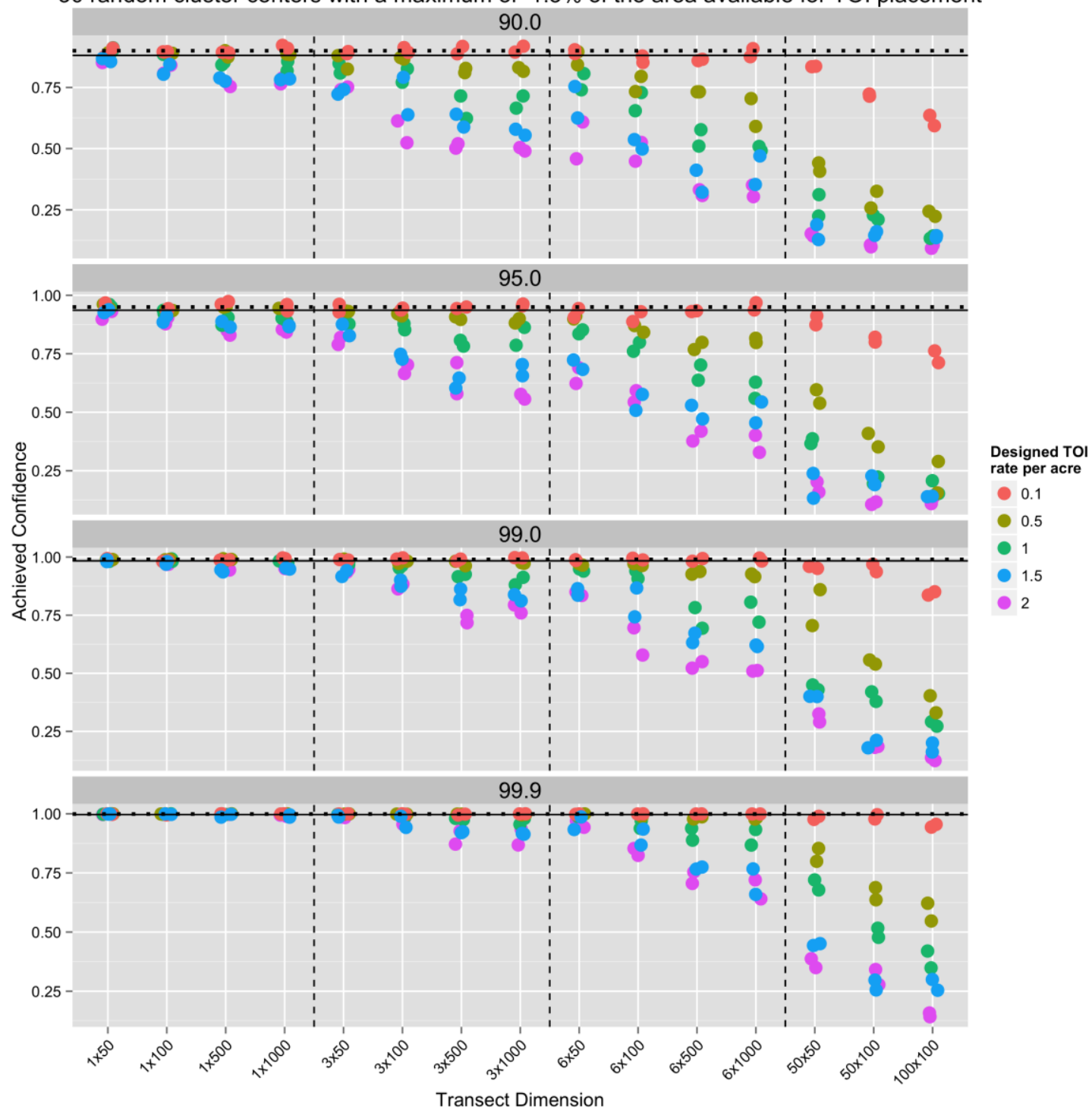

Figure C-15. Achieved confidence performance (y-axis) plots for 30 random cluster centers with all points within a square area of 0.9 acres around each grid center, which results in a maximum of $1.3 \%$ of the

Motlow boundary area of 1989 acres having potential for TOI placement. The sampling unit dimensions are shown on the x-axis. The horizontal dotted line marks the designed confidenceand the solid horizontal line is the 3 standard deviation lower bound for confidence performance of a simulation study using 2300 simulations to evaluate confidence. The vertical lines separate the three transect widths and the grid based sampling units. 
60 random cluster centers with a maximum of $11.6 \%$ of the area available for TOI placement

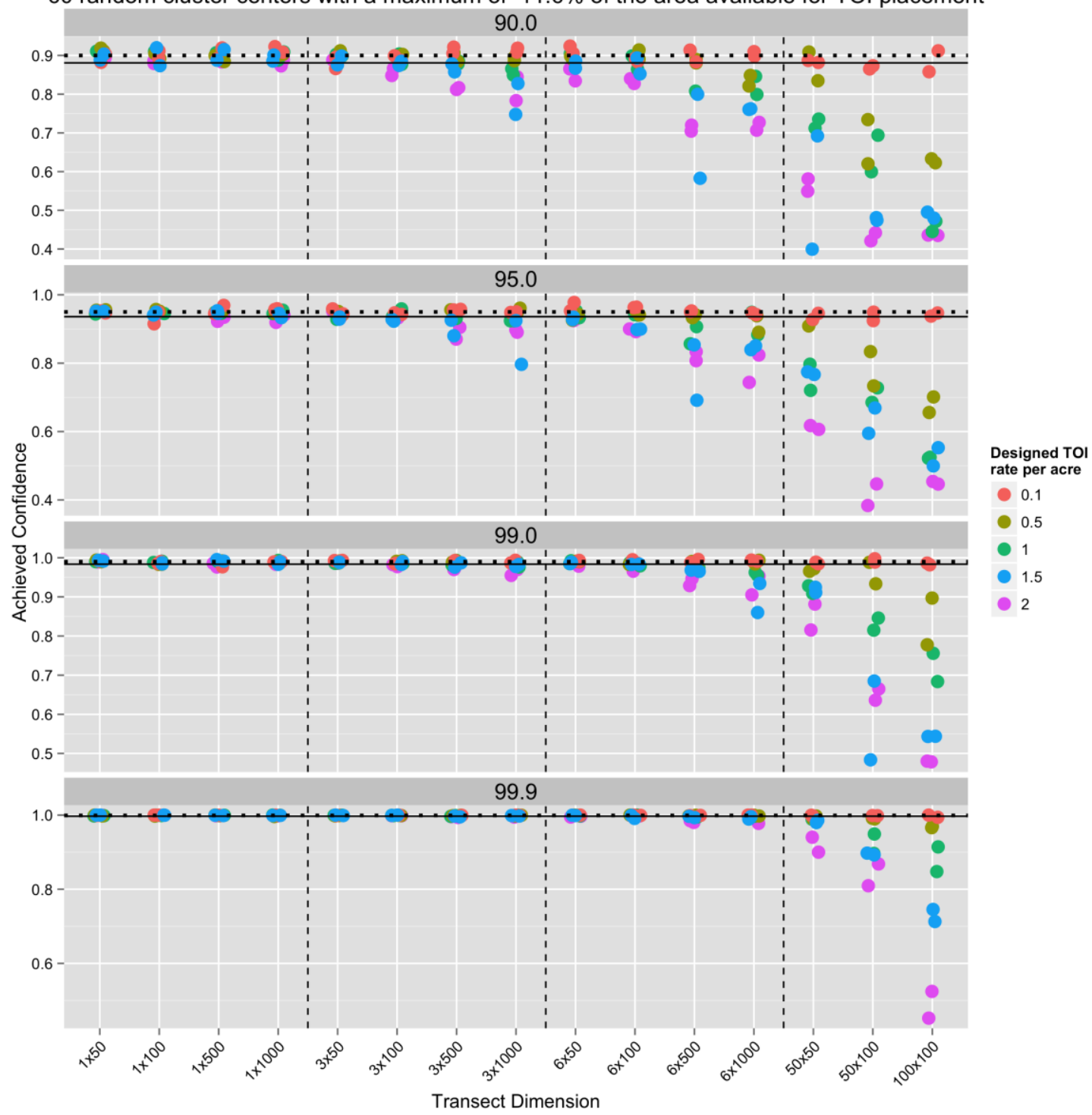

Figure C-16. Achieved confidence performance (y-axis) plots for 60 random cluster centers with all points within a square area of 3.9 acres around each grid center, which results in a maximum of $11.6 \%$ of the

Motlow boundary area of 1989 acres having potential for TOI placement. The sampling unit dimensions are shown on the $x$-axis. The horizontal dotted line marks the designed confidenceand the solid horizontal line is the 3 standard deviation lower bound for confidence performance of a simulation study using 2300 simulations to evaluate confidence. The vertical lines separate the three transect widths and the grid based sampling units. 
60 random cluster centers with a maximum of $46.6 \%$ of the area available for TOI placement

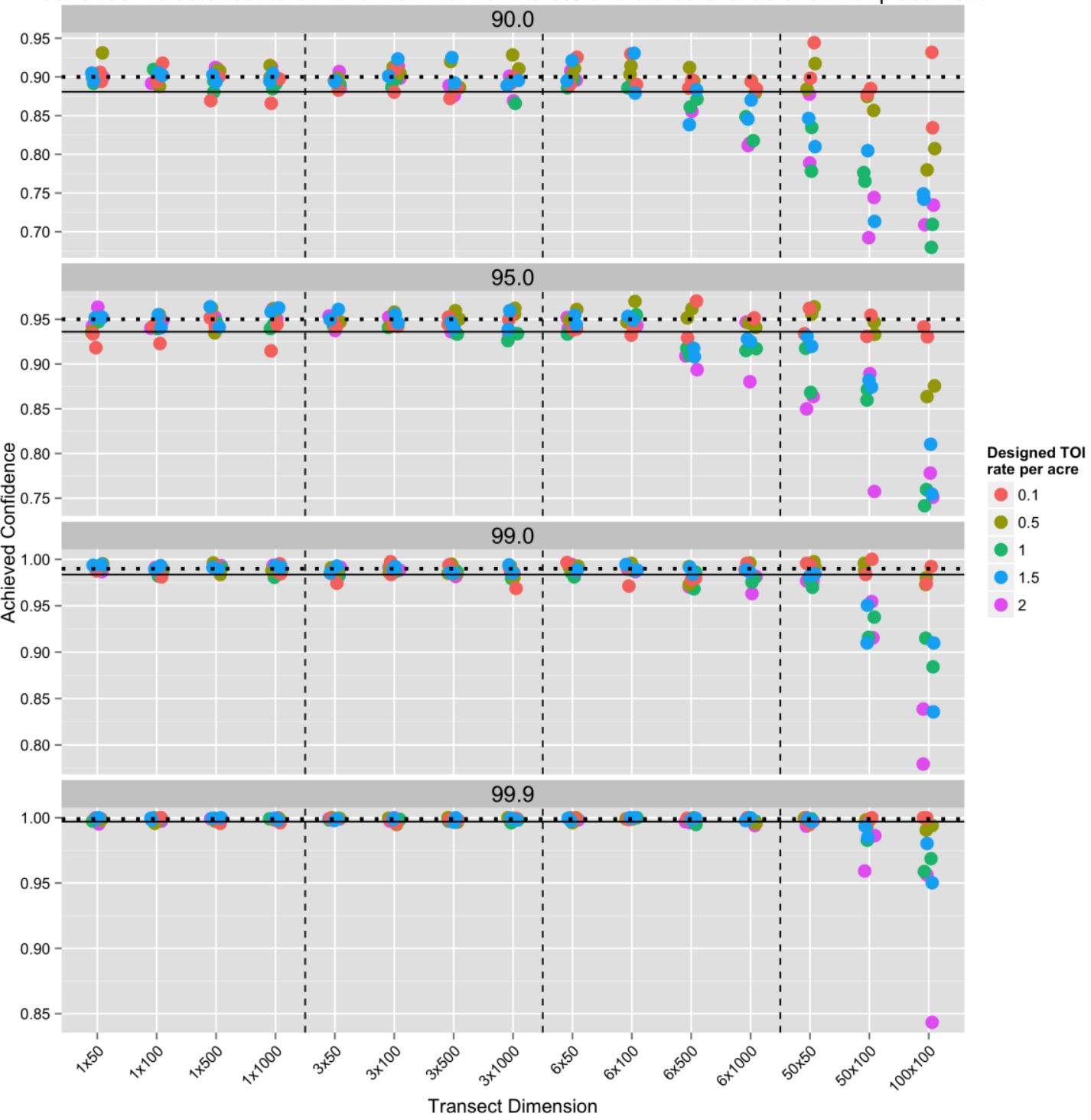

Figure C-17. Achieved confidence performance (y-axis) plots for 60 random cluster centers with all points within a square area of 15.4 acres around each grid center, which results in a maximum of $46.6 \%$ of the Motlow boundary area of 1989 acres having potential for TOI placement. The sampling unit dimensions are shown on the x-axis. The horizontal dotted line marks the designed confidenceand the solid horizontal line is the 3 standard deviation lower bound for confidence performance of a simulation study using 2300 simulations to evaluate confidence. The vertical lines separate the three transect widths and the grid based sampling units. 
60 random cluster centers with a maximum of $100 \%$ of the area available for TOI placement

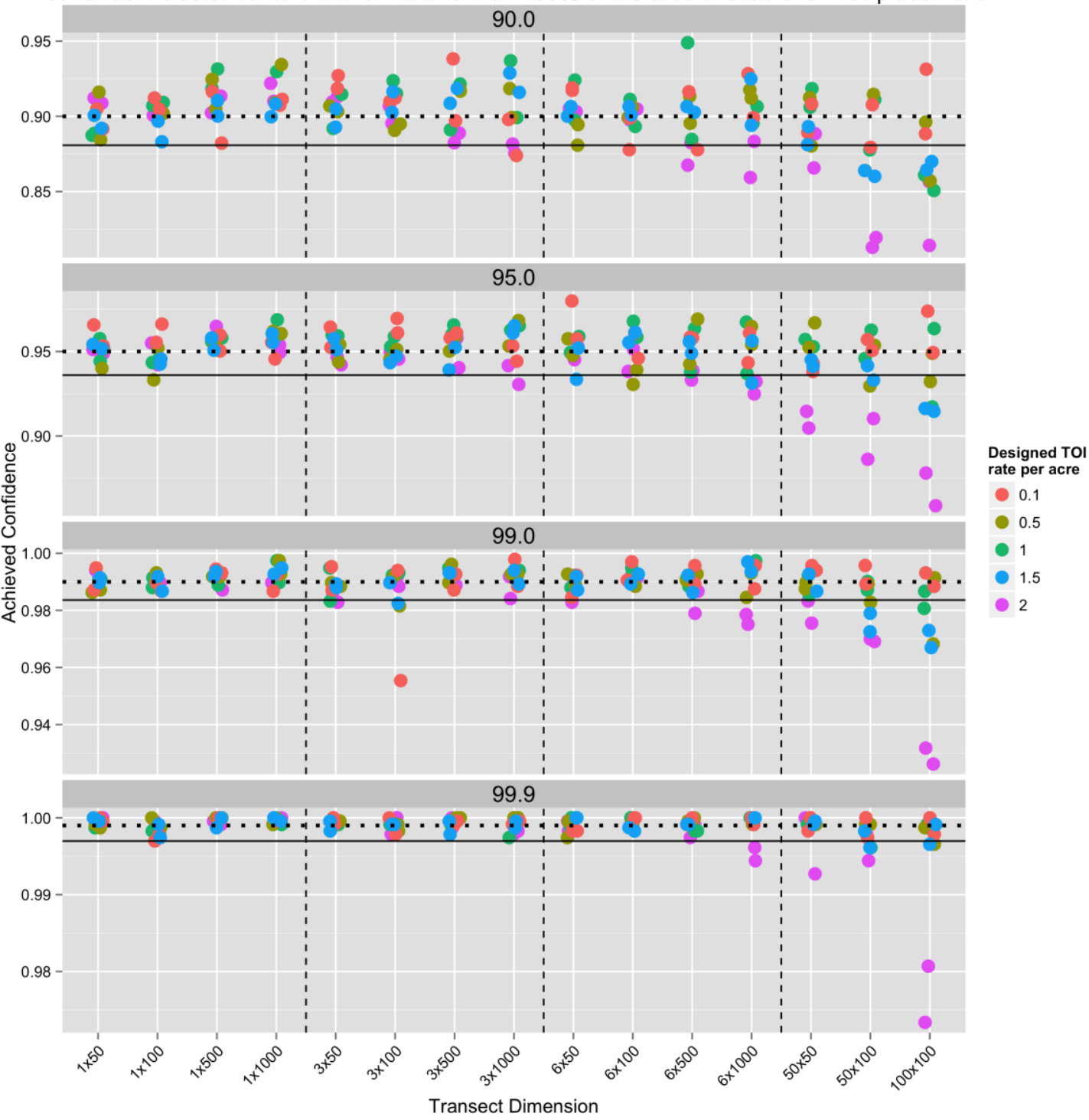

Figure C-18. Achieved confidence performance (y-axis) plots for 60 random cluster centers with all points within a square area of 61.8 acres around each grid center, which results in a maximum of $100 \%$ of the Motlow boundary area of 1989 acres having potential for TOI placement. The sampling unit dimensions are shown on the x-axis. The horizontal dotted line marks the designed confidenceand the solid horizontal line is the 3 standard deviation lower bound for confidence performance of a simulation study using 2300 simulations to evaluate confidence. The vertical lines separate the three transect widths and the grid based sampling units. 
60 random cluster centers with a maximum of $2.7 \%$ of the area available for TOI placement

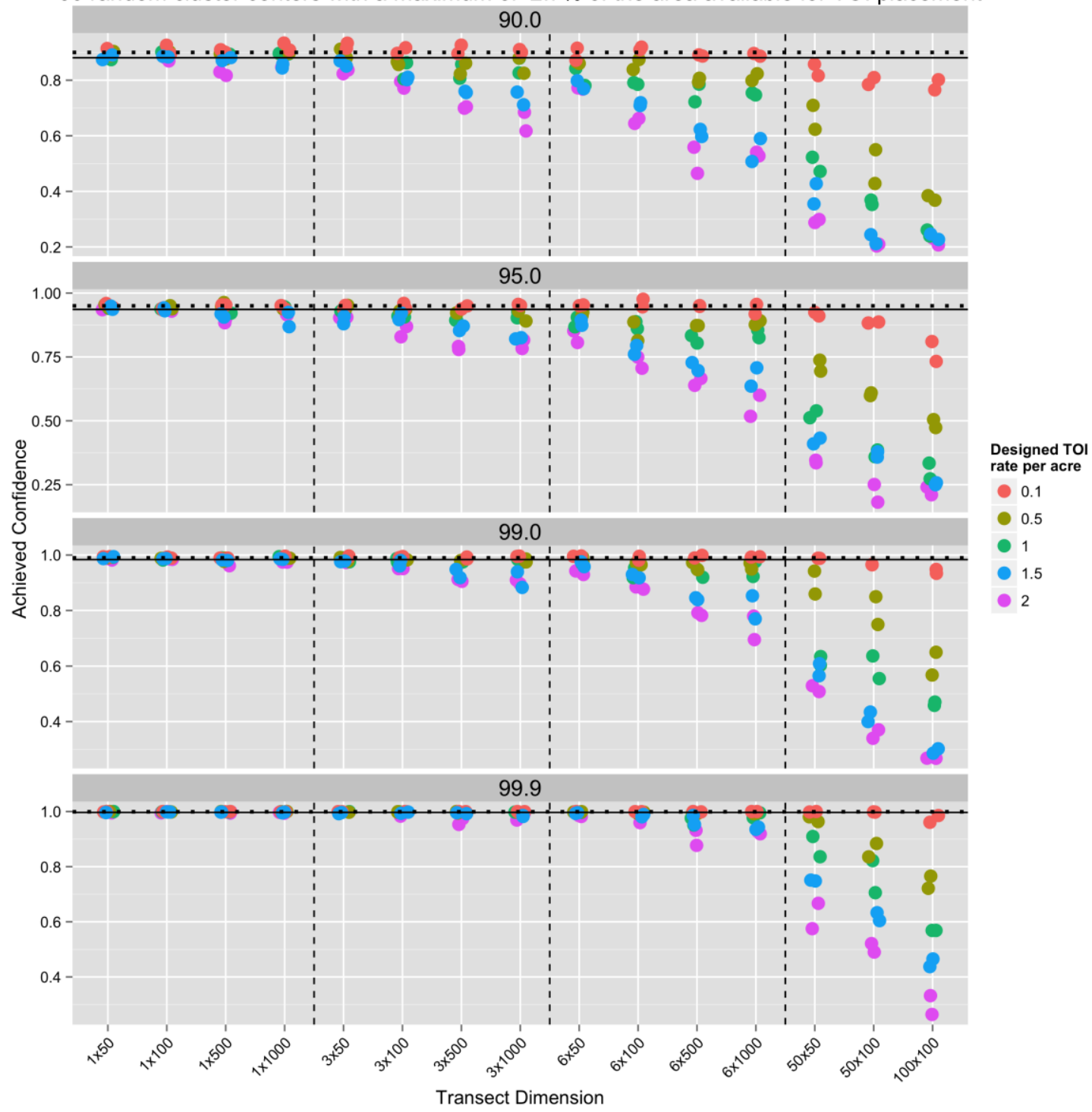

Figure C-19. Achieved confidence performance (y-axis) plots for 60 random cluster centers with all points within a square area of 0.9 acres around each grid center, which results in a maximum of $2.7 \%$ of the Motlow boundary area of 1989 acres having potential for TOI placement. The sampling unit dimensions are shown on the x-axis. The horizontal dotted line marks the designed confidenceand the solid horizontal line is the 3 standard deviation lower bound for confidence performance of a simulation study using 2300 simulations to evaluate confidence. The vertical lines separate the three transect widths and the grid based sampling units. 